九州大学学術情報リポジトリ

Kyushu University Institutional Repository

\title{
The Fires and The Weather
}

Suzuki, Seitaro

Agricultural Engineering Laboratory, Department of Agriculture, Kyushu Imperial University

https://doi.org/10.5109/22548

出版情報: 九州大学大学院農学研究院紀要. 2 (1)，pp.1-73，1928-03. Kyushu Imperial University バージョン：

権利関係 : 
Jcurnal of the Depariment of Agriculture, Kyushu Imperial University, Vol. 2, No. I.

March 20, 1928

\section{THE FIRES AND THE WEATHER}

\section{Seitaro SuzukI}

\section{CON'IEN'I'S}

I. Introduction

2. The fires and the weatlier

\section{PART I}

The Burning and the Weather
3. Change of weight and water-content
4. Clange of length and water-content
5. Self recording
6. Relation to temperature
7. On the uniformily of combustion of the incense-stick
8. Velocity of turning in relation to thickness
9. Velocity of burning in relation to the inclination of the incense-stick
10. The time of burning in relation to the relalive humidity and the temperature
1x. Efiect of wind on burning
12. Correlation tetween the burning velocity, humidity and temperature
13. Mathematical expression of the burning velocity of the incense-stick
14. Combustion of magnesium ribbon in the air
15. Variation of water-content of materials of house furnitures
r6. Influence of temperature on water-content of materials
17. General remarks on combustion

\section{PAR'T II}

The Fires and the Weather

I8. General remarks

19. Tokyo

20. Forecasting the outbreak of fires

2x. Huktroka

22. London

23. Osaka

24. Fires and wind

25. Correlation between fires and the weather in other prefectures

26. Fire seasons and cyclones

27. The variation of water-content in timber

28. Discussion and conclusion

Summary

Literature 


\section{§ I INTRODUCTION}

Many years ago I made an appeal to the public for information on any observed facts about fires, particularly in relation to weather conditions. Since then some investigations on allied subjects have appeared in the journals referred to in the appendix, in which several of those authors laid stress on the importance of the influence of meteorological conditions upon conflagrations both in buildings and in forests.

My own studies during those years have been conducted from the experimental point of view, and meanwhile for the purpose of statistical investigation, the effort has been made to make a thorough collection of materials in regard to the outbreak of fires nearly all over Japan, and to a limited extent in Europe as well.

The present report is for the most part, the result of tedious statistical computations based on the materials thus collected, and it is rather of practical than theoretical interest. Nevertheless, it is worth studing, partly because every year the material loss due to damage from fire amounts to an enormous sum, and partly because the report throws some light on the subtle relationship between fires and the weather.

This paper consists of two parts. The first of these deals mainly with the relation between fires and the weather. The second treats of the conflagration frequency in relation to the meteorological conditions then prevailing. Both of them show that atmospheric humidity plays a leading part as a controller of fires.

\section{$\S 2$ THE FIRES AND THE WEATHER}

Probably it is a commonly accepted fact in Japan, that charcoal fires and such like burn in winter better than in summer. Though this is not well founded and needs closer experimental examination, it cannot be denied that change in the rate of burning is a function of the weather, provided that the fuel material is uniform. To test it I have carried out through nearly a year and measured the time of burning. Calculating the velocity of burning we express the combustibility in numbers. Strictly speaking, our present object would not be however achieved by observing the seasonal variation of the combustibility so defined, chiefly because the surrounding conditions of a coal 
fire and that of an incense stick are not exactly alike. This method is, nevertheless, one of the best of those which are easily accessible for testing the influence of the weather, as will be demonstrated later.

The Japanese incense stick used in this experiment is a thin cylinder with diameter nearly $1.45 \mathrm{~mm}$ thick and made mainly of powder of fragrant wood bark and partly of pine-resin used as paste. When the upper end is lighted and the stick held upright, it burns down steadily without flame. If the condition remains the same, it continues to burn always at an equal rate.

Almost everyday, we used to let a couple of incense sticks burn inside a scteen out of doors, from January $14^{\text {th }}$ to December 3 rd I924, and found that the burning-rate or combustibility, as it is now called, changes from time to time. The result and some subsequent calculations will be given later.

In order both to give the necessary correction to the abserved values of the time of burning and to see the effect on the burning produced by weather conditions artificially adjusted in the closed room, we first made experiments, on some physical properties of the incense stick especially in regard to burning which will be described in the following sections.

\section{PAR'T I THE BURNING AND THE WEATHER}

\section{\& 3 CHANGE OF WEIGHT AND WATFR CONTENTS}

It is found that the incense stick changes its weight every moment, if exposed to the open air. This arises no doubt from the change in the amount of water in the stick, due principally to the variation of the relative lumidity of the surrounding air, for the weight of the incense stick is reduced to the minimum when the stick is kept and dried as long as five days in the desiccater filled with concentrated sulphuric acid, and recovers the old value if again put in the open air. For example, five incense sticks made so dry that their total weight was reduced to $1.159 \mathrm{~g}$. became in the open air gradually heavier and finally reached the maximum $1.259 \mathrm{~g}$. after the exposure of three hours and forty minutes, showing an increase of $0.100 \mathrm{~g}$. over the old weight due to the increase of humidity of the air. Taking $15^{\circ} \mathrm{C}$. as the mean room temperature during the drying process, the relative humidity in the desiccator is far less than $1 \%$ (not actually measured, 
but calculated by the table of the solution tension of sulphuric acid). The diameter, the length and the total weight of the material used in the experiment are respectively $1.47 \mathrm{~mm}, 2 \mathrm{I} \times 5 \mathrm{~cm}$ and $1.259 \mathrm{~g}$. so that more than $8 \%$ of the incense-stick by weight is wholly water, in other words, lcc of the incense stick has at least $0.055 \mathrm{~g}$. of water.'

The details of water-absorption are given in the following table.

Table 1 The Recovering of the Weight of the Incense Stick

\begin{tabular}{|c|c|c|c|c|c|c|c|c|c|}
\hline Time & Ih $25 \mathrm{~m}$ & $30 \mathrm{~m}$ & $35^{\mathrm{m}}$ & $40 \mathrm{~m}$ & $45^{\mathrm{m}}$ & $50 \mathrm{~m}$ & $55 \mathrm{~m}$ & $2 \mathrm{~h} \mathrm{om}$ & $5^{\mathrm{m}}$ \\
\hline Weight & I.I 59g & I. 1862 & 1.2032 & 1.2126 & 1.2210 & 1.2302 & x. 2364 & I. 2400 & 1.2424 \\
\hline Time & 2hIom & I $5^{\mathrm{nu}}$ & $25^{12}$ & $35 \mathrm{~m}$ & $45^{\mathrm{m}}$ & $3 \mathrm{~h} 5 \mathrm{~m}$ & $25 \mathrm{~m}$ & $45 \mathrm{~m}$ & $4^{h} 5 \mathrm{~m}$ \\
\hline Weight & $1.245^{\circ}$ & I. 2474 & 1. 2495 & I.25I8 & 1.2550 & r.2552 & I. 2554 & 1.2559 & 1.2562 \\
\hline Tine & $4^{\mathrm{h}} 35^{\mathrm{m}}$ & $5^{\mathrm{h}} 5^{\mathrm{m}}$ & $35^{\mathrm{m}}$ & & & & & & \\
\hline Weight: & I. 2565 & I. 2594 & 1.2584 & & & & & & \\
\hline
\end{tabular}

Practically the incense stick, as the table shows, accommodates its weight to the state of the surrounding air within 45 minutes, taking water vapour from the latter; and remains the same as long as the humidity of the air is constant.

\section{§ 4 CFLANGE OF LENGTH $A$ ND WATER CONTENT}

When the dried incense stick is exposed to the open air, it lengthens by degrees, first very quickly, then slowly as the table below shows.

Table 2 Recovery of the Iength of the Incense Stick from the Contracted Stale.

The length immerliately after the exposure being $19.4 \mathrm{~cm}$. Measured every minute, $4.50 \mathrm{~mm} 4.60 \quad 4.80 \quad 5.00 \quad 4.90 \quad 5.00 \quad 5.08 \quad 5.10 \quad 5.10 \quad 5.10 \quad 5.20$ $\begin{array}{lllllllllllll}5.30 & 5.40 & 5.50 & 5.56 & 5.60 & 5.65 & 5.70 & 5.70 & 5.78 & 5.80 ; & \text {; measured every }\end{array}$ three ininutes, 5.885 .935 .985 .986 .006 .026 .006 .00 6.or 6.006 .00

1 By keepring dry the chamber of the balance in which the polymeter and the incense sticks are placed, the following very satisfactory values were obtained.

$\begin{array}{ccc}\text { Kelative humidity } & \text { Weight } & \text { Temperature } \\ 84 \% & 0.527 \mathrm{~g} & 25^{\circ} \mathrm{C} \\ 40 \% & 0.499 \mathrm{~g} & 25^{\circ} \mathrm{C}\end{array}$

This shows $5.3 \%$ decrease in weight of the water content (0.085g per I cc of the incense stick) in varying the relative hamidity from $84 \%$ to $40 \%$ (i. e. $1.2 \%$ change of weight per 10\% of humidity). These values correspond to the stationary states and differ a little from those obtained in the self-recording apparatus, which are continually changing. 

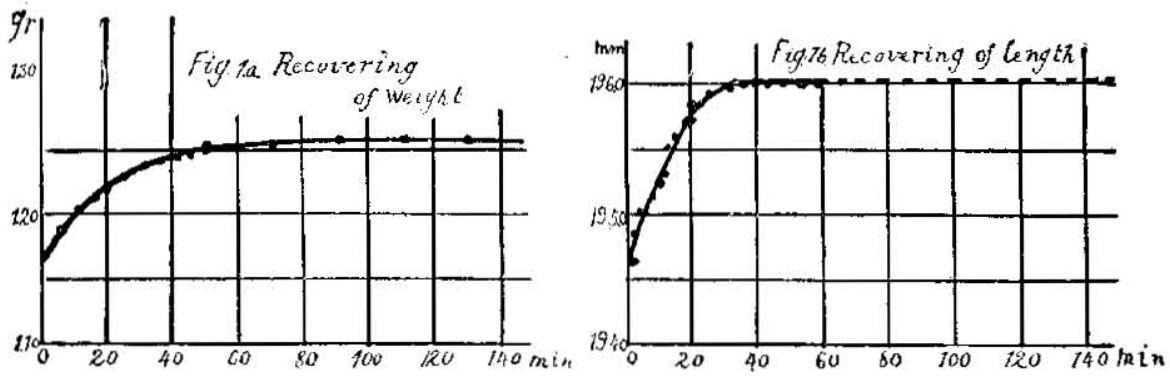

As regards both weight and length the incense stick accommodates itself to the moist air as readily as the hygroscopic salt does to the vapour, and the final stage is reached when the tension of the adsorbed water becomes equal to that of surrounding water vapour.

The above two figures give respectively the recovery curve of weight and that of length. They are in logarithmic form and may be expressed by the following equation.

$$
\mathrm{q}=\mathrm{q}_{0}-\mathrm{we} \mathrm{e}^{-\mathrm{kt}}
$$

From the table, $\mathrm{k}$ is found to be $0.058 / \mathrm{sec}$ and the time during which the amount of water becomes doubled (corresponding to " Halbierungszeit" in the disintegration of a radioactive substance) is 12 minutes.

As we shall see later, the time required for the complete combustion of a incense stick amounts to 40 minutes or more. So we can regard as the first approximation, the state of the incense stick against the surrounding, during its burning, as the equilibrium already established.

As the elongation of the rod (of $19.4 \mathrm{~cm}$ length) is $1.5 \mathrm{~mm}, 0.7 \%$ of this elongation can be considered as due solely to the humidity of the air, with a relative humidity of $75 \% .^{2}$

That a similar contraction takes place radially is beyond doubt, though the decrease of the diameter due to dryness from the rate of contraction of the length.

2 A more accurate measurement was made within the closed glass belljar in which a polymeter and a thermometer were placed beside an incense stick and in which the relative bumidity in the jar conld be regulated by means of sulphuric acid. The result was as follows:

$\begin{array}{ccc}\text { Humidity } & \text { Length } & \text { 'Temperature } \\ 13 \% & 24.75 \mathrm{~cm} & 30^{\circ} \mathrm{C} \\ 92 \% & 25.05 \mathrm{~cm} & 30^{\circ} \mathrm{C}\end{array}$

So the contraction became $1.2 \%$ (i. e. $0.15 \%$ per ro $\%$ of humidity) 


\section{$\S 5$ SELF RECORDING}

With the simple apparatus as shown in Fig 2, the variation of weight and length of the incense stick can be easily recorded.

The weight recorder is of the balance system, a long pen and a pan on which the incense sticks are placed con-

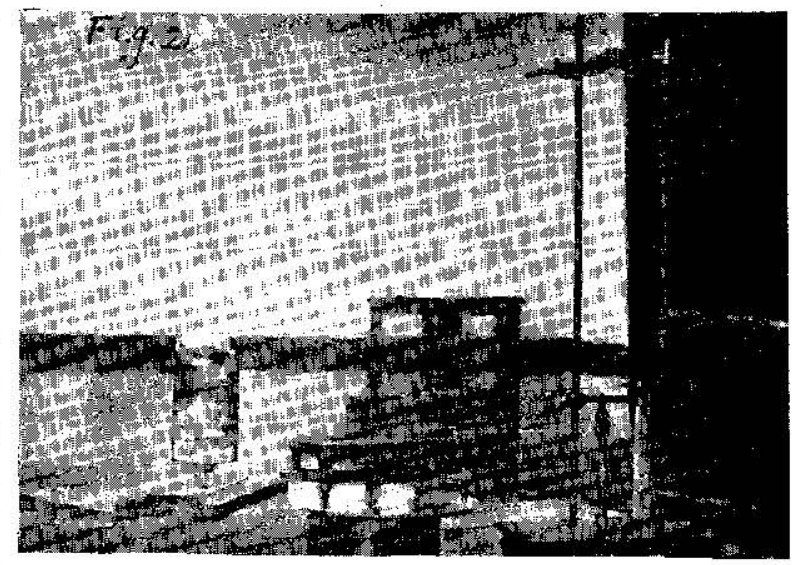
sisting of slender glass rods, so tightly connected as to prevent the swinging of the apparatus due to a small disturbance of the air. To record the length variation, we make use of the lever, one arm of which is attached to onc cond of the long incense stick, and the other is held by the immovable iron stand.

The magnification of the weight recorder is 67 , that of the length recorder being 29.

Coordinating this apparatus with a hygrograph and resting their recording pens on the same smoked revolving drum, we obtained the charts of the weight- and length-variation and the relative humidity, as shown in PL. I. This worked very well, though in the case of the weight-variation, the friction gives rise to time-lag, principally due to the smallness of the weight variation of the incense stick.

Table 3 'The Kedation Jetween the Wcight of the Incense Stick, its Lenglh and the Relative Iumidity

$\begin{array}{lcc}\text { Humidity } & \begin{array}{c}\text { Variation of weight deviation } \\ \text { from mean value } 4.28 \mathrm{~g} .\end{array} & \begin{array}{c}\text { Variation of length deviation } \\ \text { from mean value } 49.4 \mathrm{~cm}\end{array} \\ 42 \% & -1.4 \mathrm{cg} & -0.09 \mathrm{~mm} \\ 48 & 2.9 & 0.11 \\ 51 & 1.5 & 0.20 \\ 54 & 1.8 & 0.20 \\ 56 & 4.3 & 0.53 \\ 62 & 10.5 & 1.00 \\ 71 & 16.0 & 1.70\end{array}$

While the relative humidity changes from $42 \%$ to $71 \%$, the 
water-content varies from $+1.40 \mathrm{cg}$ below the mean up to $16.0 \mathrm{cg}$ above, ${ }^{3}$ and simultaneously the length undergoes the small change from $+0.09 \mathrm{~mm}$ below the mean to up to $1.70 \mathrm{~mm}$ above.

Further examination of the record reveals another fact, namely that the curve either of weight or of length rises steeply and descends down gently. This must be ascribed entirely to the time-lag of waterabsorption. Plotting the curves by using the values taken from the record, the well known hysteresis curve of weight and length becomes apparent.

With a little retarda- $W t$

tion, therefore, water is taken up or given out by the incense - stick according to the increase or decrease of the relative humi-

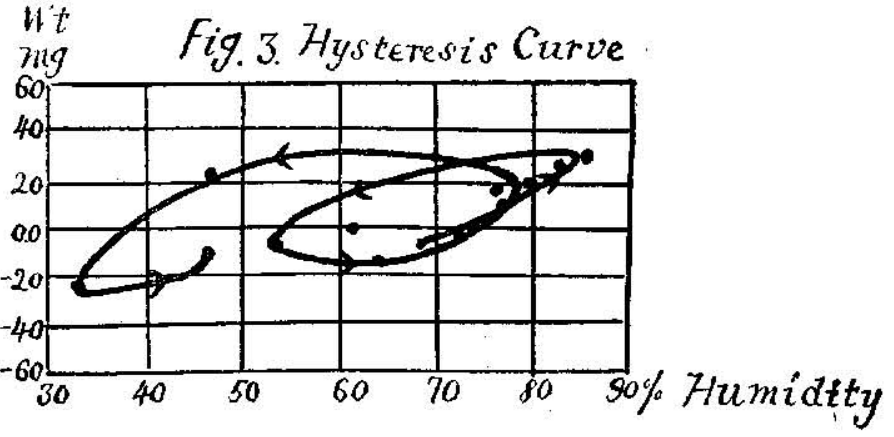
dity, so that its water-content is not always the same even in the case where the relative humidity returns to the old value. Such a fact is worth noticing, because it bears on the outbreak of fires,- - a matter to be considered later.

Besides those measurements, the incense stick corresponding to a definite relative humi-

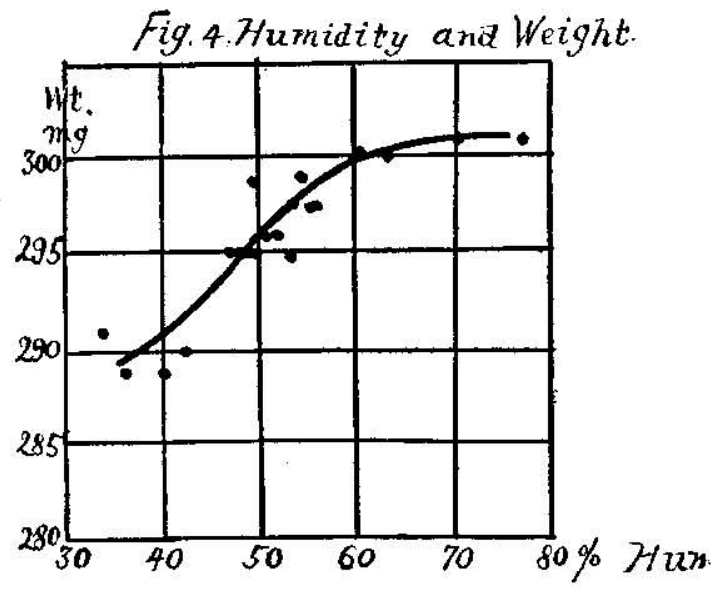
dity was weighed throughout a whole year. The results are shown in table 4 accompanied by a figure (Fig. 4), and it evinces the fact

$3 \quad 1.2 \%$ variation of weight per $10 \%$ of relative humidity, and $0.12 \%$ variation of length per Io $\%$ of relative humidity. At large, the ordinary incense stick changes in all probability its weight from $0.6 \%$ to $x .2$ per ro $\%$ of relative humidity. 
that, with the increase of humidity, the stick absorbs water logarithmically; and the same may be said about its elongation due to absorption of water. Therefore, either weight or length can be expressed by the formula.

$$
\mathrm{q}=\mathrm{a}+\mathrm{b} \log \mathrm{H}
$$

where $\mathrm{q}$ is water-content, $\mathrm{H}$ the relative humidity, and $\mathrm{a}$ and $\mathrm{b}$ are constant.

$\begin{array}{cccc}\text { Table 4 Average Water.Content and the Relative Humidity. } \\ \text { IIumidity } & \text { Weight } & \text { Fumidity } & \text { Weight } \\ 33.6 \% & 291 \mathrm{mg} & 52.0 \% & 297 \mathrm{mg} \\ 36.0 & 289 & 53.0 & 296 \\ 40.0 & 291 & 54.0 & 299 \\ 42.0 & 290 & 55.0 & 298 \\ 47.0 & 296 & 55.3 & 298 \\ 48.0 & 296 & 56.0 & 298 \\ 49.0 & 299 & 61.0 & 300 \\ 50.0 & 296 & 61.4 & 300 \\ 50.6 & 296 & 63.0 & 300 \\ 51.0 & 296 & 70.0 & 301 \\ 51.4 & 296 & 77.0 & 301\end{array}$

\section{$\S 6$ REI ATION TO TFMPERATURE}

Though the incense stick appears uniform in its constitution, the examination through a microscope even of low magnification reveals the fact that it is surprisingly porous, and when much water is absorbed, the appearance of the incense stick closely resembles that of a sponge.

As is well known, the hair lengthens as the incense stick does when it absorbs water-vapour, and the capillary theory of the hair hygrometer of Sresnevsky accounts for the phenomena to a considerable extent.

One of his deductions is that the hair elongation is proportional to the logarithm of the relative humidity of the atmosphere-a fact which also well explains that of the incense stick. It seems, therefore, most probable that such a theory as he and others advocate, i. e. that the increase of the vapour-tension expands the numerous interstices of the incense stick, applies to the case of the incense stick equally well.

On the other hand, Pircher demonstrated experimentally that the change of length of the hair is affected by the change of temperature at least only to a slight extent if at all. As regards the incense stick, 
the same relation seems to hold good and the change of its dimension may be looked upon as of the second order of magnitude, if any.

\section{$\S 7$ ON THE UNIFORMITY OF COMBUSTION OF THE INCENSE STICK ALONG ITS LENGTH}

First it is of importance to examine whether the incense stick burns steadily down to the bottom, provided all other conditions remain the same. Measuring the diminution of the length of the burning incense stick, held upright by a small metal clip, its velocity is ascer tained at every centimeter interval.

Table 5 Constancy of the Velocity of Combustion

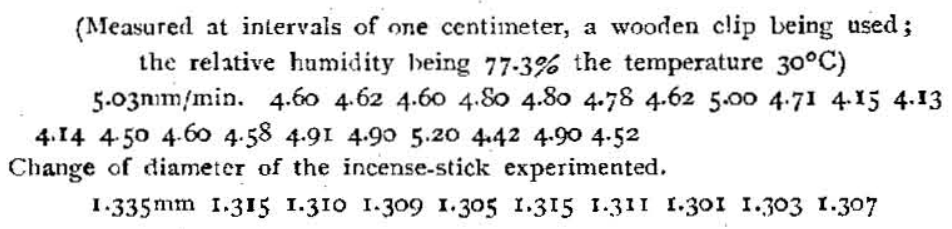

Strictly speaking, the velocity of combustion of the incense stick is not constant owing chiefly to the non-uniformity of the diameter of the rod, but the mean velocity with time of burning not less than 40 minutes for $20 \mathrm{~cm}$ length serves our purpose quite well. Of course, the burning period of a few millimeters from both ends are for the prevention of error, to be substracted from the entire length of time measured.

As to the influence of the material of the support, the examination was made by using various kinds of clips-wood, iron, zinc and copperand no appreciable difference in time, except near the bottom, was in any case recognized.

On the other hand, in the case of the closed vessel (bell-jar) which is described elsewhere, an appreciable decrease of speed of burning can be traced.

Table 6 Change of Velocity of Burning in the Closed Chamber

Length of the incense stick $=20.2 \mathrm{~cm}$, diameter $=\mathrm{r} \cdot 38 \mathrm{~mm}$, temperature of the air $=11^{\circ} 6 \mathrm{C}$, relative humidity of air $=92 \%$

Velocity of burning (mm/min) $4.6 \quad 5.04 .8 \quad 5.2 \quad 5.0 \quad 4.4 \quad 5.0 \quad 4.6 \quad 4.8 \quad 4.6$

$4.6 \quad 4.6 \quad 4.6 \quad 4.4 \quad 4.6 \quad 4.4 \quad 4.6 \quad 4.4 \quad 4.6 \quad 4.4 \quad 4.4$

The above table shows a slight fall in the velocity of burning when it comes to the end. 


\section{$\S \&$ VELOCITY OF BURNING IN RELATION TO TIIICKNESS}

The velocity of burning depends much upon the diameter of the incense stick. To find out their relation, it is very necessary to prepare many of sticks of the same density, but of different diameter. For this purpose, several large sticks are whittled to various thickness, thus securing the same sort of specimens. They are kindled at the same moment, and burn down under the same conditions.

The incense stick usually burns with ashes at the top. To the grcat inconvenience of the experiment the ashes fall to the ground, piling up to a certain height which differs according to the thickness of the stick.

Two series of experiments to measure the time of burning are there fore made, in one the ashes being shaken off by continuous tapping and in the other being allowed to fall naturally. The results are tabulated below.

\begin{tabular}{cccccc} 
Table 7 & Thickness and Time of Burning (ashes shaken off) \\
\multicolumn{5}{c}{$2 \mathrm{r}=$ Density, $\mathrm{t}=$ Time of Burning, o density } \\
$2 \mathrm{r}$ & 0 & $\mathrm{t}$ (sec/cm) & $\mathrm{t} / \mathrm{r}$ & $1 / \mathrm{r}^{\frac{1}{2}}$ & $\mathrm{t} / \mathrm{r}$ \\
7.32 & 0.73 & 323.4 & 44.2 & 119 & 72.5 \\
5.27 & 0.70 & 248.3 & 47.1 & 108 & 71.4 \\
4.15 & 0.70 & 190.0 & 45.1 & 93 & 64.8 \\
3.67 & 0.69 & 192.5 & 52.5 & 101 & 72.9 \\
2.76 & 0.73 & 157.0 & 56.8 & 95 & 73.5 \\
2.02 & 0.68 & 116.9 & 57.8 & 82 & 68.9
\end{tabular}

Table 8 Thickness and Time of Burning (ashes left)

$\begin{array}{cccccc}2 \mathrm{r} & 0 & \mathrm{t} & 1 / \mathrm{r} & 1 / \mathrm{r}^{\frac{3}{2}} & t / \mathrm{r}^{\frac{3}{4}} \\ 7.22 & 0.70 & 301.8 & 41.8 & 112 & 68.5 \\ 6.52 & 0.66 & 269.5 & 41.3 & 106 & 66.2 \\ 3.89 & 0.73 & 205.8 & 52.7 & 104 & 74.1 \\ 2.56 & 0.89 & 171.3 & 66.9 & 107 & 71.5\end{array}$

The figures given in the above tables show that $t / r$ increases slightly with the decrease of the diameter and the reverse is the case with $1 / \mathrm{r}^{\frac{1}{2}}$, so that it may be adequate to express time-relation either by $1 / r^{\frac{3}{4}}$, or by the combination of two terms $r$ and $r^{\frac{1}{2}}$.

Table 9 shows, however, that the constancy of $t / r$ holds; within a moderate range, practically better than any other relation, and with the additional advantage of being simpler in form. 




We, therefore, preferred the latter method to the former, not only because the latter method can be easily carried out, but because it saves time in calculation.

\section{\$ 9 VELOCITY OF BURNING IN RELATION TO TIIE INCLINATION OF THE INCENSE SIICK}

Next it is necessary closely to examine how the velocity of burning changes if the incense stick inclines from the vertical, because strict verticality is a necessity if a great difference in time results from even a very slight slant.

Talle 9 Velocity of Burning in Relation to the Inclination of the Incense Stick (Room Temperature $=13^{\circ} \mathrm{C}$, Relative Furnidity $=54 \%$ )

$\begin{array}{cccc}\begin{array}{c}\text { Angle of deviation } \\ \text { from vertical }\end{array} & \text { Time of burning } & \begin{array}{c}\text { Angle of deviation } \\ \text { from vertical }\end{array} & \text { Time of burning } \\ 0.0^{\circ} & 2450 \sec & \mathbf{1 1 . 2 5 ^ { \circ }} & \mathbf{2 1 6 \mathbf { s e c }} \\ \mathbf{2 2 . 5} & 2438 & \mathbf{1 3 . 5 0} & \mathbf{1 9 5 5} \\ \mathbf{4 5 . 0} & 2418 & \mathbf{1 5 . 7 0} & \mathbf{1 8 5 5} \\ \mathbf{6 7 . 5} & 2349 & \mathbf{1 8 . 0 0} & \mathbf{1 7 3 7} \\ 90.0 & \mathbf{2 2 5 0} & & \end{array}$

From the table it can be calculated that the time of burning in the case of the inverted stick is reduced to as little as $33 \%$ of that of the vertical. And the velocity increases rather suddenly if the inclination 
exceeds $45^{\circ}$, owing most probably to the conspicuous convection current of the air. At all event, the velocity varies only very little till the stick inclines to $45^{\circ}$, so that it is not necessary to take great pains to adjust the stick to the exact vertical position.

\section{$\S$ IO TITE TIME OF BURNING IN REI.ATION TO THE RELATIVE HUMIDITY AND THF TEMPERATURE}

Thus all preparatory works being done, the next step to be taken is to see the influence of the three weather elements -relative humidity, temperature, and wind upon the combustibility of the incense stick. We first examined this in a closed room, controlling the three elements by artificial means.

The effect of humidity under constant temperature is observed by burning the incense sticks, both in a closed bell-jar and in a thermostat. To raise the humidity to a required amount, the water basin is electrically heated, the measurement of it is made by the polymeter, as the volume of the jar is somewhat narrow $\left(\pi \times 10.8^{2} \times 37.5 \mathrm{cc}\right)$ leaving no room for another hygrometer. To lower the temperature below that of room, the jar is surrouned by ice, and to keep it warm, the electrical method is often used.

Table Io The time of Burning under Constant Temperature and Relative Humidity

$\mathrm{t}=$ the time of burning of $19 \mathrm{~cm}$ length of the incense stick.

$t^{\prime}=$ the time reduced to the diameter $1 \mathrm{~mm}$ thick of the incense stick

Temperature $0^{\circ} \mathrm{C}$

\begin{tabular}{cccc} 
Relative humidity (\%) & Diameter mm & $\mathbf{t}(\mathrm{sec})$ & $\mathbf{t}^{2}(\mathrm{sec})$ \\
& $\mathbf{1 . 4 2 3}$ & 2633 & 1850 \\
20 & $\mathbf{1 . 4 0 4}$ & 2602 & $\mathbf{1} 853$ \\
& 1.457 & 2658 & 1824 \\
60 & 1.435 & 2666 & 1858 \\
\multirow{2}{*}{80} & 1.438 & 2683 & 1866 \\
& 1.418 & 2644 & 1857 \\
100 & 1.407 & 2729 & 1939 \\
& 1.453 & $278 \mathbf{1}$ & 1914
\end{tabular}

Temperature $20^{\circ} \mathrm{C}$

$\begin{array}{cccc}\text { Relative humidity (\%) } & \text { Diameter mn } & \mathrm{t}(\mathrm{sec}) & \mathbf{t}^{\prime}(\mathrm{sec}) \\ 20 & \mathbf{1 . 4 6 9} & 2302 & \mathbf{1 5 6 7} \\ & \mathbf{1 . 4 4 1} & 2295 & \mathbf{1 5 9 3} \\ & \mathbf{1} .454 & 2489 & \mathbf{1 7 1 2} \\ 40 & 1.468 & 2618 & \mathbf{1 7 8 3}\end{array}$




$\begin{array}{cccc}60 & 1.434 & 2725 & 1901 \\ & 1.489 & 2833 & 1902 \\ 80 & 1.414 & 2546 & 1801 \\ & 1.433 & 2689 & 1876 \\ 100 & 1.465 & 2909 & 1986 \\ & 1.442 & 2826 & 1960\end{array}$

Temperature $25^{\circ} \mathrm{C}$

Relative humidity $(\%)$ Diameter $\mathrm{nm}$

$\begin{array}{llll}20 & 1.47^{2} & 2269 & 1541 \\ & 1.410 & 2241 & 1589 \\ 40 & 1.428 & 2323 & 1627 \\ & 1.431 & 2394 & 1673 \\ & 1.426 & 2474 & 1735 \\ 60 & 1.463 & 2643 & 1807 \\ & 1.420 & 2583 & 1819 \\ \text { So } & 1.467 & 2603 & 1774 \\ & 1.410 & 2663 & 1889 \\ 100 & 1.419 & 2595 & 1829\end{array}$

Temperature $30^{\circ} \mathrm{C}$

Relative humidity $(\%)$ Diameter mm

$\begin{array}{cccc} & & t(\mathrm{sec}) & 1 \\ 20 & \mathbf{1} 477 & 2199 & 1589 \\ & 1.433 & 2156 & 1505 \\ 40 & 1.419 & 2216 & 1562 \\ & 1.487 & 2346 & 1578 \\ 60 & 1.407 & 2292 & 1629 \\ & 1.435 & 2319 & 1616 \\ 80 & 1.421 & 2541 & 1788 \\ & 1.410 & 2557 & 1806 \\ 100 & 1.441 & 2672 & 1854 \\ & 1.423 & 2612 & 1836\end{array}$

Temperature $35^{\circ} \mathrm{C}$

Relative humidity (\%) Diameter mm

$\begin{array}{cc}\text { t }(\mathrm{sec}) & \text { t' }(\mathrm{sec}) \\ 221 \mathrm{I} & 1536 \\ 2109 & 1464 \\ 2243 & 1573 \\ 2198 & 1551 \\ 2285 & 1596 \\ 2343 & 1624 \\ 2449 & 1710 \\ 2428 & 1673 \\ 2680 & 1890 \\ 2657 & 1859\end{array}$

Temperature $40^{\circ} \mathrm{C}$

Relative humidity $(\%)$

Diameter $\mathrm{mm}$

$\mathrm{t}$ (sec) t' (sec)

20

I. 446

2133

1475

1.444

2118

1467 


$\begin{array}{cccc}40 & 1.421 & 2149 & 1512 \\ 60 & 1.434 & 2161 & 1507 \\ & 1.425 & 2468 & 173^{2} \\ & 1.408 & 2212 & 1571 \\ 80 & 1.433 & 2583 & 1803 \\ & 1.411 & 2509 & 1778 \\ 100 & 1.423 & 2651 & 1863 \\ & 1.420 & 2634 & 1855\end{array}$

From the figure it can be seen at a glance that the incence stick is apt to burn the more readily, the higher the temperature is. In regard to humidity it is quite the reverse.

To gain a concise numerical conception we take two examples from table 12. Under the same relative humidity $60 \%$ but with temperaturechange from $\mathrm{O}^{\circ} \mathrm{C}$ to $25^{\circ} \mathrm{C}$, the time of buming decreases from $1840 \mathrm{sec}$ to $1620 \mathrm{sec}$, i,e. $13 \%$ decrease. Under the same temperature $20^{\circ} \mathrm{C}$, but with humidity-change from $20 \%$ to $80 \%$, the time of burning increases from $1580 \mathrm{sec}$ to $1830 \mathrm{sec}$, i.e. $15 \%$ increase.

An air temperature of $\mathrm{O}^{\circ}-25^{\circ} \mathrm{C}$ and relative humidity of $20 \%$ $80 \%$ can be regarded in Japan as within the ordinary range of variation of both elements. In consequence, their influence on the combustibility

Fig. 6

\section{time $(\mathrm{sec})$}

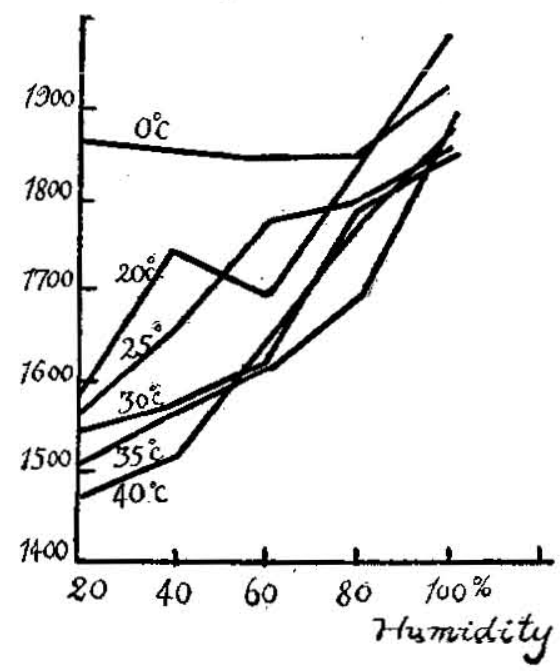

Fig. 7.

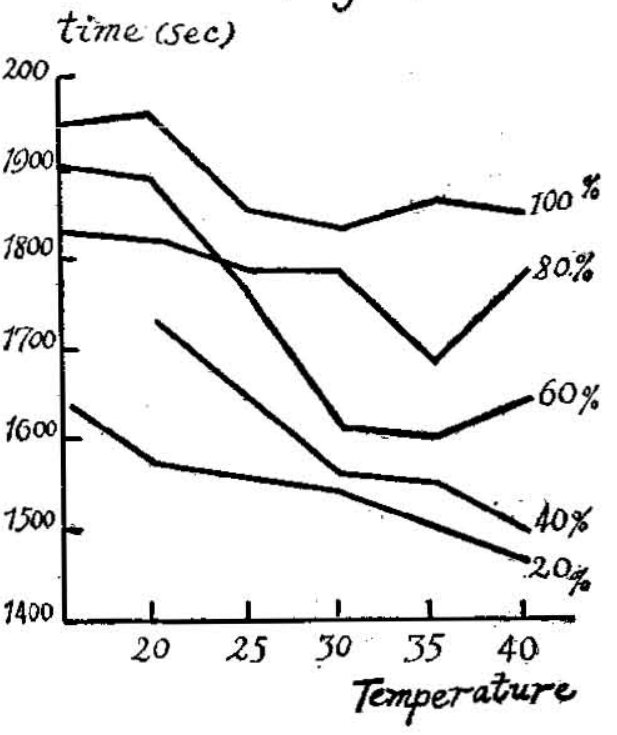


of the incense stick throughout a year may roughly be said to be of the same order of magnitude.

As previously mentioned, we carried out a long series of measurements of the burning velocity inside a screen out of doors. The results arrived at as will be explained fully elsewhere are nearly the same as those obtained with the closed chamber. Therefore the vague belief that the fire burns more intensely in winter can not be accepted as quite accurate, taking for granted that the present results are applicable to all cases of burning.

\section{§ II EFFECT OF WIND ON BURNING}

The examination of the interrelation of the velocity of burning with that of wind is made partially for the purpose of bringing into experimental evidence the correlation between the. wind and fire-outbreak, or the spreading of conflagration, owing to the absence of relevant experimental material. By no means do we imagine that thereby the problem will be wholly solved, because the conditions are far from what actually takes place.

To get the air current we employed a wind channel made of carton paper; having a length of $150 \mathrm{~cm}$ length and diameter of $30 \mathrm{~cm}$. The current is maintained by an electric fan placed at the end of the channel, and is rectified, though imperfectly, by the metal mesh inserted before the fan.

The velocity of the air current was measured with a small air meter, close to which was placed the burning incense stick exactly perpendicular to the air stream and kept always in the same position by the arm of the cathetometer pushing continuously upward. Visualising was made by means of a telescope and a mirror at a distance. The motion was recorded on the smoked drum, revolving once in fifty minutes with a pen attached to the arm of the stand. Such a device was successful in maintaining uniform conditions around the incense stick.

From the record the change of the burning velocity can be calculated, as shown in the following table, together with the corresponding air velocity.

\begin{tabular}{cccc}
\multicolumn{4}{c}{ Table II Wind Velocity and Burning Velocity } \\
I & & II & \\
Wind Velocity & Burning Velocity & Wind Velocity & Burning Velocity \\
$(\mathrm{m} / \mathrm{min})$ & $(\mathrm{m} / \mathrm{min})$ & $(\mathrm{m} / \mathrm{min})$ & $(\mathrm{m} / \mathrm{min})$ \\
0 & 5.72 & 0 & 5.30 \\
10 & 6.00 & 12 & 5.48
\end{tabular}


Fig.8. Winctivelocity and Burningtelcity

\begin{tabular}{cr}
\multicolumn{2}{c}{ III } \\
0 & 4.76 \\
6 & 5.10 \\
12 & 5.60 \\
14 & 5.98 \\
22 & $5 \cdot 54$ \\
30 & 5.56 \\
42 & 6.00 \\
52 & 5.10 \\
64 & $5 \cdot 74$ \\
76 & $5 \cdot 76$ \\
99 & 6.10 \\
127 & 6.24 \\
164 & 6.08 \\
182 & 5.76 \\
218 & 5.56 \\
Extinguished
\end{tabular}



The air current has evidently great influence upon the burning. For instance, the burning velocity $5.3 \mathrm{~m} / \mathrm{min}$ at dead calm rises to the maximum $6.3 \mathrm{~m} / \mathrm{min}$, when the air current strength becomes $110 \mathrm{~m} / \mathrm{min}$. and then gradually, though slightly, decreases till the current velocity rises up to $220 \mathrm{~m} / \mathrm{min}$, when suddenly the fire on the incense stick goes out.

4 The burnt end of the stick looks on the leeward like an inverted V and is as sharp as a chisel edge. 
From the table it can be calculated that the increase of the burning velocity of the incense stick due to the wind amounts, at most, to about I $7 \%$ of the velocity in the still air. This may be considered as the influence of the wind, as numerically expressed. ${ }^{5}$

Some interesting facts were observed during the experiment. For example, a thin column of smoke from the top end of the incense stick descends along the stick to leeward, whilst the main stream of the smoke is blown horizontally by the air current. This downward smoke column has several horizontal streaks like a comb, and keeps constantly dancing, the schema is shown in Fig.9.

This reminds us of the well-known phenomenon of chimney smoke coming down along the funnel in the presence of wind. We think that the phenomenon of such a turbulent motion of air can be studied with much advantage by this simple appliance.

\section{§ 13. CORRELATION BETWEEN TIEE BURNING VEJOCITY, MLMIDITY AND TEMPERATURE}

The results of one year's measurements of the time of burning of the incense sticks inside the thermometer shelter in the premises of the Department of Agriculture in the Kyusyu Imperial University will now be examined. The relation between the time thus measured and the corresponding meteorological


elements is illustrated by PL. II. It shows that the time of burning fluctuates constantly, from day to day, but on the whole it becomes short as the summer comes, and long when the winter approaches.

Not only the gencral trend but also the fluctuation of the short duration indicate that the higher the temperature is the more readily it burns. The parallelism of the latter is not conspicuous, probably owing to the nonuniformity of the incense stick. On the other hand, high relative humidity is associated with long duration of burning.

Usually the daily rise and fall of atmospheric temperature cause the opposite effect on the relative humidity, except the seasonal changes in Japan, in which high temperature correlates with high relative humidity. It is hardly possible therefore to determine whether this

5 Fig. 9 shows the wavy character of the wind-burning velocity curve, but whether this is due to the non-uniformity of the incense stick rod or to other causes cannot, at the moment, be determined. 
retarding effect of burning is due to the temperature or to the humidity. Hence we must resort to another method for discerning their effect-for instance, to the calculation of the correlation coefficient.

The following table shows the correlation-coefficient of each pair of five factors - the time of burning, temperature, humidity, vaporisation and vapour tension.

Table 12 Correlation-Coefficient between

$$
\begin{aligned}
& +0.21 \pm 0.05 \\
& -0.56 \pm 0.04 \\
& -0.48 \pm 0.04 \\
& -0.39 \pm 0.03
\end{aligned}
$$

$$
\begin{aligned}
& \text { Time of burning and humidity } \\
& \text { Time of burning and temperature } \\
& \text { Time of burning and vaporisation } \\
& \text { Time of buming and vapour-tension }
\end{aligned}
$$

Though the coefficient for the relative humidity is smaller than expected, its positive correlation with the burning time agrees with the experiment. The relation between the time of burning and air temperature is very intimate. ${ }^{6}$

There is another method of calculating the correlation cocfficient, called the variate difference method of $K$. Pearson, whete the differences of the successive values are employed instead of the departure from the mean, the advantage of which is to get a more correct idea of the correlation of the rapidly altering change of two series. ${ }^{7}$

$$
\begin{aligned}
\text { Table } 13 & \text { Correlation-Coefficient Between Time of Burnig and } \\
+0.34 \doteq 0.04 & \text { Relative humidity } \\
-0.13 \pm 0.05 & \text { Air temperature } \\
+0.30 \doteq 0.05 & \text { Absolute lumidity }
\end{aligned}
$$

The above two methods find agreement in the fact that the correlation coefficients due to humidity are both positive and those due to temperature are both negative, but differ in that the humidity correlation in the second method is higher than in the first, whilst the reverse is the case with the temperature correlation.

This is one of the strong supports for the statement that daily variation of burning time is due mostly to the influence of humiclity, while its seasonal change is due mainly to the temperature.

6 According to the experiment which is now going on, their coefficients arc grcater than those, i.c. the former is +0.47 while the latter -043 , the material used is little different.

7 A more thorough discussion of the subject will be attempled later. 
The vaporisation coefficient is somewhat high, not because it plays an important part in the combustibility, but because the atmospheric temperature which is highly correlated with it, has an outstanding influence on the vaporisation, otherwise it cannot be explained by any means; whereas the correlation coefficient of vaporisation is negative.

The next question is how the relative humidity comes into play during combustion. In answering the question there are only two alternatives - first the damping action of the vapour outside the incense stick, the second that of water quantity within.

If the latter were paramount, the relation of time of burning to relative humidity should be greater than that with absolute humidity, because the water quantity in the stick can be shown to vary more closely with relative humidity than with absolute humidity which denotes nothing but the actual amount of water vapour.

The correlation coefficients in question worked out show that the coefficient of absolute humidity is negative in sign and thus it favours the latter explanation. It must, however, be borne in mind that there is a conspicuous high correlation between the absolute humidity and the temperature (amounting to $+0.83 \pm 0.02$ ) and that the best method for excluding the influence of temperature is to calculate the partial correlation coefficient of both.

Such values together with other necessary statistical factors are shown below.

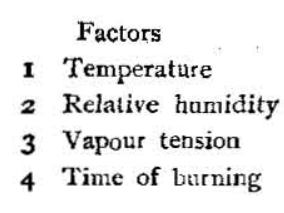

Correlation coefficient :

$$
\begin{aligned}
& -0.56 \pm 0.04 \\
& +0.83 \pm 0.02 \\
& -0.45 \pm 0.04 \\
& +0.21 \pm 0.05 \\
& -0.10 \pm 0.05
\end{aligned}
$$

\section{Table ${ }^{4}$}

Mean value
$18.0^{\circ} \mathrm{C}$
$59.1 \%$
$10.56 \mathrm{~mm}$
$1528.3 \mathrm{sec}$

Partial correlation coefficient :

$$
\begin{aligned}
& r_{42.2}=+0.19 \pm 0.05 \\
& r_{341}=+0.03 \pm 0.05
\end{aligned}
$$

$$
\begin{aligned}
& \text { between temperature and time } \\
& \text { between temperature and vapour tension } \\
& \text { between vapour tension and relative humidity } \\
& \text { between relative humidity and time } \\
& \text { between temperature and relative humidity }
\end{aligned}
$$


However small the former may be, it surpasses the latter in magnitude. Theoretically it may be conceived that such a partial correlation coefficient of time burning with relative humidity and with absolute humidity may be of the same order of magnitude, because both kinds of humidity change, under the same temperature, exactly in the same way. Were it really so, it would not matter at all, because it is better to dispense with such a correlation coefficient and to prefer the correlation between the time of burning and the weight change of the incense stick. This must be somewhat greater than that, first because there is a remarkably high correlation between the weight change of the stick and the relative humidity (amounting to +0.98), secondly because the water content of the stick diminishes slightly with the rise of temperature, even under the same relative humidity, and thirdly because it burns fast, in the hot season.

Therefore, the investigation along this line arrives at the same conclusion as in the total correlation.

\section{$\S$ I3 MATIEMATICAL EXPRUSSION OF THE BURNING VEIOCITY OF TIIE INCENSE STTCK}

There remains the great difficulty of finding the accurate mathematical formula of the velocity of burning of a rod such as the incense stick.

For the object of gaining a correct view of the burning as well as on its controlling weather factor, the deduction of the formula, however insufficient, is most desirable.

Suppose an infinitely long and thin rod burns steadily lengthwise, so that the red hot part having a breadth $h$ advances forward with a constant velucity $v$. Then the incandescent part in contact with the surrounding air has a surface of.

$$
\left(2 \pi \mathrm{rh}+\pi \mathrm{r}^{2}\right)
$$

Further denoting by $\mathrm{q}$ the amount of the oxygen expended to combine with the combustible part of the rod per unit time at the unit surface, we get

$$
\left(2 \pi \mathrm{r} h+\pi \mathrm{r}^{2}\right) \mathrm{q} d \mathrm{t}
$$

as the total oxygen consumed in dt. Some fraction of the heat of combination thus developed and denoted as to its amount by

$$
\mathrm{s}\left(2 \pi \mathrm{r} \mathrm{h}+\pi \mathrm{r}^{2}\right) \mathrm{q} \mathrm{dt} \text {. }
$$

should be considered as conduc ed through the section. This contributes 
not only to heat the portion $\pi r^{2} v d t$ immediately adjacent to the incandescent part, but also to vaporize the water within the rod, this being expressed by

$$
\pi \mathrm{r}^{2}(\mathrm{c} \rho \mathrm{T}+\mathrm{Q} \sigma) \mathrm{v} \mathrm{dt}
$$

where $c$ is the specific heat of the rod highly desiccated, $T$ the temperature of the red hot part, $Q$ the quantity of heat necessary to drive out the unit mass of the water from the interior of the rod (corresponding to the heat of adsorption of water), $\rho$ the density and $\sigma$ the amount of water per unit mass of the rod.

Equating those two terms, we obtain as the burning velocity $\mathrm{v}$

$$
\mathrm{v}=\frac{\mathrm{s}(2 \mathrm{~h}+\mathrm{r}) \mathrm{q}}{\mathrm{r}(\mathrm{c} \rho \mathrm{T}+\mathrm{Q} \sigma)}
$$

When $r$ is very small, the equation assumes the simpler form,

$$
\mathbf{v}=\frac{2 \mathrm{~s} \mathrm{hq}}{\mathbf{r}(\mathrm{c} \rho \mathrm{T}+\mathrm{Q} \sigma)}
$$

Assuming 2shq as constant, the velocity of burning is reversely proportional to the radius of the rod, which agrees pretty well with the experiment.

From (I) the expression for the time $t$ required to burn a unit length of the rod is easily obtained.

$$
\mathrm{t}=\mathrm{t}_{\mathrm{o}}\left(\mathrm{I}+\frac{\mathrm{Q} \sigma}{\mathrm{c}} \frac{\sigma}{\mathrm{T}}\right)
$$

To find the application to our actual case, we make a slight change of (II) as follows,

$$
\mathbf{t} / \mathbf{t}^{\prime}=\frac{\left(\mathbf{1}+Q \sigma-Q^{\prime} \sigma^{\prime}\right)}{\mathbf{c} \rho \mathbf{T}}
$$

where $t^{\prime}$ is the time of burning of the incense stick with values $Q^{\prime}$ and $\sigma^{\prime}$.

If $t$ and $t^{\prime}$ are measured under the same temperature, then

and formula (III) becomes

$$
Q=Q^{\prime}
$$

$$
\mathrm{t} / \mathbf{t}^{\prime}=\mathbf{1}+\frac{\mathrm{Q}\left(\sigma-\sigma^{\prime}\right)}{\mathrm{c} \rho \mathrm{T}}
$$

Using the formula (IV), $t / t^{\prime}$ can be calculated provided that 6 factors in the right hand of the equation are known. The temperature $T$ of the red hot part of the stick was measured with two different methods, one with Siemens' optical pyrometer, the other with the copper constantan thermo-junction. We are much obliged to Dr. S. 
Watanabe tor measuring $\mathrm{T}$ by the former method. According to him, one kind of incense stick gave $835^{\circ} \mathrm{C}$ except very near the bottom where the lower temperature $760^{\circ} \mathrm{C}$ was obtained, the other almost the same temperature $835^{\circ} \mathrm{C}$ to $840^{\circ} \mathrm{C}$; the relative humidity and the room temperature were respectively $87 \%$ and $25^{\circ} \mathrm{C}$.

On the other hand, the value obtained with the latter method by the writer was $570^{\circ} \mathrm{C}$ much lower than with the optical. Every precaution regarding the calibtation of temperature as well as the contact of the wire with the incense stick was taken in this measurement The writer adopts, however, $840^{\circ} \mathrm{C}$ as the most probable temperature, because even the point-like junction is apt somewhat to lower the temperature therein, probably due to the conduction of heat.

The specific heat of the incense stick $c$ was obtained by the usual method using the water calorimeter, where we could not expect to obtain results of high accuracy, due chiefly to the absorption of water in the calorimeter.

By several repetitions we got as a final value, 0.24 (specific heat at $100^{\circ} \mathrm{C}$ ), possibly a little lower than the true one, by reason of the heat of adhesion evolved when immersed in the calorimeter.

$Q$ is probably of the order of the heat of vaporisation or a little more (the heat of adsorption of nitrogen or of ammonia to carbon is about twice the heat of vaporisation). Now we assume

$$
Q=79.7 \mathrm{cal} / \mathrm{g} \text { (heat of vaporisation of water) }
$$

Taking an example from p. 4

$$
0.085 \mathrm{~g} / \mathrm{c.c} \text {. }
$$

of the incense stick, as the water deficit by relative humidity $40 \%$ from when by $84 \%$, we get.

$$
\mathrm{t} / \mathbf{t}^{\prime}=\mathbf{r}-0.077
$$

At the same time, $t / t^{\prime}$ can be calculated directly from the observations, which leads to the verification of the formula as well as to the assumption of a great influence of a small water amount in the stick. From the table on the burning time within a closed vessel, time $t$ and $t^{\prime}$ corresponding to the humidity $40 \%$ and $84 \%$ at $25^{\circ} \mathrm{C}$ are found to be $\mathrm{I} 600 \mathrm{sec}$. and $17 \mathrm{IO} \mathrm{sec}$. (reduced to $1 \mathrm{~mm}$ radius) respectively. Thereiore,

$$
\mathrm{t} / \mathrm{t}^{\prime}=\frac{\mathrm{I} 600}{\mathrm{I} 7 \mathrm{IO}}=\mathrm{I}-0.064
$$

The agreement between the values observed and calculated is quite satisfactory, in spite of many assumptions as to the constants as well as 
to deduction of the formula. This corroborates without doubt the conclusion statistically obtained, namely that the seat of the cause of ready combination lies inside the incense stick, and that the ever changing water quantity is a main factor controlling the velocity of burning.

\section{§ I $_{4}$ COMBUSTION OF MAGNESIUM RIBBON IN THE AIR}

The above conclusion leads naturally to the suspicion that a burning rod made of material quite indifferent to the variation of the relative humidity may behave quite otherwise than the one above experimented with. Any metal may, for example, serve this purpose.

We made, therefore, in a large glass chamber of $30 \times 70 \times 100 \mathrm{c}$. c. a series of experiments on the combustion of magnesium band.

Wc usually burnt it down to $5 \mathrm{~m}$. long. The band was of a dimension commonly obtainable at a chemical shop, with a width of $2.68 \mathrm{~mm}$. thickness $0.12 \mathrm{~mm}$. and weight $2.49 \mathrm{~g}$. The main results are briefly shown in the following table.

\begin{tabular}{|c|c|c|}
\hline Temperiture & Ifumidity $\%$ & Time (sec.) \\
\hline $18.0-17.8$ & $40-49$ & $35^{\circ}$ \\
\hline IS.0 -20.1 & $4^{2}-43$ & 344 \\
\hline$I 8.0-20.5$ & $55-50$ & 294 \\
\hline $18.3-20.6$ & $70-64$ & 290 \\
\hline $18.2-20.9$ & $70-67$ & 268 \\
\hline r $8.0-21.2$ & $56-98$ & 260 \\
\hline$\overline{1} \delta \cdot \bar{z}-\overline{2} \overline{1} \cdot \bar{z}$ & $94-93$ & $\overline{2} 7 \overline{3}$ \\
\hline Temperature (means) & Irumidity (means) & Time (means) sec \\
\hline $26.2^{\circ} \mathrm{C}$ & $81.2 \%$ & 318.3 \\
\hline $16.5^{\circ} \mathrm{C}$ & $82.0 \%$ & 322.3 \\
\hline
\end{tabular}

We have not rewritten the details of the time of burning with respect to temperature-change, because the manner of variation of burning time is almost the same as that of the incense stick.

Special care was taken in this experiment to burn the metal band always under the same conditions. When the magnesium ribbon is driven upward passing through two slits, it is pressed between two oppositely rotating pulleys. Fvery effort was made to keep the height of the flame

8 The influence arising directly from the moisture in the air is insignificantly small; see the section of the fire and weather. 
constantly visualized by means of a telescope. The results obtained however are not satisfactory, because the bending over the upper end of the ribbon when burning caused many disagreable consequences and made exact measurement almost impossible. Hence, only the qualitative argument in regard to this result can be applicable.

The fact revealed in the experiment is this. The effect of temperature on the time of burning is the same as before, and that of humidity gives rise to quite contrary consequences; the velocity of burning increases with the humidity. It can not be decided at present whether it has to do with the relative or the absolute humidity, because under the same temperature, we cannot vary the one, without causing corresponding change in the other.

This unexpected result seemed at first incredible, and so the same experiment was repeated polishing the metal surface to remove the thin coating film of magnesium oxide, but the results remain the same and the ribbon burns always rapidly with the increase of moisture. ${ }^{9}$

This experiment naturally cannot be considered as a final proof of the conclusion previously obtained by us. Nevertleless, it gives strong evidence in its favour.

It is highly probable that water dissociates into oxygen and hydrogen, as in high temperature as when magnesium burns in air, i.e.

$$
2 \mathrm{H}_{2} \mathrm{O}=2 \mathrm{H}_{2}+\mathrm{O}_{2}
$$

This makes the oxidation of magnesium much easier, the consequence of which is that the metal burns rapidly with the increase of humidity.

As the above experiment led to a result quite contrary to our cxpectations we carried out another one by using different material. We let stearin candles burn, varying the degree of humidity and measured the burning time.

Table 16 l3urning time of stearin candles

(diameter, $4.7 \mathrm{~mm}$, length, $5.8 \% 6.0 \mathrm{~cm}$ )

\begin{tabular}{|c|c|c|c|}
\hline Weight & Ternperature & Relative humidity & Time/weight \\
\hline $936 \mathrm{mg}$ & $17.0-17.2^{\circ} \mathrm{C}$ & $80-88 \%$ & $974 \mathrm{sec} / \mathrm{s}$ \\
\hline 912 & $17.0-17.2$ & $70-88$ & $\mathrm{I}_{44} \mathrm{O}$ \\
\hline 930 & $17.0-17.1$ & so -90 & 1120 \\
\hline 930 & $17.0-17.8$ & $46-50$ & 945 \\
\hline 934 & $17.0-17.4$ & $46-49$ & $89 \mathbf{r}$ \\
\hline
\end{tabular}

9 No change in the weight of the magnesium-ribbon, whether polished or not, could be detected, while wood, paper and the like simultaneously observed showed conspictous variation. 
As an average

relative humidity
$83 \%$
$48 \%$ time/wt
$1 \times 78 \mathrm{sec} / \mathrm{g}$
$918 \mathrm{sec} / \mathrm{g}$

Hence the increase of relative humidity by $10 \%$ increases the time of burning by $0.74 \%$.

We have also tried with vegetable oil to affirm above result, the apparatus being, in this case, the self recording. The consequence is not so accurate, as to be able to express it in numbers, yet it has scemingly to slacken its burning velocity as the humidity is lowered.

The retarding effect of humidity upon the burning of candles should be explained in other way than that upon incense stick, because the

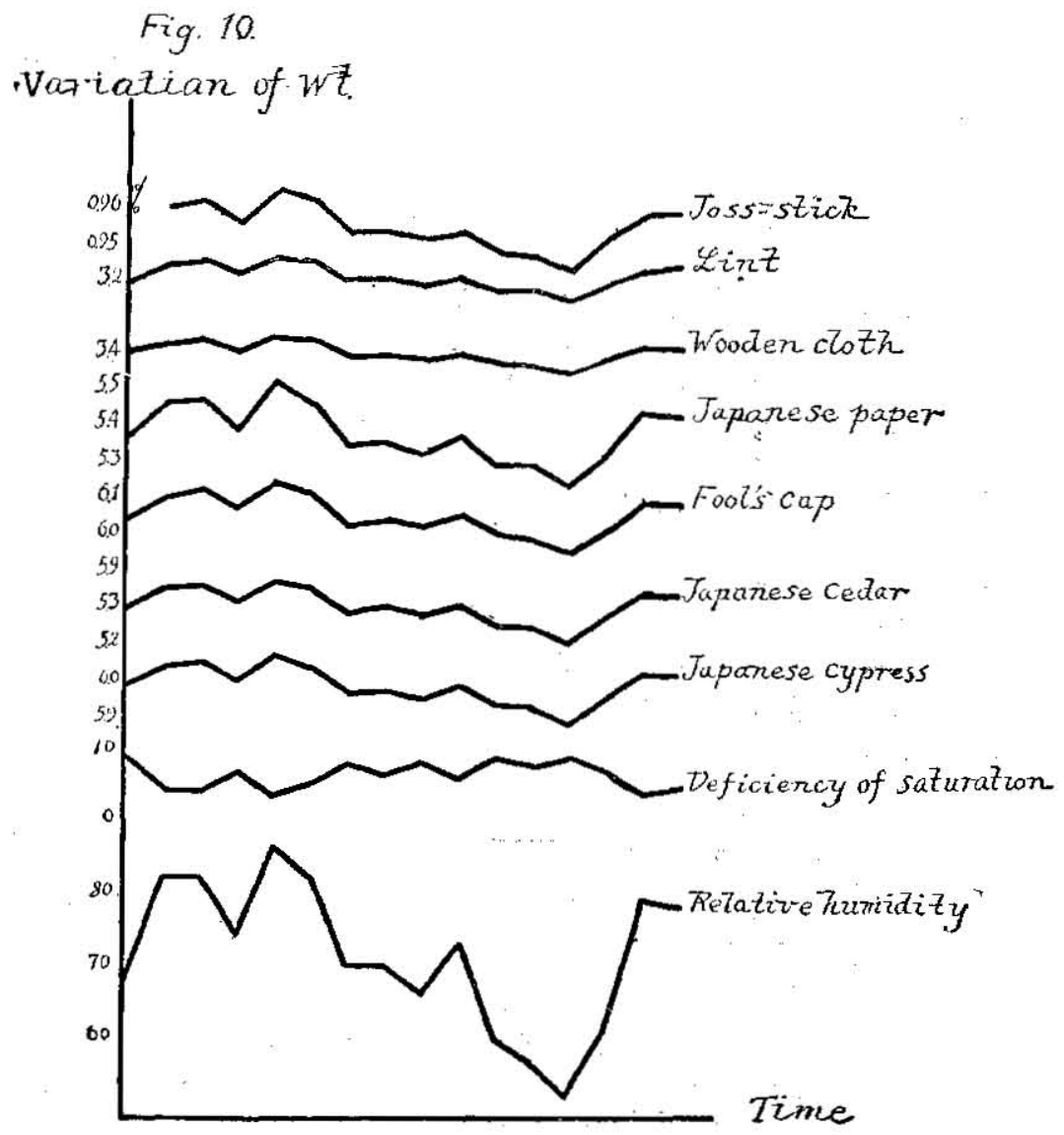


weight of candles undergoes, as the experiment shows, no daily variation due to the changing relative humidity of the surrounding air. So it seems that the humidity influence on the burning velocity of the candle and the like, which burn, with flame in air and at the temperature not so high as in the case of magnesium-combustion, should be interpreted as coming directly outside the candle stick, possibly from the water vapour formed by hydrogen constituents in fat and oil.

So it seems that the combustion of metal and oil is different from incense stick, wood and such like which burn without flame.

\section{$\S I_{5}$ VARIATION OF WATER-CONTENT OF MATERIALS OF HOUSE-FURNITURE}

In order to get some knowledge of the absorption of vapour by several materials other than wood or incense stick, we weighed daily the following materials, measuring at the same time temperature and relative humidity.

Table 17 Variation of water-content of various materials. (in gram)

\begin{tabular}{|c|c|c|c|c|c|c|c|c|c|c|}
\hline Date & Temp. & IJumid. & Sat. def. & $\begin{array}{l}\text { Japan. } \\
\text { cypr. }\end{array}$ & $\begin{array}{l}\text { Japan. } \\
\text { cedar }\end{array}$ & $\begin{array}{l}\text { Fool's } \\
\text { cap }\end{array}$ & $\begin{array}{c}\text { Rice } \\
\text { paper }\end{array}$ & $\begin{array}{l}\text { Woolen } \\
\text { cloth }\end{array}$ & I.int & $\begin{array}{c}\text { Incense } \\
\text { stick }\end{array}$ \\
\hline I & $26.1^{\circ} \mathrm{C}$ & $69.0 \%$ & $9.00 \mathrm{~mm}$ & $5.990 \mathrm{~g}$ & 5.307 & $6.05^{2}$ & $5 \cdot 370$ & $3 \cdot 396$ & 3.204 & $\ldots . .$. \\
\hline$z$ & $25 \cdot 1$ & 82.6 & 5.05 & 6.033 & $5 \cdot 307$ & 6.102 & $5.45^{\circ}$ & $3.4^{21}$ & 3.239 & 0.960 \\
\hline 3 & 25.2 & 83.0 & 4.87 & 6.046 & $5 \cdot 35^{8}$ & 6.1 16 & $5 \cdot 47^{2}$ & 3.429 & 3.247 & 0.962 \\
\hline 4 & $26 \cdot 3$ & $74 \cdot 9$ & $7 \cdot 55$ & 5.998 & $5 \cdot 316$ & 6.066 & $5 \cdot 3^{89}$ & $3 \cdot 404$ & 3.216 & 0.956 \\
\hline 5 & 27.0 & 86.9 & 4.12 & 6.059 & $5 \cdot 373$ & 6.140 & 5.517 & 3.436 & 3.263 & 0.965 \\
\hline 6 & 28.0 & 82.9 & 5.92 & 6.033 & $5 \cdot 34^{8}$ & 6.109 & 5.459 & 3.425 & 3.246 & 0.962 \\
\hline 7 & 25.1 & 70.7 & 8.46 & 5.973 & 5.292 & $6.03^{2}$ & $5 \cdot 342$ & $3 \cdot 388$ & 3.195 & 0.953 \\
\hline 8 & 22.2 & $75 \cdot 5$ & 6.87 & 5.975 & 5.299 & 5.059 & $5.35^{\circ}$ & $3 \cdot 389$ & 3.197 & 0.953 \\
\hline 9 & 23.8 & 66.8 & 8.35 & 5.955 & 5.275 & 5.018 & $5 \cdot 325$ & 3.379 & 3.184 & $0.95^{1}$ \\
\hline Io & 22.0 & 73.2 & 6.17 & 5.984 & $5 \cdot 303$ & 5.148 & 5.366 & 3.395 & 3.201 & 0.953 \\
\hline I $\mathrm{I}$ & 22.2 & 60.4 & 9.02 & 5.931 & 5.254 & 5.996 & 5.292 & 3.368 & 3.172 & 0.968 \\
\hline$x z$ & $19 \cdot 3$ & 57.4 & 8.02 & 5.922 & 5.244 & 5.983 & $5 \cdot 278$ & 3.362 & 3.165 & 0.947 \\
\hline 13 & 19.9 & $5^{2.5}$ & 9.11 & 5.878 & 5.202 & 5.947 & 5.232 & $3 \cdot 34^{2}$ & $3 \cdot 14^{2}$ & 0.943 \\
\hline 14 & 19.1 & 61.5 & $7 \cdot 17$ & $5.95^{\circ}$ & 5.271 & 6.008 & 5.310 & 3.377 & 3.178 & $0.95^{2}$ \\
\hline I 5 & 19.1 & 79.1 & 4.13 & 6.010 & $5 \cdot 328$ & 6.079 & 5.427 & 3.410 & 3.225 & $0.95^{8}$ \\
\hline \multirow[t]{4}{*}{16} & 21.5 & 78.3 & 4.88 & 6.009 & $5 \cdot 329$ & 6.084 & 5.425 & 3.4 ro & 3.220 & 0.958 \\
\hline & & & Length & Iocm & $10 \mathrm{~cm}$ & I2 & 48 & rom & $10.6 \mathrm{~cm}$ & rocm \\
\hline & & & Breadth & $5 . \mathrm{I}$ & 5.1 & sheets & sheets & $3 \mathrm{~cm}$ & $\times 5.8$ & long \\
\hline & & & Thickness & 0.25 & 0.25 & & & & 8 pieces & \\
\hline
\end{tabular}

The weight of all materials in the above table increases without single exception with the relative humidity and decreases with deficiency of saturation and vice versa. The correlation coefficient between weight and relative humidity as well as that between weight and deficiency of saturation was calculated for each material and is reproduced below. 
Table is Correlation coefficients between weight, relative humidity and saturation deficiency

\begin{tabular}{l|c|c}
\hline \multicolumn{1}{c|}{ Materials } & $\begin{array}{l}\text { Cor. coef. of weight } \\
\text { with relat. htmidity }\end{array}$ & $\begin{array}{l}\text { Cor. coef, of weight } \\
\text { wilh satur. deficien. }\end{array}$ \\
\hline Japanese cypr. & $0.984 \pm 0.005$ & $-0.802 \pm 0.060$ \\
Japanese cedar & $0.984 \pm 0.005$ & $-0.808 \pm 0.058$ \\
Fools cap & $0.988 \pm 0.004$ & $-0.822 \pm 0.048$ \\
Rice paper & $0.984 \pm 0.005$ & $-0.845 \pm 0.056$ \\
Woolen cloth & $9.988 \pm 0.004$ & $-0.815 \pm 0.054$ \\
Lint & $0.977 \pm 0.005$ & $-0.823 \pm 0.055$ \\
Incense stick & $0.976 \pm 0.008$ & $-0.858 \pm 0.046$
\end{tabular}

Thus the water content has, for all the materials, nearly the same high correlation with relative humidity and it is greater than with saturation deficiency. The average amount of the weight change for each material is more clearly brought out in the following table.

Table 19 Change of weight of various materials in percentage.

$\begin{array}{ccccccc}\text { Jap. cyp. } & \text { Jap. ced. } & \text { F. c. } & \text { Rice pap. } & \text { Wool. clot. } & \text { Lint } & \text { Incense st. } \\ \% 0.7 \mathrm{I} & \mathbf{0 . 7 4} & 0.77 & \mathbf{1 . 2 8} & 0.70 & 0.85 & 0.54^{10}\end{array}$

So we see that the weight of the various materials tested undergoes a daily change of the same degree arising from the interchange of water between the surrounding air and the material. The rice paper ${ }^{11}$ is the only exception; it is a remarkable absorber of water.

\section{§ 6 INFLUENCE OF TEMPERATURE ON WATER CONTENT}

It is of interest to know how the water quantity changes with variation of temperature, if under the same humidity. Unfortunately we have only two instances of it owing to the unfavourable circumstances.

Table 20 Weight change and temperature (gram)

\begin{tabular}{|c|c|c|c|c|c|c|c|c|c|}
\hline $\begin{array}{l}\text { Relat. } \\
\text { humid. }\end{array}$ & $\begin{array}{l}\text { Mean } \\
\text { temp. }\end{array}$ & $\begin{array}{l}\text { 'lemp. } \\
\text { diff. }\end{array}$ & $\begin{array}{l}\text { Jap. } \\
\text { cyp. }\end{array}$ & $\begin{array}{l}\text { Jap. } \\
\text { ced. }\end{array}$ & $\begin{array}{l}\text { Fool } \\
\text { cap. }\end{array}$ & $\begin{array}{c}\text { Rice } \\
\text { palper }\end{array}$ & $\begin{array}{l}\text { Wool } \\
\text { cloth }\end{array}$ & $\begin{array}{c}\text { Incense } \\
\text { stick }\end{array}$ & $\begin{array}{c}\text { Incense } 1 \\
\text { stick }\end{array}$ \\
\hline $\begin{array}{l}83.0 \% \\
82.9 \%\end{array}$ & $26.8^{\circ} \mathrm{C}$ & $2.8^{\circ} \mathrm{C}$ & .0124 & .0127 & .0066 & .0129 & .0037 & .0016 & .0040 \\
\hline $70.7 \%$ & $23.9^{\circ} \mathrm{C}$ & $3.4^{\circ} \mathrm{C}$ & .0020 & .0066 & .0068 &.$\infty 80$ & .0012 & .0017 & .0005 \\
\hline
\end{tabular}

10 This value is half of that previously obtained. Mention should however be made of the fact that in this case the measurement was made under ever changing humidity, while in the other the humidity was constant.

if The shects of Japanese rice paper are thin, light and very fibrous and translucent. 
The above data are too scanty to allow a claim to much value therein. The general trend is, nevertheless, that in spite of the same humidity the water decreases with arise of temperature.

\section{§ I7 GENERAL REMARKS ON COMBUSTION}

Generally speaking, such materials as wood, paper, wool and so on are all of fibrous structure, though differing in other properties, and take in or give out water to the same degree, as already described.

If moisture and temperature affect the combustibility of the incense stick in no small degree, why should they not likewise affect these materials of house furniture or fuel ?

Thus it seems most probable that the same conclusions already obtained are applicable generally to almost all cases of fire burning.

\section{PART II THE FIRES AND THE WEATHER}

\section{§ I8 GENFRAL REMARKS}

The fact that fires break out oftener in the cold season is well known in Japan, and it seems to be so also all over the world. We now cite two instances to illustrate this, one from fire statistics in Japan and another from London.

Table 2I Annual frequency of fire-outbreak per day in Japan (excluding her colonies) 1889-1918.12

Jan. Feb. Mar. Apr. May June July Aug. Sept. Oct. Nov. Dec.

$\begin{array}{llllllllllll}597.7 & 609.5 & 553.7 & 537.8 & 509.0 & 375.7 & \mathbf{2 9 2 . 2} & 330.8 & \mathbf{2 8 9 . 6} & \mathbf{2 9 4 . 4} & 390.0 & \mathbf{5 2 5 . 4}\end{array}$

Remark: The cold months December to May have a remarkably large number of fires, while in the warm months June to November they are very few. The numbers rise and fall with considerable regularity, and there are two showing a maximum (February and August) and two showing a minimum (July and September).

Table 22 Annual frequency of fires per day in London r912-1921.13

Jan. Feb. Mar. Apr. May June July Aug. Sept. Oct. Nov. Dec. $\begin{array}{llllllllllll}13.80 & 13.26 & 12.3^{6} & x_{1.31} & 10.94 & 11.67 & 9.19 & 8.77 & 9.14 & 10.18 & 13.31 & 13.00\end{array}$

Remark: The cold season November to March is visited more frequently by fires than the warm season, April to October.

12 These values are taken from the Japanese year-book of statistics 1921 compiled by the Board of the Census.

13 This is taken from Daily Report of Fires in the County of London Fire Brigade 1912-1921 
Whether this is due entirely to greater use of fires in the winter is a question which awaits an answer and which is a subject to be treated of in the subsequent sections.

In advance it should be stated however that the occurence of fires is not a function solely of temperature in conjunction with human negligence, but of other meteorological conditions. This indicates clearly, that the rise and fall of the frequency of fires come partly from physical causes. As one proof of this we take one example from the fire statistics of Tokyo, reserving its detailed explanation till later.

Table 23 The correlation coefficient between the outbreak of fires and meteorological conditions

$\begin{array}{rlc}\text { correlation coef. bet. } & \text { probable error } \\ \text { fre outlreak and } & \\ 2 \text { Specific humidity } & -0.80 & 0.03 \\ 3 \text { Least relative humidity } & -0.76 & 0.04 \\ 4 \text { Vapour tension } & -0.72 & 0.04 \\ 5 \text { Absolute humidity } & -0.72 & 0.04 \\ 6 \text { Temperature } & -0.71 & 0.05 \\ 7 \text { Precipitation } & -0.70 & 0.04 \\ 8 \text { Vaporisation } & -0.54 & 0.06 \\ 9 \text { Atmospheric pressure } & -0.45 & 0.07 \\ \text { 10 Sunshine hours } & +0.32 & 0.07 \\ \text { II Mean wind velocity } & +0.28 & 0.07 \\ \text { 12 Maximum wind velocity } & +0.23 & 0.08 \\ \text { I3 Stormy hours } & -0.11 & 0.08 \\ \end{array}$

From the above table it should be admitted that the roble played by temperature is rather subordinate, and that the other elements, especially moisture are prominent factors with respect to fire occurrence.

In the subsequent treatment of the fire-problem, we confine our attention mostly to statistical study, paying attention to the laboratory side, when necessary.

The best weapon with which to attack such a problem is doubtless the coefficient of correlation. But there are several kinds of correlation coefficient to work with. What is constantly used however in our calculations is the ordinary one i.e. the coefficient of correlation between the departures from the mean value. Another often employed is called the method of variate difference,---correlation between the successive differences.

Since its appearance, this method has been advocated by several 
statisticians and meteorologists, and it will still remain a useful method for the solution of statistical problems, though recently Walker and Bliss have pointed out that it leads in some cases to erroneous conclusions.

When a series of subsequent events $A$ undergoes a change with two sets of events $B$ and $C$ which differ both in origin and period (if the change is oscillatory), the method of variate-difference is markedly advantageous, especially if the object is to seek the correlation between $\mathrm{A}$ and $\mathrm{B}$ of a considerably shorter period, whilst if the reverse is the case, the usual method is preferable. ${ }^{14}$ Of course, each has its weak points as well as strong ones. So we sometimes employ both methods together with a view to determine what part is played by temperature and humidity respectively.

Besides the above two, another course is taken to find the correlation between $\mathrm{A}$ and $\mathrm{B}$, one or both of which are long periodic with large amplitude, superposed with small fluctuation.

First expressing two sets of events with Fourier's series, each departure is reckoned from the corresponding value calculated from the above series, instead of using, as usual, the mean value. This method is found effective when employed in the study of fires in London, and we belicve that in this way the correlation between the second minor factor sometimes comes to light. For brevity we call this the harmonic method.

In the computation of correlation coefficient $r$, very often the table of correlation was used; yet Sheppard's correction was dispensed with, because in our case sufficient accuracy up to two decimals was obtainable without it.

The material used in this investigation was obtained by the courtesy of thirty provincial governments as well as six municipal offices from their official returns, for which we express our best thanks.

\section{\$19 TOKYO.15}

The correlation coefficient between fires and certain meteorological elements in Tokyo is shown in the forcgoing section, according to which the relative humidity is the most highly correlated of all factors

14 See an appendix at the end of this section.

15 Its population and the number of families respectively are $2,173,201$ and 456,820 (1920) 
with the outbreaks of fire, the specific humidity less highly and the other meteorological elements still less, in the order of the numbers in the table. All of them are negatively correlated except the pressure, sunshine, wind and stormy hours. ${ }^{16}$

(I) Humidity and temperature. The five elements of relative humidity, specific humidity, least humidity, vapour tension and absolute humidity are altogether nothing but the expression of the hygrometric state of the atmosphere, so that in short they may be regarded as the operating causes of similar effects on the fire, and may be treated, for the time being, simply as a moisture element.

So it is obvious from the correlation coefficients that the temperature element plays a less important part in the fire than it has been or is believed, and that the moisture element as a controlling factor is paramount over any other weather factor.

Neither the moisture nor the temperature is, however, as closely correlated in actuality as its correlation coefficient indicates, because in Japan it is very dry in the winter and moist in the summer; thus for example the coming of the seasonal dryness enhances the hazard of fire not only from itsclf, but from the lowering of temperature (particulary due to much use of fire), we must however be ware of being misled, on account of the fact that the daily hygrometric variation is, as a rule, opposite in sense to the temperature-variation, so that the correlation due to daily temperature-change acts quite differently from that due to the seasonal change.

Fortunately, however, to get the correlation coefficient bearing solely on a weather factor - say humidity - we have at our command two or three methods. One is to rely on the calculation of the partical correlation, another is to get rid of fire-occurrence arising entirely from the heating apparatus so much used in the cold season.

(a) A partial correlation coefficient. As the correlation coefficient between temperature and humidity is +0.87 , two partial correlation coefficients become respectively.

$-0.54 \pm 0.06$ between fire outbreak and relative humidity

$-0.01 \pm 0.08$ between fire outbreak and temperature

So we see that the correlation of fire outbreak with humidity is decirledly higher than with tem icrature. Or going a step further we may say that the latter coefficient might be positive, for its probable 
error is far so great that we can find hardly reason to ascribe a great meaning to its negative sign.

(b) The elimination of fire occurrence caused by heating apparatus. As regards the second method above mentioned, there are at our disposal (though they cover only two years 1917, 1918) the monthly fire statistics of Tokyo giving details of the origin of the conflagrations.

Table 24. Statistics ot hres for Tokyo. (daily)

\section{A: all causses included; B: heating sources excluded.}

1917. Jan. Feb. Mar. Apr. May June July Aug. Sept. Oct. Nov. Dec. $\begin{array}{lllllllllllll}\text { No. of occ. of } A & 0.97 & 1.46 & 0.74 & 0.83 & 0.68 & 0.63 & c .58 & 0.65 & c .20 & 0.97 & 0.87 & 1.5^{8}\end{array}$


$\begin{array}{lllllllllllll}\text { relative humidity } & 58.5 & 56.3 & 65.5 & 68.6 & 73.0 & 82.2 & 73.0 & 75.5 & 86.6 & 82.3 & 69.3 & 59.1\end{array}$ $\begin{array}{lrrrrrrrrrrrr}\text { tcmperature } & 2.3 & 4.5 & 6.4 & 12.7 & 15.8 & 19.6 & 25.7 & 25.0 & 22.0 & 16.8 & 8.1 & 4.0\end{array}$ 1918



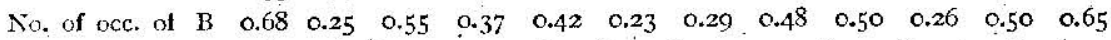
$\begin{array}{lllllllllllll}\text { relative humidity } & 54.9 & 6 \mathbf{I . 6} & 65.1 & 72.7 & 76.1 & 83.9 & 8 \mathrm{~s} .9 & 79.5 & 80.7 & 83.0 & 74.8 & 7 \mathbf{x . x}\end{array}$ $\begin{array}{lllllllllllll}\text { temperature } & 1.6 & 3.6 & 6.7 & 1 \times .7 & 16.7 & 20.1 & 26.0 & 26.1 & 22.6 & 16.0 & 10.4 & 3.9\end{array}$

The correlation coefficient between humidity and the fire in case

$$
\mathrm{B}=-0.48 \pm 0 . \mathrm{I}
$$

The correlation coefficient between temperature and fires in case

$$
\mathbf{B}=-0.4 \mathrm{I} \pm 0 . \mathrm{I}
$$

It is to be added that the two correlation coefficients in case $A$ corresponding to the above two are found respectively to be

$$
-0.79 \pm 0.05 \text { and }-0.70 \pm 0.07
$$

remarkably well coinciding with the values of six years' statistics.

The first two correlation coefficients, derived from cases free of heater accidents are notably small, as we have anticipated. And it is worthy of note that the correlation coefficient between humidity and the fire is nearly equal to the partial correlation coefficient of those two factors.

The fact that the correlation coefficient between the fire and temperature diminishes in magnitude far less than might have been expected is not very surprising, because temperature and humidity are very closely correlated in a positive sense, so that it can not be reduced to a low value, except by means of partial correlation.

The method of the variate difference gives the following coefficients, between fire and humidity $-0.64 \pm 0.05$ between fire and temperature $-0.37 \pm 0.07$ 
As will be analytically demonstrated in the notes at the end of this section, the value -0.64 can be considered nearly as the total correlation coefficient between the monthly variation of fire occurrence and that of the humidity, their general trend (mainly temperature influence) being eliminated. On the other hand, the correlation coefficient -0.80 seems adequate to be regarded as that between the annual changes of fire and of humidity, where that due to the monthly change is though imperfectly, removed.

Therefore taking the above results into consideration, it is evident that the supremacy of the influence of relative humidity over other elements is conspicuous.

Monthly change of coefficient of correlation. Those correlation coefficients vary from month to month. A cursory glance at the diagram of regression lines (Fig. I I) convinces us of the fact that their correlation is perfect during the period when both the humidity and the temperature are high. These facts are recognised not only in Tokyo but everywhere with the exception of a very few cases, as is shown later

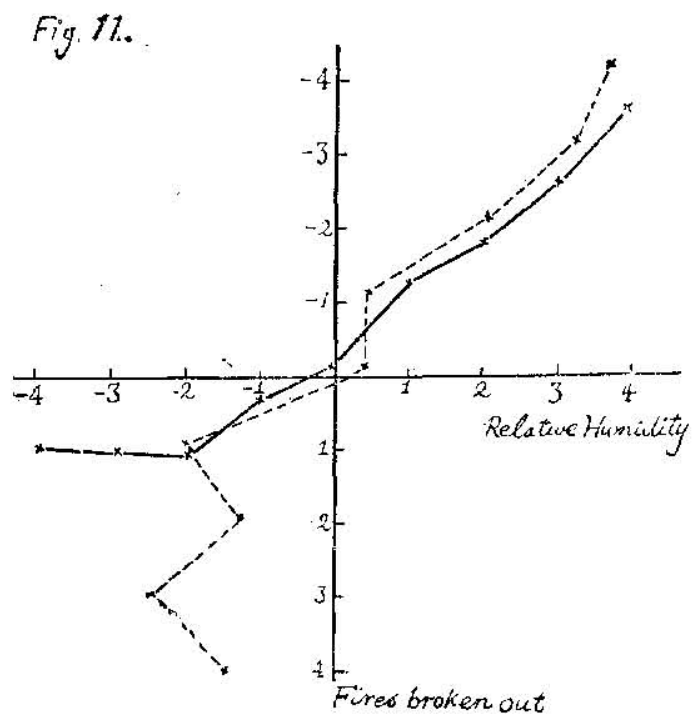
and fully discussed.

In this connection it would not be out of place to say something about the rectilinearity of regression. As the diagram shows, this condition is nearly satisfied in the two cases, though in less degree in that of temperature.

(II) Minimum relative humidity. The monthly minimum value of relative humidity correlates with fire to a high degree, second only to the specific humidity. According to the statistics of forest fires for Hokkaido, its correlation with minimum relative humidity is highest in the month May. This result is in accordance with ours, but only in the same month and October. Nevertheless it is of interest, because it suggest the possibility of an origin common to both. 
(III) Evaporation, vapour tension, and specific humidity. The study of forest fires in California is said to show a higher degree of correlation with the amount of evaporation than with any other factor; the above recorded house-fire investigation is however unfavourable to this view, for the degree of its correlation with evaporation is not so great as that with relative humidity. The same relation can be enunciated in the case of vapour-tension, and so it is with either monthly mean value of absolute- or specific humidity. These correlation coefficients are of the same order and never exceed that of relative humidity. This fact reveals at length the true nature of the underlying interrelation between fire and moisture. ${ }^{17}$

(IV) Precipitation. The correlation coefficient between fire and the monthly amount of precipitation is -0.54 . Judging by the diagram of regression lines, they correlate well when the two elements are small in magnitude. Its effect on fire is possibly two-fold.

The damping action of precipitation on fire seems seldom to come directly from rain, because the statistics of daily outbreaks of fire in Osaka reveal the fact that there are many rainy days in which fires very often occur (the correlation between rain and relative humidity is not so great as one would expect) so that its high corrclation is only apparent, and due to the indirect effect of the precipitation enhancing relative humidity, to which the real cause of control of fire occurrence can be attributed, as the correlation cuefficient between fire and humidity is larger than that between the fire and precipitation, and all the more so, as there is a high correlation between precipitation, and humidity.

(V) Multiple correlation between the fire, relative humidity, temperature and precipitation. Further detail comes to light, if we direct attention to multiple correlation among these weather-elements. Denoting the frequency of fire-occurrence, relative humidity, temperature and the amount of precipitation by the numbers 1, 2, 3 and 4 and using the following total correlation-coefficients, we get,

Table 25 Multiple correlation,

$$
\begin{array}{rrrr}
r_{1.2}=-0.80 & r_{1.3}=-0.70 & r_{1.4}=-0.54 & r_{2.3}=+0.87 \\
r_{3.4}=+0.44 & r_{2.4}=+0.65 & & \\
r_{123}=-0.54 & r_{12.4}=-0.70 & r_{13.4}=-0.6 \mathbf{I} & r_{234}=+0.84 \\
\pm 0.06 & \pm 0.04 & \pm 0.05 & \pm 0.03
\end{array}
$$

$17 \sec \S 28$. 


$$
\begin{aligned}
& \mathbf{r}_{13.2}=-0.0 \mathrm{I} \quad \mathbf{r}_{14.2}=-0.04 \quad \mathrm{r}_{14.3}=-0.36 \quad \mathrm{r}_{24.3}=+0.60 \\
& \pm 0.08 \quad \pm 0.08 \quad \pm 0.07 \quad \pm 0.05 \\
& r_{23.1}=+0.72 \quad r_{24.1}=+0.43 \quad r_{34.1}=+0.10 \quad r_{34.2}=-0.33 \\
& \pm 0.04 \quad \pm 0.07 \quad \pm 0.08 \quad \pm 0.07 \\
& r_{1234}=-0.44 \quad r_{14.23}=-0.05 \quad r_{13,42}=-0.03 \quad r_{34.12}=-0.34 \\
& \pm 0.07 \quad \pm 0.06 \quad \pm 0.08 \quad \pm 0.07 \\
& r_{32.1 ;}=+0.76 \\
& \pm 0.04
\end{aligned}
$$

Relatively considered, either $r_{14,23}$ or $r_{13,42}$ is numerically far less than $r_{1234}$ (partial correlation-coefficient between fire and relative humidity, both temperature and precipitation being constant) though naturally much smaller than the total correlation-coefficient.

Further making use of the following mean value, standard deviation of all orders with mean errors, are

$$
\begin{aligned}
& \mathrm{M}_{1}=1.18 \quad \mathrm{M}_{2}=74.27 \% \quad \mathrm{M}_{3}=14.08^{\circ} \mathrm{C} \quad \mathrm{M}_{4}=4.68 \mathrm{~mm} / \mathrm{day} \\
& \sigma_{1}=0.52 \mathrm{I} \quad \sigma_{2}=8.229 \quad \sigma_{3}=7.982^{\circ} \mathrm{C} \quad \sigma_{4}=2.90 \mathrm{I} \\
& \sigma_{1,234}=0.312 \quad \sigma_{2,134}=2.912 \quad \sigma_{3,124}=3.707 \quad \sigma_{4,123}=2.074
\end{aligned}
$$

All the four regression-equations of the third order can be readily obtained, but at present we confine ourselves to the equation giving the number of daily fire-occurrences $X_{1}$ in terms of three other variables, namely relative humidity $\mathrm{X}_{2} \%$, atmospheric temperature $\mathrm{X}_{3}{ }^{\circ} \mathrm{C}$ and daily amount of precipitation $\mathrm{X}_{4} \mathrm{~mm}$.

$$
\mathrm{X}_{1}=4.723 \mathrm{I}-0.04674 \mathrm{X}_{2}-0.00252 \mathrm{X}_{3}-0.00775 \mathrm{X}_{4}
$$

The results of calculation from this equation compared with observed facts are not so satisfactory.

(VI) Wind and atmospheric pressure. They both correlate positively with occurrence of fire as shown above, though considerably low in value. The correlation with wind is however found in a higher degree in other places than in Tokyo. To this subject we shall return later.

(VII) The spreading of fire in relation to meteorological elements. Both the number of the outbreaks of fire and the corresponding extent of the burnt area vary in amount from month to month, but not always in the same manner.

We will now turn attention to this subject and consider, for convenience, the ratio of the latter to the former-burnt area per one occurrence of fire-outbreak. This quantity "a" is very useful for obtaining the numerical expression of the rate of spreading of a fire, or for the inflammable state of the building material. This is quite analogous to the combustibility or burinability of the incense-stick. 
If the fire statistics under consideration are confined only to the cases when the fire spreads out in one direction, the above quantity fits our purpose well, otherwise $\sqrt{a}$, or something like it, seems rather preferable to a, because in the majority of cases, it spreads out in all directions. The result of calculation however indicates no great difference between them. So the following set of correlation coefficients was calculated, taking $\mathrm{a}$ as the moment for determining the firespreadings.

Table 26 Correlation coefficients between a and the meteorological elements.

Daily mean amount of precipitation

Monthly mininum humidity

Monthly mean relative humidity

Monthly mean temperature

Monthly mean wind velocity

Monthly mean evaporation
Correlation coefficients between a and

$-0.21 \pm 0.076$

$-0.20 \pm 0.076$

$-0.19 \pm 0.077$

$-0.13 \pm 0.078$

$-0.03 \pm 0.079$

$-0.03 \pm 0.079$

The role of the precipitation is in this case preponderate, whilst on the other hand the mean relative humidity now loses much of its significance.

Wind influence on the spreading of fire is surprisingly small, quite contrary to our expectation. The comparatively great checking effect of precipitation on fire-spreading does not lie, presumably in the extinguishing action of rain, but negatively in action of the drought which reduces the water-supply of the fire-pump to a considerable extent, and so on. The somewhat high correlation between fire-spreading and relative humidity favours this view.

Supplement to $\S 19$. On the method of the variate difference.

To find the correlation coefficient between two series $\mathrm{x}$ and $\mathrm{y}$ by the method of variate difference, we make use of the formula

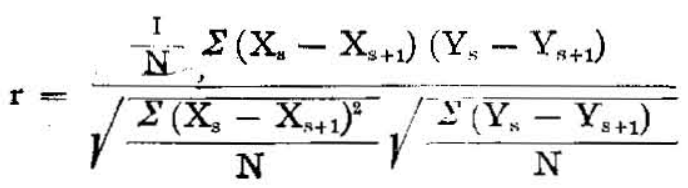

where $\mathrm{x}_{1}, \mathrm{y}_{2}, \ldots \ldots \ldots \ldots \ldots \ldots \mathrm{x}_{\mathrm{s}} \mathrm{y}_{\mathrm{s}} \ldots \ldots \ldots \ldots \ldots \ldots \ldots$ are the measurements of quantities at successive intervals.

Now suppose that $\mathrm{x}$ and $\mathrm{y}$ consist of two parts respectively, that is 


$$
\begin{aligned}
& \mathrm{x}_{1}=\mathrm{a}_{1}+a_{1}, \mathrm{x}_{2}=\mathrm{a}_{2}+\alpha_{2}, \ldots \ldots \ldots \ldots \ldots \mathrm{x}_{\mathrm{s}}=\mathrm{a}_{\mathrm{s}}+\alpha_{\mathrm{s}}, \ldots \ldots \ldots \ldots . . \\
& y_{1}=\mathrm{b}_{1}+\beta_{1}, \mathrm{y}_{2}=\mathrm{b}_{2}+\beta_{2}, \ldots \ldots \ldots \ldots \ldots \mathrm{y}_{\mathrm{s}}=\mathrm{b}_{\mathrm{s}}+\beta_{\mathrm{s}}, \ldots \ldots \ldots \ldots . .
\end{aligned}
$$

then

$$
\begin{aligned}
& r=\frac{\frac{I}{N} \sum\left(a_{s}-a_{s+1}-a_{s}+\alpha_{s+1}\right)\left(b_{s}-b_{s+1}-\beta_{s}+\beta_{s+1}\right)}{\sqrt{\frac{\sum\left(a_{s}-a_{s+1}-\alpha+\alpha_{s+1}\right)^{2}}{N}} \sqrt{\frac{\sum\left(b_{s}-\overline{\left.b_{s+1}-\beta_{s}+\beta_{s+1}\right)^{2}}\right.}{N}}}
\end{aligned}
$$

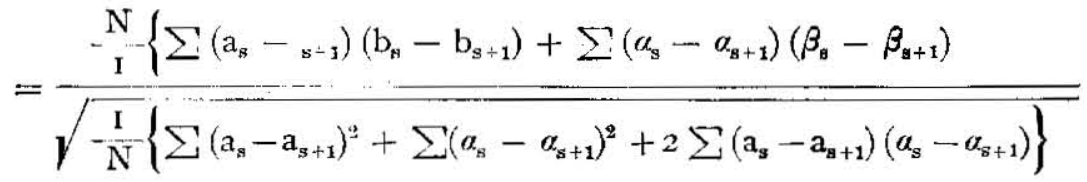

$$
\begin{aligned}
& \frac{\left.+\sum\left(a_{s}-a_{s-1}\right)\left(\beta_{s}-\beta_{s+1}\right)+\sum\left(b_{s}-b_{s+1}\right)\left(\alpha_{s}-\alpha_{s+1}\right)\right\}}{\times \sqrt{1}\left\{\sum\left(b_{s}-b_{s+1}\right)^{2}+\sum\left(\beta_{s}-\beta_{s+1}\right)^{2}+2 \sum\left(b_{s}-b_{s+1}\right)\left(\beta_{s}-\beta_{s+1}\right\}\right.}
\end{aligned}
$$

Assuming firstly that both $\mathrm{a}$ and $\mathrm{b}$ fuctuate rapidly about their mean value while $\alpha$ and $\beta$ go up and down very slowly, and secondly that $\mathrm{a}$ and $\mathrm{b}$ as well as $\alpha$ and $\beta$ correlate so strongly that the first and the second terms in the numerator remain finite and the last two terms in the numerator and the last one in the denominator can be considered as very small, for not only either $\left(\alpha_{s}-\alpha_{s+1}\right)$ or $\left(\beta_{s}-\beta_{s+1}\right)$ is small in magnitude and varies slowly from term to term, but also usually consecutive terms $\left(a_{s}-a_{s+1}\right),\left(b_{s}-b_{s+1}\right)$, are used to differ in sign, Consequently,

$$
\mathbf{r}=\frac{{ }^{\mathrm{I}}\left\{\sum\left(\mathrm{a}_{\mathrm{s}}-\mathrm{a}_{\mathrm{s}+1}\right)\left(\mathrm{b}_{\mathrm{s}}-\mathrm{b}_{\mathrm{s}+1}\right)+\sum\left(\alpha_{\mathrm{s}}-\alpha_{\mathrm{s}+1}\right)\left(\beta_{\mathrm{s}}-\beta_{\mathrm{s}+1}\right)\right\}}{\sqrt{\mathrm{N}^{-}\left\{\sum\left(\mathrm{a}_{\mathrm{s}}-\mathrm{a}_{\mathrm{s}+1}\right)^{2}+\sum\left(\alpha_{\mathrm{s}}-\alpha_{\mathrm{s}+1}\right)^{2}\right.} \sqrt{\frac{\mathrm{I}}{N}\left\{\sum\left(\mathrm{b}_{s}-\mathrm{b}_{\mathrm{s}+1}\right)^{2}+\sum\left(\beta_{\mathrm{s}}-\beta_{\mathrm{s}+1}\right)^{2}\right\}}}
$$

Usually the first term is larger than the second in both the numerator and the denominator, so that

$$
\mathbf{r}=\frac{\frac{\mathrm{I}}{\mathrm{N}} \sum \frac{\left(\mathrm{a}_{\mathrm{s}}-\mathrm{a}_{\mathrm{s}+1}\right)}{2} \frac{\left(\mathrm{b}_{\mathrm{s}}-\mathrm{b}_{\mathrm{s}+1}\right)}{2}}{\sqrt{\mathrm{I} \sum\left(\frac{\mathrm{a}_{\mathrm{s}}-\mathrm{a}_{\mathrm{s}+1}}{2}\right)^{2}} \sqrt{\frac{\mathrm{I}}{\mathrm{N}} \sum\left(\frac{\left.\mathrm{b}_{\mathrm{s}}-\mathrm{b}_{\mathrm{s}+1}\right)^{2}}{2}\right.}}
$$


Where $\frac{a_{s}-a_{s+1}}{2}$ and $\frac{b_{s}-b_{s+1}}{2}$ may be regarded as the deviation from the mean value, as far as the first order of magnitude is concerned. Therefore, $\mathbf{r}$ becomes ultimately the correlation coefficient between a and $\mathrm{b}$.

On the other hand, the expression of the usual correlation coefficient $r$ resumes the following form, if transformed in the same way as above.

$$
\begin{gathered}
r=\frac{\frac{\mathrm{I}}{\mathrm{N}} \sum\left(\mathrm{a}_{\mathrm{s}}+\alpha_{\mathrm{s}}\right)\left(\mathrm{b}_{\mathrm{s}}+\beta_{\mathrm{s}}\right)}{\sqrt{\frac{\mathrm{I}}{\mathrm{N}} \sum\left(\mathrm{a}_{\mathrm{s}}+\alpha_{\mathrm{s}}\right)^{2}} \sqrt{\frac{\mathrm{I}}{\mathrm{N}}-\sum\left(\mathrm{b}_{\mathrm{s}}+\beta_{\mathrm{s}}\right)^{2}}} \\
=\frac{\frac{\mathrm{I}}{\mathrm{N}}\left\{\sum \mathrm{a}_{\mathrm{s}} \mathrm{b}_{\mathrm{B}}+\sum \alpha_{\mathrm{s}} \beta_{\mathrm{s}}+\sum \alpha_{\mathrm{s}} \mathrm{b}_{\mathrm{s}}+\beta_{\mathrm{s}} \mathrm{a}_{\mathrm{s}}\right\}}{\sqrt{\frac{\mathrm{I}}{\mathrm{N}}\left\{\sum \mathrm{a}_{\mathrm{s}}{ }^{2}+\sum \alpha_{\mathrm{s}}{ }^{2}+2 \sum \alpha_{\mathrm{s}} \mathrm{a}_{\mathrm{s}}\right\}} \sqrt{\frac{\mathrm{I}}{\mathrm{N}}\left\{\sum \mathrm{b}_{\mathrm{s}}{ }^{2}+\sum \beta_{\mathrm{s}}{ }^{2}+2 \sum \beta_{\mathrm{s}} \mathrm{b}_{\mathrm{s}}\right\}}}
\end{gathered}
$$

Where all the symbols a, b \& so on denote respectively the departure from the mean value. Under the same assumption as before,

$$
r=\frac{\frac{I}{N}\left\{\sum a_{s} b_{s}+\sum \alpha_{s} \beta_{s}\right\}}{\sqrt{\frac{I}{N}\left(\sum a_{s}^{2}+\sum \alpha_{*}^{2}\right)} \sqrt{\frac{I}{N}\left(\sum b_{s}^{2}+\sum \beta_{s}^{2}\right)}}
$$

As the last term is, in this case, larger than the first,

$$
r=\frac{\mathrm{I}-\sum \alpha_{\mathrm{s}} \beta_{\mathrm{s}}}{\sqrt{\frac{\mathrm{I}}{\mathrm{N}} \sum \alpha_{\mathrm{s}}^{2}} \sqrt{-\mathrm{I} \cdot \sum \beta_{\mathrm{s}}^{2}}}
$$

Thus, $\mathrm{r}$ becomes the correlation coefficient between $\alpha$ and $\beta$.

It must be borne in mind however that the above two results are only applicable when

( I) $\mathrm{a}$ and $\mathrm{b}$ are short periodic and highly correlated, and their amplitude is not great.

(2) $\alpha$ and $\beta$ are long periodic and highly correlated, and their amplitude is large.

Thesc conditions are, though imperfectly, fulfilled in the case where $x$ is the fire-frequency, $y$ the relative humidity, while $a$ and b correspond to the monthly variation, $\alpha$ and $\beta$ to the annual change. 
$\S 20$ FORECASTING THE OUTRREAK OF FIRES

The precise prevision of fires is hardly possible even by means of some mechanical device, for instance by measuring minutely the change of the electric conductivity of timber in a room, which responds quickly to the variation of the relative humidity.

At present, for such a purpose, a regression-equation for telling the number of fire occurrences of the following month $X_{1}$, is obtained by knowing the mean value of relative humidity $X_{2}$ as well as temperature $X_{3}$ of the previous month.

Denoting by 1,2 and 3 the daily mean value of outbreaks of fire in the month under question, the monthly mean value of humidity and of temperature, the following statistical constants are discernible.



The correlation coefficient between fires and the relative humidity of the previous month, whether partial or total, is not high.

The regression equation is,

$$
\mathrm{X}_{1}=\mathrm{I} .284-0.00098 \mathrm{I} \mathrm{X}_{2}-0.04 \mathrm{I} 7 \mathrm{I} \mathrm{X}_{3}
$$

The accordance between the values calculated and observed is not good, so that this equation is not expected to be of great assistance in forecasting fires.

\section{§21 IIUKLOKA ${ }^{13}$}

The fire statistics in the prefecture of Hukuoka are superior in two respects to those of Tokyo, first the period of statistics covers about as much as 14 years, I9I 2 to 1925, and secondly the monthly amount of the consumption of coal gas in this town is at our disposal.

This prefecture is somewhat wide in area, but all the meteorological elements in this calculation are taken from a single observatory located in the City of Hukuoka, because there are not many well-equipped meteorological stations other than in this town.

18 Its population and the number of houses (1920) are respectively $1,849,938$ and 389,311 
First for the comparison, we show below all the correlation coeffcients between fire and each of the meteorological elements.

Table 28

Relative humidity
Absolute humidity.
Air temperature
Precipitation
Maximum wind velocity
Mean wind velocity

Correlation coefficient between outbreak of fire and

$$
\begin{array}{ll}
-0.62 & \pm 0.03 \\
-0.59 & \pm 0.03 \\
-0.55 & \pm 0.04 \\
-0.33 & \pm 0.05 \\
-0.09 & \pm 0.05 \\
+0.18 & \pm 0.05
\end{array}
$$

By using the method of variate difference,

$$
\begin{aligned}
& \text { Correlation coefficient } \\
& \begin{aligned}
\text { between outbreak and } \\
-0.36 \pm 0.05 \\
-0.29 \pm 0.05 \\
+0.21 \pm 0.06
\end{aligned}
\end{aligned}
$$$$
\text { Relative humidity }
$$$$
\text { Air temperature }
$$$$
\text { Consumption of coal-gas }
$$

In either case, the correlation coefficient in relation to humidity stands high. The low correlation between gas consumption and fire again makes untenable the view that the frequent occurrence of fires during the winter is due solely to much use of fire; although the amount of gas-supply can not be regarded simply as the measure of heating-fuel.

The fact that all these coefficients of correlation are smaller than in Tokyo arises from using the meteorological observations of one station only, not from a weak relation among the elements.

Monthly correlation coefficients between fires and the weather elements. The correlation coefficient differs from season to season, as has already been stated briefly; the following monthly investigation throws much light on this matter.

Table 29 The crrrelation coefficients between fire and the meteorological elements (by usual method)

The number of olscrvation is $\mathbf{1} 4$.

$\begin{array}{lcccc}\text { Month } & \text { Rel.t. humidity } & \text { Min. humidity } & \text { Temperature } & \text { Wind-velocity } \\ \text { January } & \text { - } 0.22 \pm 0.17 & -0.27 \pm 0.16 & -0.05 \pm 0.18 & -0.52 \pm 0.13 \\ \text { Feluruary } & -0.26 \pm 0.17 & -0.09 \pm 0.18 & -0.19 \pm 0.17 & -0.28 \pm 0.17 \\ \text { March } & -0.52 \pm 0.13 & -0.29 \pm 0.17 & -0.29 \pm 0.17 & -0.17 \pm 0.18 \\ \text { April } & -0.49 \pm 0.14 & -0.10 \pm 0.18 & -0.27 \pm 0.17 & -0.50 \pm 0.13 \\ \text { May } & -0.49 \pm 0.14 & -0.60 \pm 0.12 & +0.06 \pm 0.18 & -0.10 \pm 0.18 \\ \text { June } & -0.49 \pm 0.14 & -0.36 \pm 0.16 & -0.20 \pm 0.17 & -0.07 \pm 0.18 \\ \text { July } & -0.53 \pm 0.13 & -0.43 \pm 0.15 & -0.10 \pm 0.18 & +0.02 \pm 0.18\end{array}$




$\begin{array}{lllll}\text { August } & -0.34 \pm 0.16 & -0.15 \pm 0.17 & -0.22 \pm 0.17 & -0.21 \pm 0.17 \\ \text { September } & -0.61 \pm 0.11 & -0.03 \pm 0.18 & -0.31 \pm 0.16 & +0.02 \pm 0.18 \\ \text { October } & -0.45 \pm 0.15 & -0.52 \pm 0.14 & +0.02 \pm 0.19 & -0.56 \pm 0.13 \\ \text { November } & -0.23 \pm 0.18 & -0.40 \pm 0.15 & +0.07 \pm 0.19 & +0.01 \pm 0.19 \\ \text { December } & -0.76 \pm 0.05 & -0.35 \pm 0.15 & -0.66 \pm 0.11 & +0.17 \pm 0.18\end{array}$

Table 30 The correlation coefficients between fire and weather elements

(by the method of variate difference)

Temperature,

Jan. Feb. Mar. Apr. May June July Aug. Sept. Oct. Nov, Dec. $+0.14+0.14-0.30-0.08+0.02+0.22+0.20-0.32+0.26+0.45-0.19-0.72$ $\pm 0.18 \pm 0.18 \pm 0.17 \pm 0.19 \pm 0.19 \pm 0.18 \pm 0.18 \pm 0.18 \pm 0.17 \pm 0.16 \pm 0.19 \pm 0.09$

Humidity,

$-0.09-0.23-0.68-0.77-0.74-0.41-0.86+0.40-0.66-0.21-0.59-0.77$

$\pm 0.18 \pm 0.18 \pm 0.10 \pm 0.08 \pm 0.08 \pm 0.16 \pm 0.05 \pm 0.16 \pm 0.11 \pm 0.19 \pm 0.13 \pm 0.08$

In this table excepting during December we find hardly a trace of temperature influence on fires whilst relative humidity governs them almost completely throughout the year. The infuence of the latter is comparatively great during the period from spring to summer (March to August) and small from autumn to winter (September, October and November). Its high correlation in March and Decenber is worth mentioning, especially so, because they are the fire hazard months; also because in this period there is a great possibility of forecasting fires by means of simply measuring relative humidity, and thereby warning tine public. $^{19}$

\section{§ 22 LONDON}

By taking two examples from Japan we have already shown the existence of a close relation between fires and the weather elements, humidity being conspicuous among the other.

England differs conspicuously from Japan not only in climate, but

19 In March 1925, Tokyo was visited by a series of fires, and on the $17^{\text {th }}$ of the same month ( $14^{\text {lh }}$ ) by a sever conflagration, when the relative humidity was lowered to $23 \%$. In March 1926 a host of fires thrice assailed the prefecture of Hukuoka; the first group IoI2th, the second 14-I7th, the third 24th-26th; this month has, in relative humidity, three conspicuous minima, i. e. on the rith $(58 \%$ mean), the 15 th $(53 \%$ mean) and the 26 th (48\% mean) each of which falls within the corresponding hazard period. On January $17^{\text {th }}$ ( $4^{\mathrm{b}} \mathrm{a}$. m) IG22, a lig fire took place at the town of IIukuoka when the relative humidity came down to $51 \%$ at $22^{\mathrm{h}}$ on the previous day.

So these fow examples give ample evidence of the important bearing of humidity on conflagrations. We may say with little reserve that $30 \%$ of relative humidity is an index of a critical state for fire-hazard in Tokyo and $50 \%$ for Hukuoka. 
also in house construction consequently the examination of its fire-statistics may lead to the upsetting of the conclusions already derived, so that it is worth while in the following to study, along the same line as before, the outbreaks of fire in the City of London.

According to ten years's statistics ${ }^{20} 1912-1921$ in that great town, July is the warmest month, its mean temperature being $62.1^{\circ} \mathrm{F}\left(16.7^{\circ} \mathrm{C}\right)$ and January is the coldest, the mean temperature being $40.7^{\circ} \mathrm{F}\left(4.8^{\circ} \mathrm{C}\right)$ while June is the dryest, having $67.8 \%$ as the mean relative humidity and December the most humid, having $85.1 \%$ as its mean value of humidity. Thus, humidity in London behaves quite differently from that in Japan.

It happens very seldom in England that a fire destroys a whole building exactly, contrary to what happens in an ordinary fire in Japan. And we therefore make it a rule to count the fire as one when a room in a flat burns, and two when two consecutive rooms in a flat burn simultaneously and so on. According to the Reports of the Fire Brigade of London, January the hazard month has the highest number of fires, its

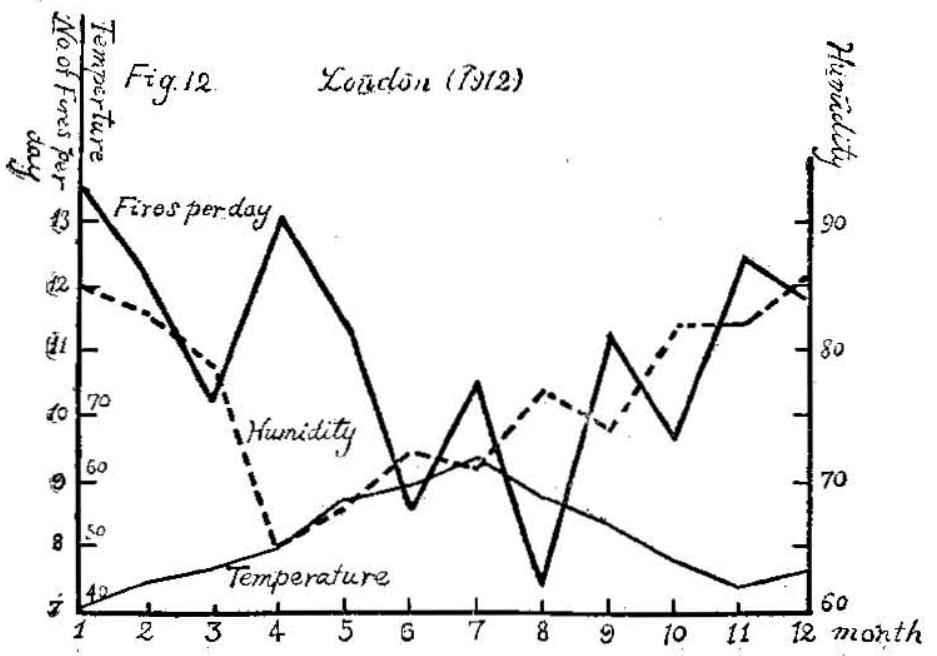

20 We have copied this statistical report through the kindness of the librarians in the British Museum, from " Daily Report of Fires in the County," London Fire Brigade, as mentioned before, also the weather data from the "Weekly and Monthly Weather Report" 1912 to $192 \mathrm{r}$, Meteorological Office. We are indepted to the officials of both offices for the permission to use these valuable data.

The corresponding weather elements in 'Tokyo are :

$$
\begin{array}{ll}
\text { January }: 3.1^{\circ} \mathrm{C} & \text { August }: 25 \cdot 3^{\circ} \mathrm{C} \\
\text { February }: 62 \% & \text { both months July and Septemver }: 83 \%
\end{array}
$$


daily mean value running up to 13.9 ; while August the quietest month has a low value, its daily mean value coming down to 8.4. This relation and its monthly change are shown in Fig. 12. Another damp year is not as clear as this and is not reproduced here.

The correlation coefficients are:

between fires and air temperature $\quad-0.50 \pm 0.047$

between fires and relative humidity $\quad+0.02 \pm 0.063$

Thus, there exists no correlation at all between fire and humidity.

By the method of variate difference, however they increase a little more, thus fire and humidity ................. 0.1 $7 \pm 0.06 \mathrm{r}$

Such a small correlation is due partly of the incompleteness of the mathematical treatment, partly to the way of selection of the unit in the fire-statistics.

The number of fire-outbreaks measured by such unit as defined before corresponds rather to that of the dimensions of the burnt area, which has already been shown to be less correlated with the weather element than the number of outbreaks of fire.

The fact that the small fluctuation of relative humidity keeps pace from month to month with that of fires tells eloquently of the existence of a close connection between them. This relation becomes however a little obscure, when the year turns out to be damp; for instance during the period of these ten years there are six damp years and four dry years, and all these years without exception bear testimony in favour of the closeness of the relation.

With a view to make it suitable to our purpose, the method of harmonic analysis already briefly described, is adopted. First, we express in the simplest form the monthly number of fire-occurrences, and the monthly mean values of temperature as well as humidity, as follows:

$$
\begin{aligned}
& f_{c}=11.0667+2.3378 \cos \frac{2 \pi t}{T}+0.543^{8} \sin \frac{2 \pi t}{T} \\
& \mathrm{f}_{\mathrm{r}}=76.79+7 . \mathrm{II} \quad \cos \frac{2 \pi \mathrm{t}}{\mathrm{T}}-5.00 \quad \sin \frac{2 \pi \mathrm{t}}{\mathrm{T}} \\
& \mathrm{f}_{\mathrm{b}}=50.44-\mathrm{II} .20 \cos \frac{2 \pi \mathrm{t}}{\mathrm{T}}-\mathrm{I.02} \sin \frac{2 \pi \mathrm{t}}{\mathrm{T}}
\end{aligned}
$$

where

$f_{s}=$ the daily mean value of fire occurrence in a month.

$f_{t}=$ the monthly mean value of air temperature.

$f_{\mathrm{h}}=$ the monthly mean value of atmospheric pressure

The following numbers are values calculated by the above formulae:-

(The letter with a dash denotes the values observed) 
Taljle $3 \mathbf{I}$ London fires and weather elements.

Month Jan. Feb. Mar. Apr. May Jun. Jul. Aug. Sept. Oct. Nov. Dec. $\begin{array}{lllllllllllll}f_{c} & 13.40 & 13.37 & 12.70 & \text { II.61 } & 10.37 & 9.78 & 8.73 & 8.77 & 9.44 & 10.5^{2} & 11.77 & 12.82\end{array}$

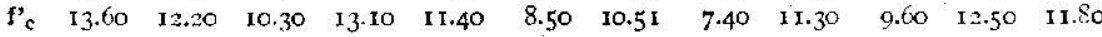
$\begin{array}{lllllllllllll}12.70 & 14.10 & 12.00 & 12.40 & 10.60 & 10.40 & 7.10 & 9.20 & 9.70 & 8.80 & 11.50 & 15.30\end{array}$ $\begin{array}{llllllllllll}17.30 & 11.30 & 10.60 & 13.50 & 12.90 & 12.00 & 12.30 & 9.50 & 11.20 & 10.60 & 10.60 & 12.20\end{array}$ $\begin{array}{llllllllllll}13.50 & 11.30 & 13.20 & \text { IX.10 } & \text { I } 2.00 & 11.10 & 9.50 & 7.50 & 9.40 & 9.10 & 13.30 & \text { I } 1.20\end{array}$ $\begin{array}{lllllllllllll}12.20 & 12.00 & 12.30 & 11.00 & 8.20 & 7.50 & 6.70 & 7.90 & 6.40 & 7.50 & 11 . c 0 & 14 . c 0\end{array}$ $\begin{array}{llllllllllll}16.20 & 16.10 & 1_{3.20} & 11.40 & 9.90 & 10.60 & 8.10 & 6.80 & 7.60 & 8.80 & 11.20 & 14.40\end{array}$ $\begin{array}{llllllllllll}\text { I3.20 II.60 } & 12.00 & 8.40 & 6.70 & 9.20 & 8.00 & 6.60 & 6.40 & 7.10 & 10.10 & 10.30\end{array}$

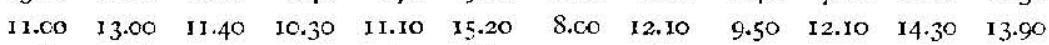
$\begin{array}{lllllllllllll}15.80 & 14.80 & 14.30 & 10.40 & 11.30 & 8.80 & 7.70 & 8.90 & 9.40 & 13.60 & 23.70 & 12.40\end{array}$ $\begin{array}{llllllllllll}12.50 & 16.20 & 14.30 & 11.50 & 15.30 & 23.40 & \text { I } 4 . C 0 & \text { II.8O } & 11.10 & 14.60 & 14.50 & 14.50\end{array}$ $\begin{array}{llllllllllllll}\mathbf{f}_{\mathrm{t}} & 39.24 & 40.23 & 43.96 & 49.44 & 55.16 & 59.63 & 62.08 & 60.65 & 56 . \mathrm{gz} & 5 \mathrm{r} .46 & 45.72 & 41.25\end{array}$ $\begin{array}{lllllllllllll}f^{\prime} t & 40.80 & 44.10 & 46.70 & 49.10 & 56.50 & 50.00 & 63.80 & 57.70 & 53.70 & 47.50 & 43.80 & 45.80\end{array}$ $\begin{array}{lllllllllllll}41.50 & 41.40 & 45.00 & 47.20 & 55.30 & 60.00 & 60.00 & 61.40 & 58.90 & 53.60 & 48.00 & 42.10\end{array}$ $\begin{array}{llllllllllll}38.40 & 44.70 & 44.20 & 50.40 & 53.60 & 60.40 & 63.50 & 63.40 & 57.70 & 52.00 & 45.60 & 42.40\end{array}$

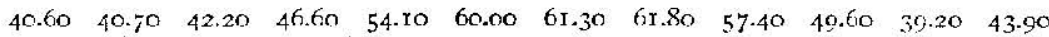
$\begin{array}{lllllllllllll}45.80 & 40.00 & 40.00 & 48.40 & 55.40 & 54.80 & 6 c .90 & 64.00 & 56.20 & 53.10 & 43.90 & 37.00\end{array}$ $\begin{array}{lllllllllllll}35.90 & 35.90 & 3^{8.70} & 42.80 & 57.40 & 63.20 & 63 . c 0 & 61.70 & 59.30 & 46.50 & 47.60 & 36.20\end{array}$ $\begin{array}{lllllllllllll}30.10 & 43.80 & 43.90 & 45.10 & 56.90 & 57.60 & 62.00 & 62.50 & 55.90 & 49.40 & 42.50 & 46.30\end{array}$ $\begin{array}{lllllllllllll}38.20 & 36.60 & 40.80 & 46 . \mathrm{co} & 57.50 & 59.70 & 58.30 & 63.70 & 57.20 & 45.30 & 39.30 & 42.80\end{array}$


$\begin{array}{llllllllllll}46.00 & 41.60 & 46.50 & 48.30 & 55.10 & 60.20 & 68.30 & 62.80 & 59.80 & 56.20 & 40.50 & 44.80\end{array}$ $\begin{array}{lllllllllllll}f_{h} & 83.90 & 80.45 & 76.02 & 71.79 & 68.95 & 68.14 & 69.68 & 73.1_{3} & 77.56 & 81.79 & 84.63 & 8_{5.44}\end{array}$ $\begin{array}{lllllllllllll}f^{\prime}{ }_{h} & 85.00 & 83.00 & 79.00 & 65.00 & 68.00 & 72.00 & 71.00 & 77.00 & 74.00 & 82.00 & 82.00 & 86.00\end{array}$

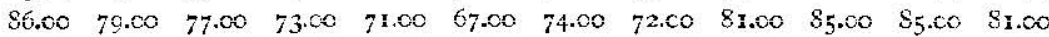
$\begin{array}{llllllllllllllll}81.00 & 83.00 & 78.00 & 69.00 & 68.00 & 68.00 & 70 . c 0 & 74.00 & 70 . c 0 & 79 . c 0 & 81.00 & 84.00\end{array}$ $\begin{array}{lllllllllllllll}81.00 & 82.00 & 77.00 & 60.00 & 67.00 & 67.00 & 70.00 & 76 . c 0 & 75.00 & 83.00 & 84.00 & 87.00\end{array}$ $\begin{array}{lllllllllllllllll}84.00 & 79.00 & 82.00 & 69.00 & 70.00 & 73.00 & 71.00 & 72.00 & 78 . c 0 & 81.00 & 86.00 & 89 . c 0\end{array}$ $\begin{array}{lllllllllllllll}7 \text { S.co } & 82.00 & 79.00 & 72.00 & 66.00 & 64.00 & 69.00 & 75.00 & 79.00 & 80.00 & 84.00 & 81 . c 0\end{array}$ $\begin{array}{lllllllllllll}83.00 & 81.00 & 74.00 & 80.00 & 67.00 & 64.00 & 71.00 & 71.00 & 75.00 & 83.00 & 86.00 & 86.00\end{array}$


$\begin{array}{llllllllllllll}82.00 & 84.00 & 79.00 & 67.00 & 69.00 & 74.00 & 71.00 & 79.00 & 82.00 & 87.00 & 86.00 & 86.00\end{array}$ $\begin{array}{llllllllllllllll}85.00 & 80.00 & 74.00 & 69.00 & 67.00 & 60.00 & 55.00 & 66.00 & 70.00 & 77.00 & 85.00 & 81.00\end{array}$

Each difference between the value calculated and observed is singly obtained, and then by correlating them we get

Table 32

Correlation ccefficient between fires and By usual method Jy variate difference

Hunidity $-0.43 \doteq 0.05$ $-0.3^{8} \pm 0.05$ Temperature $+0.33 \pm 0.06$ $+0.01 \pm 0.06$

Of course such a method must be applied only after careful examination. But it seems that this is more reasonable than the method of the variate difference usually employed. 
The correlation coefficients now obtained show the negative correlation between fres and humidity, and, though a little surprising, the positive correlation between fires and temperature.

And hence it needs scrupulous reexamination. They are therefore computed from month to month, as follows:-

Table 33

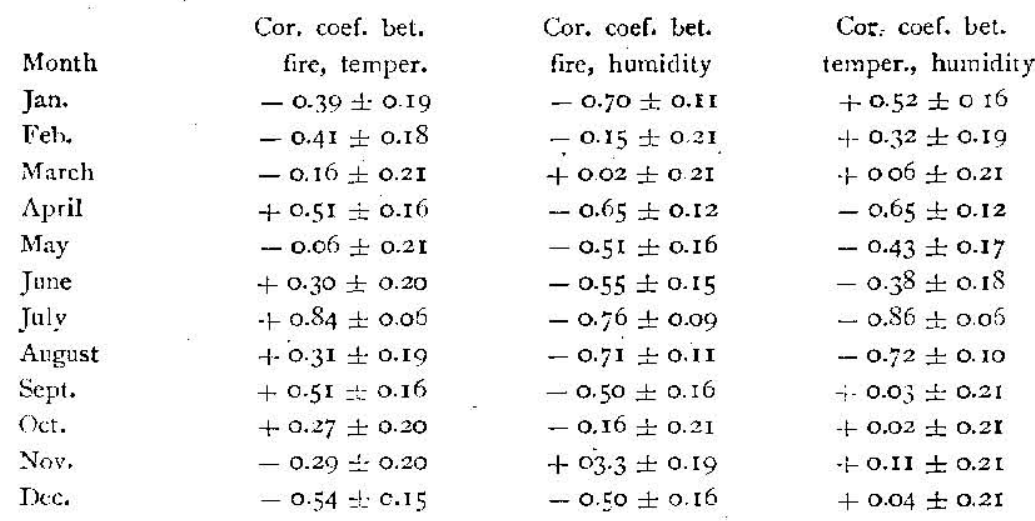

Although the mean error is so great that it sometimes makes the correlation obscure, two facts are quite clear, nameiy, the correlation of fres with humidity is distinctly negative, and with temperatute positive particularly in summer. Such a correlation during the hot months is found also not seldom in Japan.

Tahle 34* Correlation coefficients with temperature during the hot month.

$\begin{array}{lccc}\text { Prefecture } & \text { July } & \text { August } & \text { Throughout the year } \\ \text { Osaka } & +0.67 \pm 0.15 & +0.28 \pm 0.25 & -0.41 \pm 0.05 \\ \text { Vamaguti } & +0.56 \pm 0.19 & +0.44 \pm 0.22 & -0.59 \pm 0.04 \\ \text { Nagasaki } & +0.63 \pm 0.14 & +0.03 \pm 0.24 & --0.63 \pm 0.04 \\ \text { Vhime } & -0.55 \pm 0.19 & +0.14 \pm 0.26 & -0.65 \pm 0.04 \\ \text { Aomori } & +0.03 \pm 0.34 & +0.25 \pm 0.32 & -0.43 \pm 0.07 \\ \text { Ilukui } & +0.07 \pm 0.27 & -0.65 \pm 0.16 & -0.22 \pm 0.06 \\ \text { Saitama } & +0.22 \pm 0.26 & +0.43 \pm 0.22 & -0.79 \pm 0.02 \\ \text { Aiti } & +0.25 \pm 0.25 & +0.22 \pm 0.26 & -0.7 \pm \pm 0.03 \\ \text { Yamanasi } & +0.14 \pm 0.26 & +0.36 \pm 0.23 & -0.68 \pm 0.03 \\ \text { Hukusima } & -0.10 \pm 0.34 & +0.34 \pm 0.39 & -0.60 \pm 0.04 \\ \text { Kagawa } & +0.61 \pm 0.17 & -0.08 \pm 0.27 & -0.62 \pm 0.04 \\ \text { Saga } & +0.17 \pm 0.26 & +0.02 \pm 0.17 & -0.52 \pm 0.04 \\ \text { Akita } & -0.10 \pm 0.27 & +0.62 \pm 0.27 & -0.40 \pm 0.05 \\ \text { Miyazaki } & +0.39 \pm 0.23 & +0.55 \pm 0.19 & -0.43 \pm 0.05 \\ \text { Nara } & -0.43 \pm 0.22 & -0.57 \pm 0.18 & -0.58 \pm 0.04\end{array}$


The places selected in the above calculations cover nearly all the principal parts of Japan, so that the figures in the table may be regarded as representing the main features of her meteorological relation to fires. According to this table, the places of positive correlation during a few warm months are enormous in number in spite of the negative correlation during all the remaining months.

This has no doubt a close bearing on the fast burning of incensesticks during the hot season.

Above all, it is worth while, paying special attention to the fact that the same relation holds good in such a country as England, quite different though it is in every respect from Japan.

\section{$\S 23$ OSAKA.21}

The statistical investigation of fires hitherto dealt with is concerned entirely with their monthly mean values. So a objection might be raised against such a way of solving the fire problem. The method of correlating the weather factor with the daily number of fires should be approved as better suited to the purpose.

However daily statistics together with the corresponding weather conditions were not easily obtainable, except that of the city of Osaka, so that we shall be content to confine ourselves to a study of one particular locality, namely Osaka, the second greatest city in Japan.

Before proceeding, we show, for reference's sake, the monthly number of fire for Osaka, together with an analysis of the causes and several correlation coefficients referring to the weather conditions.

Table 35 Statistics of fires in Osaka

rgi7. Jan. Fel. Mar. Apr. May June July Aug. Sep. Oct. Nuv. Dec.

$\begin{array}{lllllllllllll}\text { A. Fire-ucc. per day } & 0.60 & 1.21 & 0.74 & 0.97 & 0.74 & 0.57 & 0.77 & 0.61 & 0.20 & 0.26 & 0.73 & \text { I.38 }\end{array}$

$\begin{array}{llllllllllllll}\text { B. Fire-occ. per day } & 0.77 & 0.93 & 0.71 & 0.97 & 0.74 & 0.57 & 0.77 & 0.61 & 0.20 & 0.23 & 0.73 & 1.00\end{array}$

$\begin{array}{lllllllllllll}\text { Temperature } & 3.2 & 4.3 & 7.0 & \mathbf{2} 2.8 & \text { I6.5 } & 21.1 & \mathbf{2 7 . 4} & 26.6 & 24.3 & \text { I8.2 } & 9.6 & \mathbf{5 . 2}\end{array}$

$\begin{array}{lllllllllllll}\text { Humidity } & 65.0 & 66.8 & 70.7 & 69.9 & 70.7 & 77.4 & 76.7 & 74.7 & 80.5 & 79.0 & 72.5 & 63.6\end{array}$

I918.

$\begin{array}{lllllllllllll}\text { A. Fire-occ. per day } & \mathbf{1} .22 & 1.18 & 0.97 & 0.80 & 0.71 & 0.53 & 0.61 & 0.97 & 0.63 & 0.74 & 0.93 & 1.16\end{array}$

$\begin{array}{llllllllllllll}\text { B. Fire-occ. per day } & 1.00 & 1.04 & 0.81 & 0.77 & 0.71 & 0.53 & 0.61 & 0.97 & 0.63 & 0.74 & 0.07 & 1.00\end{array}$

$\begin{array}{lllllllllllll}\text { Teinperature } & 2.8 & 4.1 & 7.3 & 13.2 & \mathbf{x} 7.1 & 21.2 & 26.9 & 26.9 & 23.0 & 17.6 & \mathbf{1} \times 3.3 & 6.4\end{array}$

$\begin{array}{llllllllllllll}\text { Humidity } & 64.6 & 70.5 & 66.9 & 72.7 & 73.5 & 82.0 & 77.5 & 76.9 & 77.8 & 78.4 & 74.3 & 73.9\end{array}$

$2 x$ These results are in accordance, in the main point, with those of $\mathrm{K}$. laguti, thougn in regard to the wind influence, his and ours are somewhat different. 
rgrg.

$\begin{array}{lllllllllllllllllll}\text { A. Fire-occ. per day } & 1.03 & 0.73 & 0,90 & 0.70 & 0.87 & 0.77 & 0.78 & 0.81 & 0.83 & 0.45 & 0.70 & 1.55\end{array}$

$\begin{array}{llllllllllllll}\text { B. Fire-occ. per day } & 0.68 & 0.50 & 0.81 & 0.67 & 0.87 & 0.77 & 0.77 & 0.81 & 0.83 & 0.43 & 0.67 & \mathbf{1} \cdot 32\end{array}$

$\begin{array}{lllllllllllll}\text { Temperature } & 4.5 & 4.9 & 8.5 & 13.8 & 17.8 & 21.7 & 25.4 & 26.8 & 23.0 & 17.9 & 12.8 & 6.8\end{array}$

$\begin{array}{llllllllllllll}\text { Humidity } & 69.4 & 73.3 & 71.8 & 69.6 & 71.5 & \mathbf{7 8 . 2} & \mathbf{7 7 . 9} & \mathbf{7 5 . 7} & \mathbf{7 6 . 2} & \mathbf{7 4 . 5} & 76.8 & 68.9\end{array}$

A ; all causes included

B; heating sources excluded

As to the monthly distribution of fire-frequency, the figures in the table are found to be not perfectly consistent with those obtained in Tokyo. With regard to the correlation coefficients however they are nearly in accord..$^{22}$

The correlation coefficient between one of the meteorological elements and fire is

Table 36

All causes included

Correlation coefficient between fires and

\begin{tabular}{|c|c|c|}
\hline $\begin{array}{l}\text { Humidity } \\
\text { Temperature }\end{array}$ & $\begin{array}{l}\text { By usual method } \\
-0.79 \pm 0.042 \\
-0.69 \pm 0.05^{8}\end{array}$ & $\begin{array}{c}\text { By variate difference } \\
-0.57 \pm 0.077 \\
-0.25 \pm 0.107\end{array}$ \\
\hline \multicolumn{3}{|c|}{ The cause due to the heater excluded } \\
\hline Humidity & $-0.52 \pm 0.0 .52$ & $-0.22 \pm 0.108$ \\
\hline Temperature & $-0.31 \pm 0.101$ & $-0.19+0.111$ \\
\hline
\end{tabular}

Osaka daily fire statistics now at our disposal cover three years, consequently there are $3 \times 365$ daily observations, as much as the total of ten year's monthly statistics.

The daily occurrence of fires however seldom exceeds three, so that the statistical conclusions derived therefrom cannot be said to be quite trustworthy.

Correlation coefficient between fires and humidity

$$
=-0.13 \pm 0.20
$$

Correlation coefficient between fires and temperature

$$
=-0.08 \pm 0.20
$$

22 Population and number of families rre respectively $1,252,98_{3}$ and 276,331 (1920) 
Such a small correlation arises from having too small a range of fire frequency, and the only means of escaping from this is to take a much longer interval than one day and yet shorter than one month. We take therefore every ten days' statistics and deduce the following correlation coefficients :

Correlation coefficient between fires and humidity

$$
=-0.48 \pm 0.049
$$

Correlation coefficient between fires and temperature

$$
=-0.42 \pm 0.054
$$

They become, thus, a little greater than before, although still considerably less than for one month's statistics. The cause of this is understood as due either to too small a number of fire-occurrences during the interval, or to the fact that fire is influenced by the weather of a few days previous. The former cause is the more probable, because the correlation coefficient between the mean humidity of either ten days or twenty days previous is found to be $-0.44 \pm 0.05$, or $-0.29 \pm 0.06$, respectively smaller than that obtained just before, so that fires would seem to be under the control of present weather conditions or of those shortly preceding.

With the object of making the forecasting regression-equation expressed by the average value of relative humidity and of temperature of each preceding ten days, the following correlation coefficient both total and partial is calculated.

Denoting the fire, humidity and temperature by 1,2 and 3 we get,

Table 37

$$
\begin{array}{rlcc}
\multicolumn{1}{c}{\text { Kind }} & \text { Mean } & \text { Standard deviation } \\
& \text { fire outbreak } & 8.24 & 3.46 \\
2 & \text { relative humidity } & 73.58 \% & 5.86 \% \\
3 \text { air temperature } & \mathbf{4} 4.90^{\circ} \mathrm{C} & 8.13^{\circ} \mathrm{C} \\
\mathbf{r}_{12}=-0.44 \pm 0.05 & \mathbf{r}_{13}=-0.43 \pm 0.05 & \mathbf{r}_{23}= \pm 0.65 \pm 0.04 \\
\mathbf{r}_{1 \mathrm{~s} 3}=-0.24 \pm 0.06 & \mathbf{r}_{13.2}=-020 \pm 0.06 & \mathbf{r}_{23.1}= \pm 0.57 \pm 00.4
\end{array}
$$

Further expressing their quantities by $X_{1}, X_{2}$ and $X_{3}$, the regression equation is

$$
\mathrm{X}_{1}=23.93-0.19 \mathrm{X}_{2}-0.1 \mathrm{I} \mathrm{X}_{3}
$$

As may be imagined this equation does not tell the number of fire-occurrences in advance. The correlation coefficient is too small to do this. 


\section{\$24 FIRES AND WIND}

On this subject we have already touched slightly, in investigating the fires of two towns and found that the correlation coefficients between mean wind velocity or maximum wind velocity and the occurrences or spread of fires are both small. The same can be said about Osaka where the correlation coefficient is found to be 0.37 .

The opinion prevails however amongst the public that the wind comes into play very remarkably when a conflagration is going on or is about to take place, so that it is necessary to make further inquiry into the matter.

(I) First comes the consideration of the correlation between the area of conflagration and the mean wind velocity.

Among 28 provinces and 3 great towns, the majority, (7 provinces and one town are excepted) have a positive coefficient, which is however very small in amount, the greatest being +0.28 in the prefecture of Hukusima, and the least so low that it can hardly be considered as correlated.

We have adopted, in much of this calculation, the mean velocity of the wind as best suited to the surpose. The maximum wind velocity will do equally as well. But the correlation between those two velocities is very high. So the same degrec of correlation will naturally be expected in the latter case also. Therefore, the attempt to find it has better be dispensed with. ${ }^{23}$

The spread of a fire is subject to the force of the wind actually raging. So in such a case, statistics daily kept are rather preferable. Thus the coefficident of correlation becomes $+0.20 \pm 06$, a little larger if the mean value of every ten days instead of every month is selected as the factor, the coefficient in the latter case being $+0.16 \pm 0.111$. Still this cannot be regarded as very convincing.

The investigation on conflagrations at Hakodate enlightens us considerably in this matter.

\footnotetext{
23 Further the attempt to find the connection between fires and the numler of stormy days or hours is still more discouraging, for their correlation coefficients are :$$
\begin{array}{lll}
\text { Iwate }+0.52 \pm 0.045 & \text { Tokyo } \$+0.11 \pm 0.086 & \text { Hukui }+0.28 \pm 0.058 \\
\text { Osaka } \S+0.24 \pm 0.065 & \text { Koti }+0.07 \pm 0.063 & \text { Hukuoka }+0.17 \pm 0.057 \\
& & \text { Hukuoka } \$ 0.22 \pm 0.062
\end{array}
$$

The coefficient marked with $\S$ is that with stormy hours, that unmarked that with stormy

Thus all coefficients are of the same order as that with the wind velocity.

24 IIakodate is a city in the district of IIokkaido with about I45,000 inhahilants and experienced during past years a large number of disastrous fires, several of which bad des. troyed almost the whole city.
} days. 
Table $3^{8}$ Wind-infuence on great fires at Hakodate in which more than a hundred houses were burnt.

\begin{tabular}{|c|c|c|c|c|c|}
\hline $\begin{array}{l}\text { Number of } \\
\text { houses burnt }\end{array}$ & Wind-velocity & Wind-direction & \multicolumn{3}{|c|}{ Dates } \\
\hline 8,977 & I0 $-16 \mathrm{~m}$ & SE & August & 25 & 1907 \\
\hline 140 & $15 \mathrm{~m}$ & $\mathrm{~N}$ & March & 23 & I9I I \\
\hline 733 & $14-16 \mathrm{~m}$ & $w$ & April & I2 & 1912 \\
\hline 1,532 & $14-16 \mathrm{~m}$ & IV & May & 4 & 1913 \\
\hline 277 & $\mathrm{II}-15 \mathrm{~m}$ & $\mathbf{E}$ & May & 24 & 1913 \\
\hline 849 & $13 \mathrm{~m}$ & $\mathrm{E}$ & April & 8 & 1914 \\
\hline 673 & $\mathrm{I}_{3}-\mathrm{I}_{5} \mathrm{~m}$ & NW & Decem. & I & 1914 \\
\hline 1,763 & $45 \mathrm{~m}$ & $\mathrm{E}$ & August & 2 & 1916 \\
\hline $2,14 \mathrm{r}$ & $8-13 \mathrm{~m}$ & $\mathrm{E}$ & $\Lambda_{\text {pril }}$ & 14 & 1921 \\
\hline
\end{tabular}

The table show that the number of houses destroyed in such conflagrations are vey little affected by the increasing velocity of the wind ${ }^{25}$, in consequence of which its correlation coefficient is possibly reduced to the minimum.

On the other hand, it points to the fact that during the period of such a conflagration a strong wind exceeding $8 \mathrm{~m} / \mathrm{sec}$ in speed always prevails over the town.

For the purpose of elucidating such a complicated relation it is therefore necessary in following the development of a fire, always to refer to the chart of wind velocity. We have, at the present, two instances, in one of which the wind increased in strength whilst the fire was spreading, and in the other it had just begun blowing when the fire broke out.

( I) A grcat fire that broke out in Tokyo: 14 h March I 7 th 1925. $\begin{array}{llllll}\text { Time } & \text { I } 4 \mathrm{~h} & \text { I5 } & \text { I6 } & \text { I7 } & \text { I8 }\end{array}$

$\begin{array}{llllll}\text { Wind-velocity } & \mathrm{NW}_{4.9 \mathrm{~m} / \mathrm{s}} & \mathrm{NNW}_{7.4} & \mathrm{~N} 8.5 & \mathrm{~N}_{9.4} & \mathrm{~N} 7.6\end{array}$

(2) A fire that took place in Hukuoka $4 \mathrm{~h}$ 'anuary 17 th

Time $2 \mathrm{~h} \quad 6$ Io

Wind-velocity NNW9.9m/s NW 9.0 NW 7.I

Both those cases show the existence of a close correlation between the wind and the fire, and no doubt many other evidences could be found elsewhere. Nevertheless, if judged from the statistical point of view, the answer is always negative.

25 The yearly mean velocity of wind at Hakodate is $5 \cdot 7 \mathrm{~m} / \mathrm{sec}$ and wind with a velocity of more than $10 \mathrm{~m} / \mathrm{sec}$ is not frequent there.

26 The samc fire as referred to on page 53 . 
This contradiction is however removed by the supposition that a great fire is stirred up by a moderately strong wind, and that the area burnt is not influenced by the excessive force of the wind but by some other powerful factor (lack of water or human agency), or by a second assumption namely that a moderately strong wind is quite enough to start a fire which gives rise to a fierce convection current and hence makes the spreading easy.

The former supposition is supported by the fact that there is a pretty intimate connection between the outbreak of fire and the velocity of the wind which is soon discussed in (II). And the second becomes highly probable if account is taken of two evidences, one of which was observed by Prof. S. Nakamura and also by Prof. S. Fujiwara on the occasion of the great earthquake fire of September 1, 1923, and the other of which was noted by foresters on several occasions.

(II) The correlation between the outbreak of fire and wind is more conspicuous than that between the wind and the area burnt. Such an instance we have found already in Tokyo, and subsequent researches establish ultimately the fact that this relation applies to every prefecture and every city without single exception. This correlation coefficient is on the average about 0.34 , those in which it is lower than 0.2 being very few.

Great as it is, yet it is smaller than that of humidity, with only two exceptions out of 30 cases. These two abnormal prefectures (Simane and Hukui) both face the Japan Sea.

Table 39

Correlation coefficient between

\begin{tabular}{c|c|c}
\hline Ordinary method & Variate difference & \\
\hline IIukui $-0.22 \pm 0.06$ & $\begin{array}{l}-0.34 \pm 0.06 \\
-0.41 \pm 0.05\end{array}$ \\
$\begin{array}{l}\text { Simane }-0.55 \pm 0.04 \\
\text { Hukui }+0.39 \pm 0.05\end{array}$ & $\begin{array}{c}\text { the fire outbreak and } \\
\text { relative humidity }\end{array}$ \\
$\begin{array}{l}\text { Simane }+0.56 \pm 0.04 \\
\text { Hukui }-0.55 \pm 0.04\end{array}$ & $\ldots .36 \pm 0.06$ & the fire outl,reak and mean velocity \\
Simane $-0.59 \pm 0.04$ & $\ldots \ldots \ldots \ldots \ldots \ldots . .$. & the fire outbreak and temperature
\end{tabular}

As the above table shows, this exceptional relation comes back to normal, when the cuefficient is calculated after the method of variate 
difference. So the comparatively great coefficient between fires and wind may be only apparent, and due to the influence of a third factor, possibly the temperature, for by such a method of calculation, the influence of this weather element can not be largely eliminated from both of the coefficient. ${ }^{27}$

All things taken into account, therefore, the infuence of wind on fires, with regard to its velocity is not so great as most people believe, anyhow so far as the present statistical research is concerned.

(III) The direction of the wind and fire. The direction of the wind has a great influence on the fire, not only on its outbreak but also on its spreading.

Fig. 13.

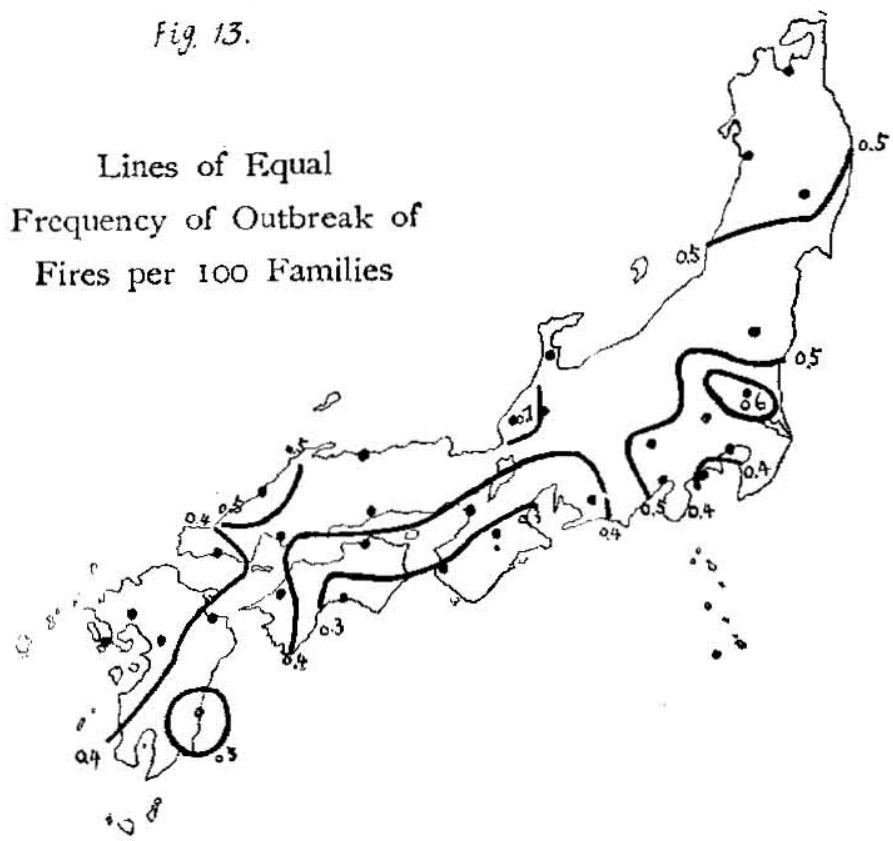

If the Hukuoka fire-statistics during last 14 years is refered to, the WNW or W wind is found to be the harbinger of the worst calamities in this district, and very likely in many districts of Japan.

As to the spreading of fire, the direction of the wind seems to have an important relation to it. The great conflagration at Hakodate

27 Referring to the fact that the correlation coefficient between the outbreak of fire, and temperature in these prefectures is greater than in the others. 


$$
\text { Fig. } 14
$$

Lines of Equal Coefficient of

Correlation between Humidity and Frequency of Fires

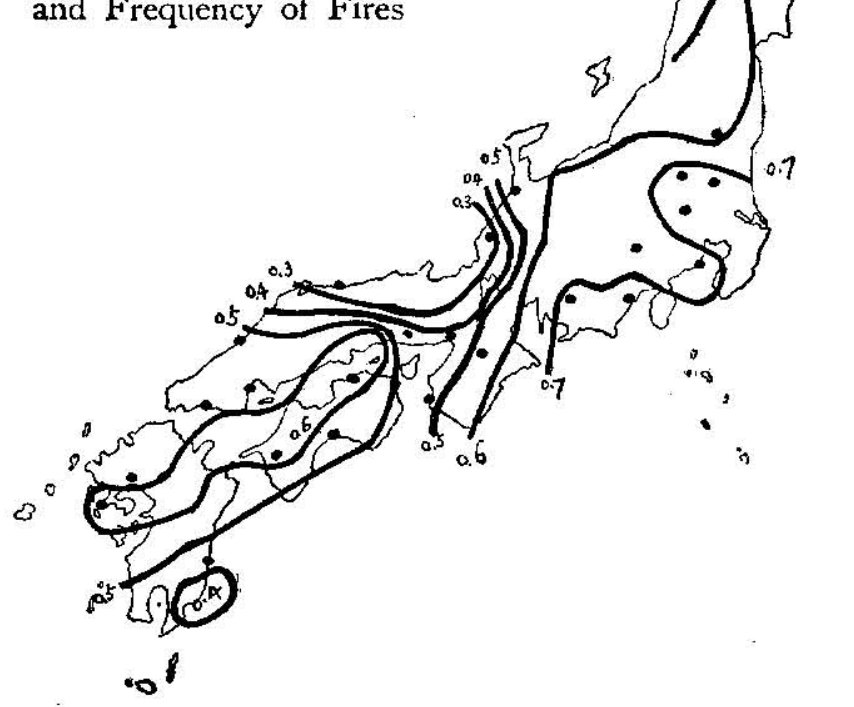

furnishes us a very good example of that. In five cases out of nine the calamity ensued when an easterly wind prevailed over the town. This deals partly with the direct and partly with the indirect effects of the wind, for the particular direction is associated closely with the dryness of the air blown in. The foen like wind brings a parching air to the land, while the north-west wind from a Siberian high pressure zone carries, during the winter, cold and dry air to the mainland of Japan, which often causes serious damage by giving a chance of conflagration breaking out.

\section{$\S 25$ CORRELATION BETWEEN FIRES AND THE WEATHER IN OTHER PREFECTURHS}

(I) The results of the statistical study of fires in three great cities and one prefecture are, in the main, consistent with each other. It is, however, important to confirm this by examining the correlation between fires and the meteorological factors in many other districts and towns. 


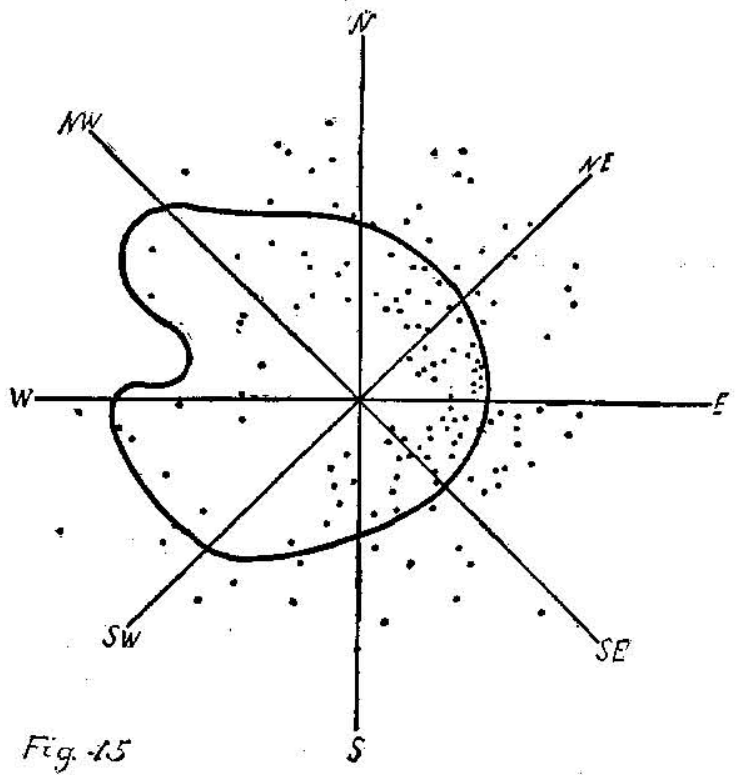

The radial distance from the origin represents the total number of fires that broke out in that direction.

With this in view, the fire statistics of $1917-1925$ years for 29 prefectures and 4 great towns (including three already studied) were examined. The mean monthly fire frequency of fires, the number of families of the corresponding places and the correlation coefficient between the outbreaks of fire or the area burnt and the meteorological factors (relative humidity, temperature, amount of precipitation and mean velocity of wind) with mean values of those meteorological factors for each prefecture and town were thoroughly worked out and examined thoroughly. Figures I3 and I4 show more clearly its general aspect; from these it can be seen that fire-occurrence is most frequent in the Kwanto district, while less frequent in the north-west part of Kyusyu; and on the other hand, it is noteworthy that the districts along the coast of the Japan Sea in spite of scarcity of population are often assaulted by fires.

Among the four meteorological elements as was usually the case also in the former study, the relative humidity has, for most places, the highest correlation with fires, their coefficients ranging from -0.80 (Tokyo) to -0.19 (Hakodate). The temperature has a less intimate 
correlation with fires, its coefficient falling to between -0.74 (Totiki) and -0.09 (Aomori). The mean velocity of the wind, and the amount of precipitation correlate with fires in the same degree of magnitude, the former coefficient varying from +0.77 (Saitama) to -0.22 (Nagasaki), and the latter from -0.57 (Totiki) to -0.0 I (Hukui).

The area burnt has a small correlation coefficient with the mean velocity of the wind, fluctuating between +0.28 (Hukusima) and -0.40 (Totiki).

All these results coincide with those obtained in the places already investigated.

(2) The annual variation of the frequency of fires in Japan has been already stated. It has two maxima, in the months of February and August; and two minima, in July and September, these months exactly corresponding to those of yearly minima and maxima of the relative humidity, as shown in Fig. 5 .

As has often been mentioned before, fire-frequency during the cold season is much larger than what would correspond actually to the dry state of the air, and the difference of successive monthly values (first differencial coefficient of fire frequency to time) answers the purpose much better.

\begin{tabular}{c|cc}
\hline Month & Jan. Feb. Apr. May June July Aug. Sep. Oct. Nov. Dec. Jan. \\
\hline $\begin{array}{c}\text { Succ. diff. of } \\
\text { fire-occurrences }\end{array}$ & II.8-55.8-15.9-28.8-133.3-83.5+38.6-41.2 4.8 95.6 I35.4 72.3
\end{tabular}

A slight change is, however, introduced in the periodic change, i.e. the maximum month of fire occurrence is displaced one month or so later, to March or April.

Fig. I5 lucidly brings out the close connection between the relative humidity and fires. The fire frequency varies instantly in response to prevailing relative humidity, so that there is no lag of time in the outbreak of fires, at any rate only one month at the most. This can be numerically proved, by taking and comparing the correlation coefficient between the monthly mean value of the relative humidity and that of the fire of the next month, or of the next one, and so on. For instance, in Tokyo it decreases stexdily as the month advances, thus showing the correlation as being the highest, if two factors are taken simultaneously.

It is to be renembered that the hazard month tends, somewhere in 
the north-eastern part of Japan, to move with the Table 38 increase of latitude a little toward the warm month, though in the majority of the other districts it remains at the same month namely about January or

\section{Correlation coefficient}

With Ist month and month $3^{\text {rd month }}$ $4^{\text {th }}$ month $5^{\text {th }}$ month

February.

(3) Daily change of fire occurrence. This investigation was a most difficult task arising simply from the want of necessary information on the subject. However, partly in the light of two year's statistics of Hukuoka prefecture prepared, partly by making use of the firereports of the current numbers of newspapers, 1924-1926, we get the following table :

Talle 40 Daily frequency of fires in Japan.

\begin{tabular}{|c|c|c|c|c|c|}
\hline I Iours & $\begin{array}{r}\text { Numl } \\
\text { in }\end{array}$ & $\begin{array}{l}\text { iber of fires } \\
\text { n Japan }\end{array}$ & $\begin{array}{l}\text { Number of fires } \\
\text { in IIukuoka }\end{array}$ & Relative humidity & Temperature \\
\hline $\mathbf{I}$ & * & 219.0 & $1.7 \mathrm{r}$ & $83.7 \%$ & I $3.47^{\circ} \mathrm{C}$ \\
\hline 2 & & 177.0 & 1.63 & $84 \cdot 3$ & 13.25 \\
\hline 3 & & 188.5 & 0.83 & 84.7 & 13.07 \\
\hline 4 & & $x_{37.0}$ & 0.42 & 85.0 & $12.9 x$ \\
\hline 5 & & 97.5 & 0.67 & $\S 85.3$ & 12.77 \\
\hline 6 & & 58.0 & 0.42 & 85.2 & 12.80 \\
\hline 7 & & 40.0 & $0.3^{8}$ & 83.0 & 13.40 \\
\hline 8 & $\S$ & 37.0 & $\S 0.6_{3}$ & $7^{8.4}$ & 14.67 \\
\hline 9 & & $54 \cdot 5$ & 0.42 & $7^{2.6}$ & 16.13 \\
\hline 10 & & 74.5 & 0.42 & 68.0 & 17.11 \\
\hline II & $*$ & 93.5 & $* 0.60$ & 64.9 & 18.12 \\
\hline 12 & . & 72.5 & 0.50 & 63.2 & I 8.65 \\
\hline 13 & $\$$ & 60.5 & 0.83 & 62.1 & 18.77 \\
\hline 14 & & 70.5 & $8 \mathrm{I} \cdot 38$ & * $6 \mathrm{I} .9$ & 19.06 \\
\hline I5 & $*$ & 88.5 & * I.04 & 62.5 & I 8.89 \\
\hline I6 & & $6_{3} \cdot 0$ & I. $5^{8}$ & $64 \cdot 3$ & 18. 38 \\
\hline 17 & $\S$ & 47.0 & $\S 0.7 \mathrm{I}$ & 67.8 & 17.54 \\
\hline I8 & & 53.0 & 0.63 & 72.0 & I6.57 \\
\hline 19 & & 68.5 & 0.75 & $75 \cdot 7$ & 15.71 \\
\hline 20 & & 89.5 & $1 . \infty$ & $7^{8 \cdot 3}$ & 15.12 \\
\hline 21 & * & 97.0 & $1.2 \mathrm{I}$ & 80.0 & 14.67 \\
\hline 22 & $\S$ & $8_{4.5}$ & * 1.50 & 81.2 & $14.3^{\circ}$ \\
\hline 23 & & I1 8.0 & $\$ 1.29$ & 82.2 & $r_{3.98}$ \\
\hline 24 & & $\mathbf{r}_{4} 6.5$ & * I. 83 & ${ }_{83.0}$ & $13.7^{\circ}$ \\
\hline
\end{tabular}


If the curve of fire-occurrence be examined, there is absolutely no denying the existence of four crests (maxima) and four troughs (minima), the former at

$$
\begin{array}{ll}
\text { I Ioh } 30 \mathrm{~m}-\mathrm{IIh} 30 \mathrm{~m} & \text { III } 20 \mathrm{~h} 30 \mathrm{~m}-2 \mathrm{Ih} 3 \mathrm{om} \\
\text { II I } 4 \mathrm{~h} 30 \mathrm{~m}-\mathrm{I} 5 \mathrm{~h} 30 \mathrm{~m} & \text { IV } \mathrm{oh} 30 \mathrm{~m}-\text { Ih } 30 \mathrm{~m}
\end{array}
$$

The alarm of a fire (better perhaps the discovery of a fire) received at the fire brigate station is said to be one or two hours later than the time of the outbreak, so that the first three maxima might be considered as corresponding to the Japanesc meal time, in consequence of which one inclines to assign the cause of fire accidents wholly to human negligence. On the other hand, the investigation of forest fires along the railroad caused by the scattering of sparks from the chimney of the locomotive brings us to about the same result as that of housefires, thus

Table $4 \mathrm{I}$ Forest fires caused by locomotives along the railroad in the charge of the Sendai Railroad Bureau (1915-1925) ${ }^{\text {zt }}$

\begin{tabular}{|c|c|c|c|}
\hline Four & No. of fires & No. of trains passed & No. of trains passed \\
\hline I- 2 & o & 74.0 & 0.000 \\
\hline $2-3$ & $\circ$ & 71.0 & 0.000 \\
\hline $3-4$ & 0 & 70.0 & $0.0 c 0$ \\
\hline $4-5$ & $\circ$ & 78.0 & 0.000 \\
\hline $5-6$ & o & 137.0 & 0.000 \\
\hline $6-7$ & 2 & I $6 \mathrm{r} .0$ & 0.012 \\
\hline $7-8$ & 6 & 157.5 & $* 0.038$ \\
\hline $8-9$ & 5 & 152.5 & 0.033 \\
\hline $9-10$ & $\circ$ & 150.0 & $\S 0.000$ \\
\hline $10-11$ & 12 & 157.0 & 0.077 \\
\hline II-I2 & 18 & 161.0 & $* 0.112$ \\
\hline $12-x_{3}$ & 6 & $15^{f \cdot, 5}$ & $\S 0.03^{8}$ \\
\hline $13-14$ & $2 \mathrm{I}$ & 148.5 & * 0.141 \\
\hline$I_{4}-I_{5}$ & 14 & 152.0 & 0.092 \\
\hline $15-16$ & 12 & 159.0 & 0.075 \\
\hline $16-17$ & 8 & 160.5 & 0.047 \\
\hline $17-18$ & 5 & 169.0 & 0.030 \\
\hline $18-19$ & 1 & 161.0 & $\S 0.006$ \\
\hline $19-20$ & I & 148.5 & 0.007 \\
\hline $20-21$ & 3 & $x 44.0$ & $* 0.021$ \\
\hline $21-22$ & I & 135.5 & 0.007 \\
\hline $22-23$ & 0 & 109.5 & $\S 0.0 \infty$ \\
\hline $23^{-24}$ & 4 & 92.0 & 0.043 \\
\hline $24-1$ & 3 & 81.0 & 0.037 \\
\hline
\end{tabular}

No. of fires

28 These numbers were communicated to me in letters by Mr. Wasio, Engineer of the Railroad Bureau at Sendai, to whom my cordial thanks are due. 
As the figure illustrates well, there is much resemblance between the house and forest-fire occurrence; they have two maxima at nearly the same hour that is

$\begin{array}{lcc} & \text { House fires } & \text { Forest fires } \\ \text { Ist maximum } & \mathrm{I} 5 \mathrm{~h} & \mathrm{r} 3 \mathrm{~h} 30 \mathrm{~m} \\ \text { 2nd maximum } & 2 \mathrm{Ih} & 20 \mathrm{~h} 30 \mathrm{~m}\end{array}$

As we have, in the above statistics, taken account of the number of trains that passed in an hour, there may be much more meaning in them than can be attributed to mere accident, at least as far as the first hazard time can be considered as corresponding to the driest hour of the day. (1)

\section{$\S 26$ FIRE-SEASONS AND CYCLONES}

There are, throughout a year, three kinds of depression which visit Japan. One of them is certainly the extratropical cyclone which, coming from the Asiatic continent, causes much rain and snow during the months December-March, more especially along the coast of the Japan Sea, and is followed by cold north-westerly wind with dry air.

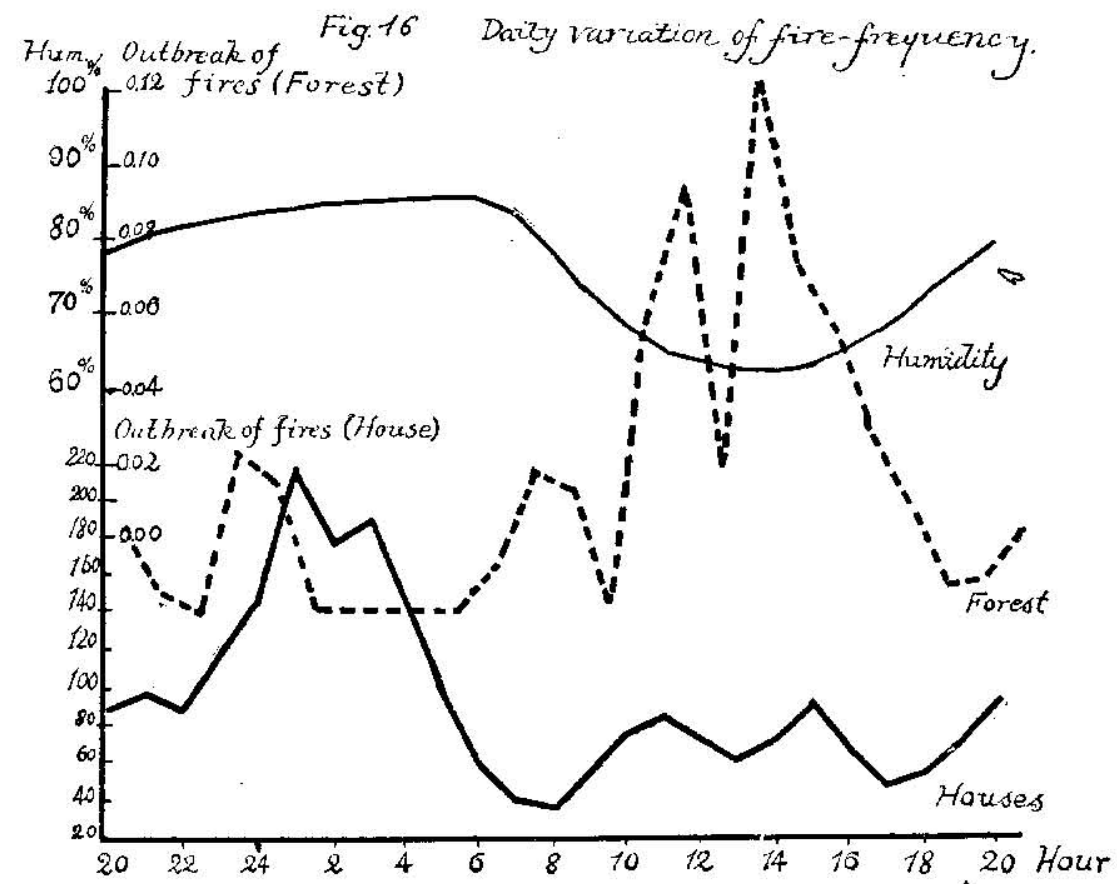


The second is the series of shallow depressions which originated in the Youngtze-Kiang River district during about June or July and come across the eastern Chinese Sea and bring dreary wet weather to Japan. The third is the well known tropical cyclone (the so called typhoon) which at the end of the summer does much damage through heavy rain and gales.

These depressions have a close association with the recurrence of the fire-hazard; thus the first maximum of fires occurs with the extratropical cyclone, the first minimum with the wet season of early summer and the second minimum with the typhoon season in the late summer.

\section{Fig. 17}



Fig. 18 .

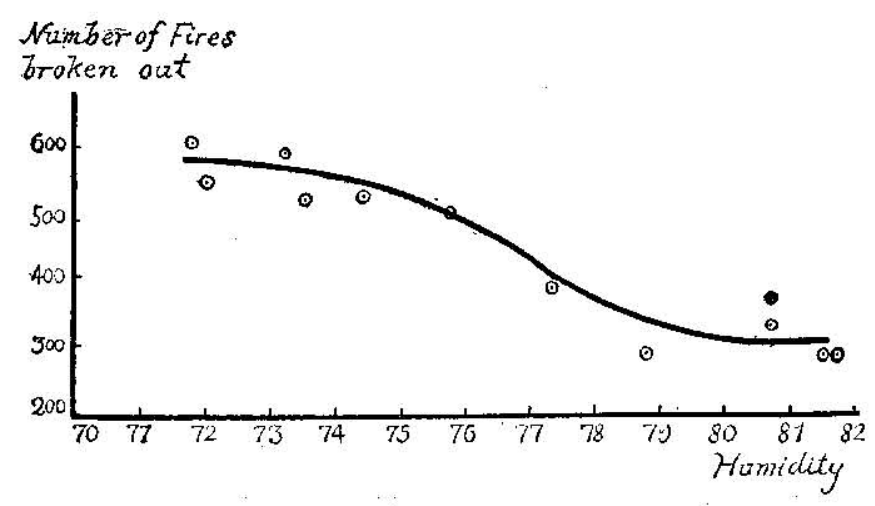


The second maximum in the curve (in August) is largely due to the counteraction of the considerable diminution in both side of it, partially due to a cause as yet unknown. It may be connected with the following fact. Some places not small in number have, as in London or in Hukuoka, the positive correlation coeff cient between the fires and air temperature during the hot season, July or August. (More examples of this will be given below)

Table 42 Correlation coefficient between fires and temperature

\begin{tabular}{lccc} 
Month & \multicolumn{1}{c}{ Osaka } & Yamaguti & Nagasaki \\
January & $-0.36 \pm 0.22$ & $-0.37 \pm 0.22$ & $-0.80 \pm 0.08$ \\
February & $-0.74 \pm 0.12$ & $+0.15 \pm 0.25$ & $-0.67 \pm 0.12$ \\
March & $+0.21 \pm 0.24$ & $+0.04 \pm 0.25$ & $-0.32 \pm 0.20$ \\
April & $-0.91 \pm 0.05$ & $+0.39 \pm 0.22$ & $-0.19 \pm 0.22$ \\
May & $+0.36 \pm 0.22$ & $+0.17 \pm 0.25$ & $-0.59 \pm 0.15$ \\
June & $+0.53 \pm 0.18$ & $+0.46 \pm 0.20$ & $+0.36 \pm c .20$ \\
July & $+0.67 \pm 0.15$ & $+0.56 \pm 0.19$ & $+0.63 \pm 0.14$ \\
August & $+0.28 \pm 0.25$ & $+0.44 \pm 0.22$ & $+0.03 \pm 0.24$ \\
September & $+0.52 \pm 0.20$ & $+0.21 \pm 0.26$ & $-0.40 \pm 0.20$ \\
Octoher & $-0.20 \pm 0.26$ & $+0.26 \pm 0.25$ & $-0.06 \pm 0.24$ \\
Novenl,er & $-0.06 \pm 0.27$ & $+0.45 \pm 0.21$ & $-0.33 \pm 0.2 \mathrm{I}$ \\
December & $-0.09 \pm 0.27$ & $+0.67 \pm 0.15$ & $+0.32 \pm 0.21$
\end{tabular}

Selecting the principal parts from many prefectures, we get their coefficients for the two hot months, (order of places is from north to south)

Table 43

$\begin{array}{lcccc} & \text { Aomozi } & \text { Akita } & \text { Hukusima } & \text { Hukui } \\ \text { July } & 0.03 \pm 0.34 & -0.10 \pm 0.27 & -0.10 \pm 0.39 & 0.07 \pm 0.27 \\ \text { August } & 0.25 \pm 0.32 & 0.20 \pm 0.27 & 0.34 \pm 0.30 & -0.65 \pm 0.16 \\ & \text { Saitama } & \text { Yamanasi } & \text { Aiti } & \text { Nara } \\ \text { July } & 0.22 \pm 0.26 & 0.14 \pm 0.26 & 0.25 \pm 0.25 & -0.43 \pm 0.22 \\ \text { August } & 0.43 \pm 0.22 & 0.36 \pm 0.23 & 0.22 \pm 0.26 & -0.57 \pm 0.18 \\ & \text { Kagawa } & \text { Lhime } & \text { Miyazaki } & \text { Saga } \\ \text { July } & 0.6 \mathbf{0 . 1 7} & -0.55 \pm 0.19 & 0.39 \pm 0.23 & 0.17 \pm 0.26 \\ \text { August } & 0.08 \pm 0.27 & 0.14 \pm 0.26 & 0.55 \pm 0.19 & 0.62 \pm 0.17\end{array}$

Such a positive correlation between fires and temperature during the hot season may be explained by the fact that the incense-stick burns rapidly in Summer.

In conclusion, a good example to illustrate the great influence of the weather on fire is taken from several of a long series of fires that broke out one after another and proceeded from west to east in March 
1926. The data are taken from the fire-reports that appeared daily in the newspaper at Hukuoka, Osaka, Tokyo and Sapporo.

Table 44 is prepared to facilitate the understanding of this. The numbers cnclosed by a square indicate what may be considered as fires belonging to the same group.

There are 4 series of successive groups of fires, at intervals of three days or a week, each advancing from Hukuoka (south-west Japan) to Hokkaido (north-east) and causing much damage along their route, the journey requiring two days or so. It is noteworthy that the extratropical cycilone passes in succession before or after the fires sweep over Japan. As before mentioned, in such a case, a westerly wind blows and brings much cold and aridity, while the anticyclone stretching its limb toward Japan dominates the continent of Asia.

\section{\$ 27 THE VARIATION OF WATER CONTENT} IN TIMBER

The daily and weekly change of the length of timber exposed to the humid air has already been studied by self registering apparatus.

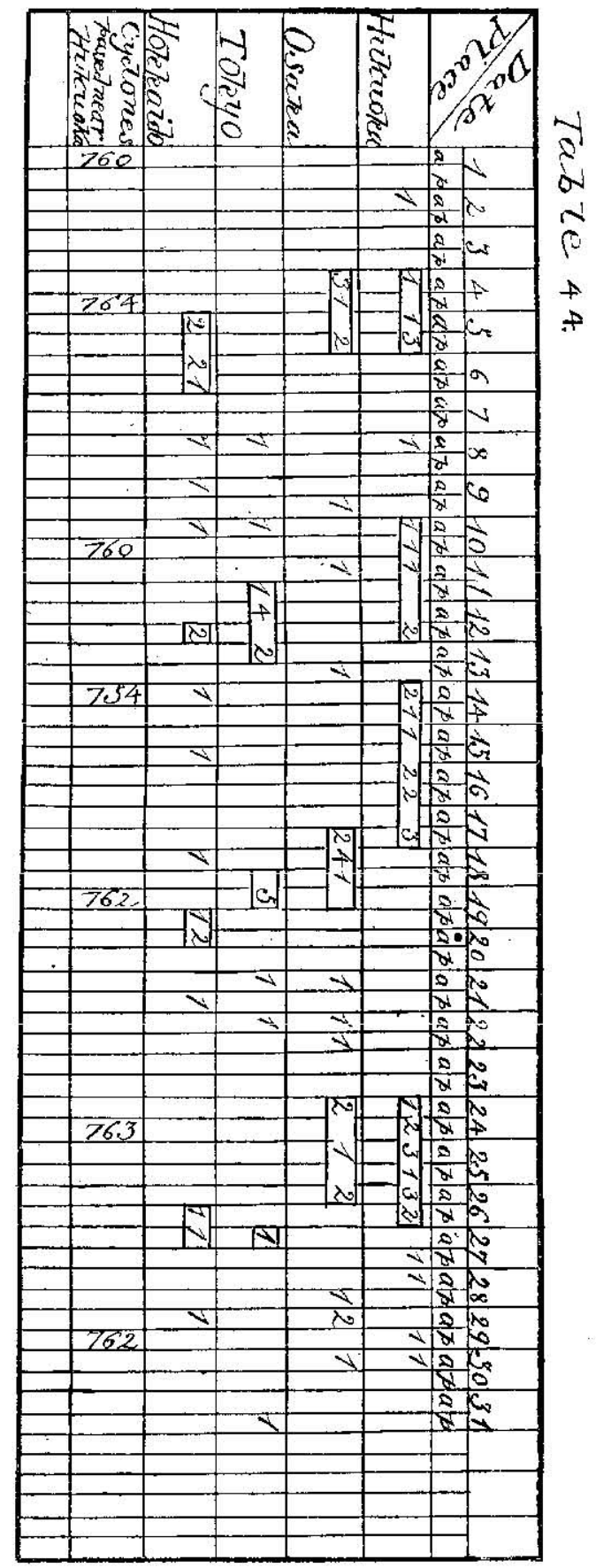


Its water content probably undergoes a similar change in response to the humidity-change of the surrounding air, when the wooden rod is as thin as the incense-stick.

It is desirable to obtain information as to the minute variation of total water content of a wooden house-pillar or household-furniture in order to elucidate its bearing on time-lag in relation to the humidity variation. For this purpose, the weight of a wooden prism whose thickness and width are of the same dimensions as those of an actual pillar and the ends of which are painted with varnish, was recorded on smoked paper. Roughly speaking, as this prism behaves in respect to water absorption in the same way as the pillars commonly found in Japan, the following results may be regarded as those of the actual pillar. The material used was Abies sachalineusis, Mast.

Table 45 The weight of a wooden block and its relative humidity.

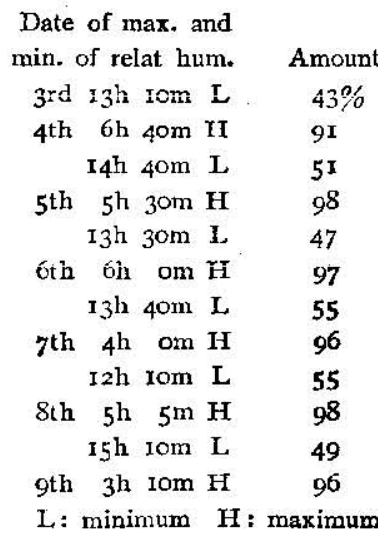

\begin{tabular}{|c|c|c|}
\hline $\begin{array}{l}\text { Date of max. and } \min \text {, } \\
\text { of weight of wood }\end{array}$ & Amount & $\begin{array}{l}\text { Phase diff, } \\
\text { bet. hum. a wt. }\end{array}$ \\
\hline $\mathrm{I}_{7} \mathrm{l}_{\mathrm{i}} 45 \mathrm{~m} \mathrm{I}$ & $0.00 \%$ & $4 \mathrm{~h} 35 \mathrm{~m}$ \\
\hline $8 \mathrm{~h}$ or II & 0.78 & Ih $20 \mathrm{~m}$ \\
\hline Igh $35 \mathrm{~m} \mathrm{I}$ & I. 30 & $4 \mathrm{~h} 55 \mathrm{~m}$ \\
\hline $8 \mathrm{~h} 20 \mathrm{~m} \mathrm{H}$ & 1.56 & $2 \mathrm{ll} 55^{\mathrm{m}}$ \\
\hline rgh $35 \mathrm{~m} \mathrm{I}$ & 1.56 & $6 \mathrm{~h} \quad 5 \mathrm{~m}$ \\
\hline $8 \mathrm{~h} 25 \mathrm{~m} \mathrm{Hi}$ & $1.5^{6}$ & $2 \mathrm{~h} 25 \mathrm{~m}$ \\
\hline $18 \mathrm{~h} 35 \mathrm{~m} \mathrm{~L}$ & 0.96 & $4 h 55 \mathrm{~m}$ \\
\hline $8 \mathrm{~h} 25 \mathrm{~m} \mathrm{H}$ & 1.30 & $4 \mathrm{~h} 25 \mathrm{~m}$ \\
\hline $17 \mathrm{~h} 35 \mathrm{~m} \mathrm{~L}$ & 1.30 & $5 \mathrm{~h} 25 \mathrm{~cm}$ \\
\hline $7 \mathrm{~h} 45 \mathrm{~m} \mathrm{H}$ & 1.22 & $2 h 40 m$ \\
\hline $2 \times 45 \mathrm{~m} \quad \mathbf{L}$ & I.56 & $6 \mathrm{~h} 35 \mathrm{~m}$ \\
\hline $8 \mathrm{~h} 50 \mathrm{~m} \mathrm{H}$ & 1.04 & $6 \mathrm{~h} 40 \mathrm{~m}$ \\
\hline
\end{tabular}

Thus the phase difference between two minima amounts to $5 \mathrm{~h} 36 \mathrm{~m}$, and that between two maxima to $3 \mathrm{~h} 24 \mathrm{~m}$. Its determination in the case of the maximum of relative humidity is found in no less degree indeterminate, because it often remains almost constant, nearly saturated throughout the night.

One of the best methods for our purpose is to pass an electric current of varying strength through the standing column. However, an easier method is available by means of an apparatus by which the change of strength of an electric current through a thick wooden block is recorded photographically on revolving bromide paper by a light beam reflected from the small mirror of a galvanometer (Ayrton-Mather 


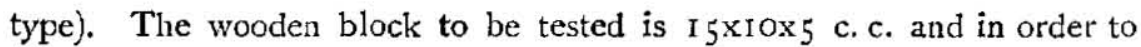
make contact good is powdered thickly with graphite on both sides of the transverse section, before being coated with tin-foil, which is again closely fitted with copper plate, the latter forming at the same time the electrodes. To meet the conditions postulated by mathematics as closely as possible, we contrived to leave one face of the block (transversal section of $15 \times 10 \mathrm{~cm}^{2}$ ) expose to the air, while, to prevent free communication with the surrounding air the back face and two side planes were painted thickly with paraffin wax. This block was nailed to the wall. So far, only two materials have been tested, Pinus densiflora, S. et $Z$. and Abies sachalineusis, Mast. For the first material, we made use of a 22.5 volt battery of sufficient capacity, and one of r. 5 volts for the second. The strict constancy of the voltage during a week's operation is perhaps doubtful, but the error arising therefrom is of small consequence because the resistance of the material under test is very great. By such an apparatus several photographically recorded resistance-variation charts were obtained during the winter and compared with the hygrographic records simultaneously prepared. Owing to the bad season, the variation is too irregular to admit of elaborate analysis and the following values are nothing but an estimate.

Table 46



It is known that the conductivity of wood is very small and varies with time, though differing greatly according to its kind. The most predominating factor affecting conductivity is certainly either the water content or the temperature. The increase of the former and the decrease of the latter both call forth the same effect giving rise to increasing conductivity. To determine which is more prominent, we made use of a small wooden block $10.6 \mathrm{~cm}$ long, $4.8 \mathrm{~cm}$ wide and 4.7 thick, the weight and the current strength of which could be selfregistered in the same way as before, only differing slightly in certain details. That is, 
a light conducting copper-spring was fastened to each of the electrodes in such a way as to cause no hindrance to the free movement of the suspended block. This apparatus has very well fulfilled the dual purpose of registering the weight-change and conductivity-variation of the wood. The mutual time-relation between the maxima and minima of the three factors-relative humidity, weight-variation of the wood and electrical conductivity-are shown below.

Table 47. The change of conductivity and of weight of wood.

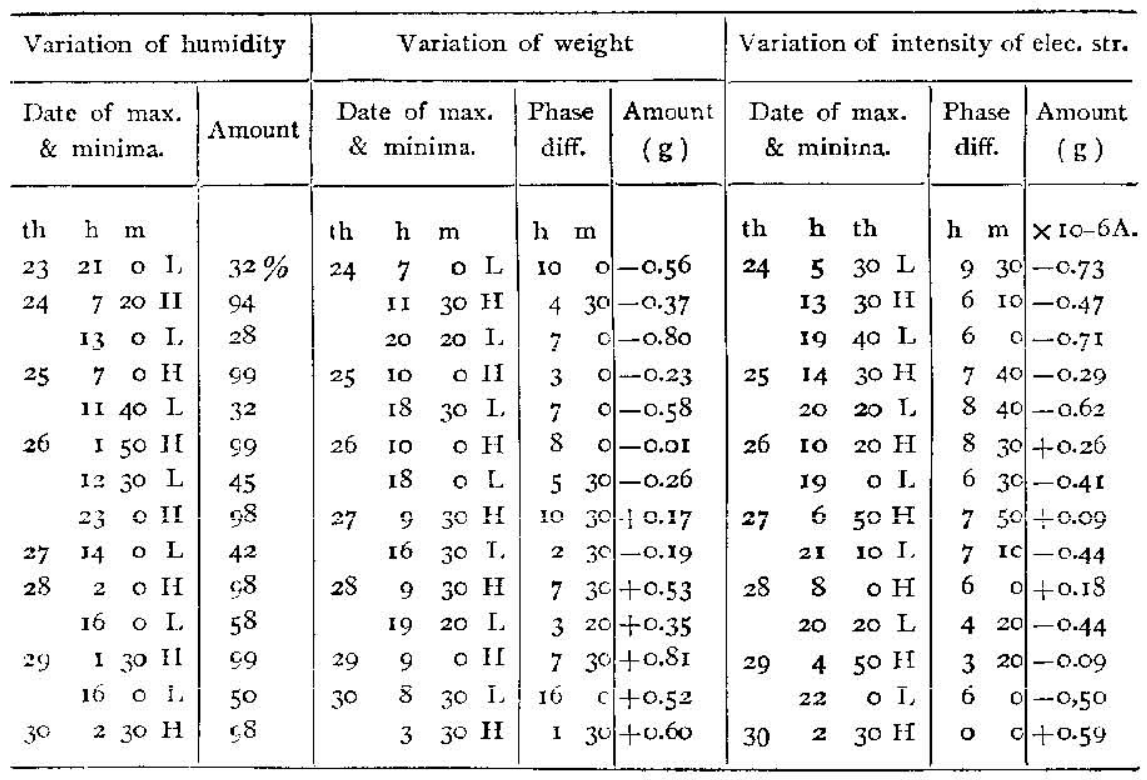

L: Minimum, H: Maximum.

The weight of the timber varies in harmony with the change of relitive humidity, only differing with regard to the time. The time nay be retarded by several hours, the actual amount of which depends on the manner of the variation of the humidity. The mean value of time-lag is about 6 hours in the case of daily variation, though it should be mentioned that the lag of the maximum and of the minimum are not the same.

As regards the electric current almost the same thing can be said, though the time of appearance of the maxima and minima of the current do not coincide precisely with those of weight-change and 
rather come a little later, its main cause apparently lying in the temperature-variation.

We have ascertained, so far, that the maximum of water-content of timber, and also presumably of current-strength, appears about at Ioh a.m. and the minimum usually at $6-8 \mathrm{~h} \mathrm{p.m}$. So the use of the electric method of measuring the water-content is recommended in cases where direct weighing of the material is found impossible; moreover it may be employed with much more advantage, if a knowledge of cetailed changes is desired. And the results obtained as shown in table 47 , are, in the first order, the same as those obtained by weighing of the timber. Next the mathematical solution of the absorption will be briefly compared with experimental results.

Let us suppose that the timber is exposed to the air in an infinite horizont 1 plane surface and extends downward to infinity. Taking $x$ as axis vertically downward (toward the interior of timber) and choosing the origin at the boundary, we get the following expression :

$$
\frac{\partial \sigma}{\partial t}=\frac{\partial}{\partial \mathbf{x}} \mathbf{k} \frac{\partial \sigma}{\partial \mathbf{x}}
$$

where $\sigma$ denotes the water-content, in unit volume of material and is called absolute moisture, and $\mathrm{k}$ is called diffusibility of water and equal to the water-quantity which would diffuse through the material of unit thickness perpendicular to the surface of unit area in unit time, when the water content differs by unity. $\mathrm{k}$ differs, of course according to direction, ${ }^{9}$ but may be conceived of as invariable throughout the same direction.

Assuming $\mathrm{k}$ as independent of $\mathrm{x}$, we get :

$$
\frac{\partial \sigma}{\partial \mathrm{t}}=\mathrm{k} \frac{\partial^{2} \sigma}{\partial \mathrm{x}^{2}}
$$

Now let us consider that the relative humidity of the air near the boundary surface varies as $\mathrm{H}_{\circ} \cos$ (bt) where $\mathrm{H}_{\circ}$ is a constant and $\mathrm{b}$ is $2 \pi$ by frequency; for example, $b$ becomes $\frac{2 \pi}{24}$ when the problem is concerned with daily variation of humidity and $\frac{2 \pi}{24 \times 365}$ for seasonal variation. Again denoting the saturation water content in material by $\sigma_{m}$, and by taking the ratio $\frac{\sigma}{\sigma_{m}}$ corresponding to the atmospheric re-

2 It differs by the tangential, radial and cross section. 
lative humidity, we can get an idea of a degree of moisture in timber and we call it "relative moisture" of wood. As subsequent experiments indicate, absolute moisture varies with the relative humidity of the surrounding air and in less degree with the temperature. The determination of an absolute moisture is not so difficult, but with relative moisture it is quite other-wise. At present it is beyond our reach to measure the latter as well as $\sigma_{\mathrm{tin}}$.

Presumably, there exists a high correlation between relative moisture and relative humidity, whereby the dependency of absolute moisture $\sigma$ on relative humidity may be considered to be an indirect consequence, and it changes with the latter probably because the saturation water content $\sigma_{m}$ is, to certain extent, independent of temperature. An exception arises, however, when the temperature becomes very high, in which case the saturation water content is gradually affected and is reduced in value. Thus, assuming the intimate connction between relative moisture and humidity, we have two alternatives as the condition to be satisfied in the boundary. (at $x=0$ )

$$
\begin{aligned}
& \text { (I) } \mathrm{H}^{\circ} \cos \mathrm{bt}=\mathrm{c} \frac{\sigma}{\sigma_{\mathrm{m}}} \\
& \text { (2) } \mathrm{H}^{\circ} \cos \mathrm{bt}-\frac{\sigma}{\sigma_{\mathrm{m}}}=-\mathrm{k}^{\prime} \frac{\partial \sigma}{\hat{c} \mathrm{x}}
\end{aligned}
$$

where $\mathrm{c}$ and $\mathrm{k}$ are constant.

As the solution of (I), we get

$$
\sigma=\frac{\mathrm{H}_{0} \sigma_{\mathrm{m}}}{\mathrm{c}} \mathrm{e}^{-\sqrt{\frac{\mathrm{b}}{2 \mathrm{k}} \mathrm{x}}} \cos \left(\mathrm{bt}-\sqrt{\frac{\mathrm{b}}{2 \mathrm{k}}} \mathrm{x}\right) \ldots \ldots \ldots \ldots(\mathrm{I})
$$

The total quantity of water in the timber per unit area $Q$ is

$$
\begin{array}{ll}
\text { or } \quad & \frac{\mathrm{H}_{0} \sigma_{m}}{\mathrm{c}} \sqrt{\frac{\mathrm{k}}{\mathrm{b}}} \cos \left(\mathrm{bt}-\frac{\pi}{4}\right) \\
\frac{\mathrm{H}_{0} \sigma_{\mathrm{m}}}{\mathrm{c}} \sqrt{\frac{\mathrm{kT}}{2 \pi}} \cos \frac{2 \pi}{\mathrm{T}}\left(\mathrm{t}-\frac{\mathrm{T}}{8}\right)
\end{array}
$$

Therefore,

(a) $Q$ is proportional to the amplitude of humidity and to the square root of its period and of the diffusibility of the wood.

(b) Time-lag is just 8 th of the period; for example, the maximum and minimum value of the total water content come in the daily variation three hours later than those of the relative humidity, and in the annual variation one month and a half later. 
The variation of the total water content subjected to two different hygrometric oscillations becomes:

$$
\frac{\boldsymbol{a}_{m}}{\mathrm{c}} \sqrt{\frac{\mathrm{k}}{2 \pi}}\left\{\mathrm{H}_{\circ} \sqrt{\mathrm{T} \cos } \frac{2 \pi}{\mathrm{T}}\left(\mathrm{t}-\frac{\mathrm{T}}{8}\right)+\mathrm{H}^{\prime} \circ \sqrt{\mathrm{T}^{\prime}} \cos \frac{2 \pi}{\mathrm{T}^{\prime}}\left(\mathrm{t}-\frac{\mathrm{T}^{\prime}}{8}\right)\right\}
$$

To take an example from Hukuoka we have

Relative humidity ${ }^{30} \quad 88.4 \%$ the greatest at $5 \mathrm{~h} \mathrm{a.m.}$

(daily) $62.9 \%$ the smallest at $\mathrm{I}-2 \mathrm{~h}$ p.m.

Difference $\quad 25.5 \%$ its half value I $2.8 \%$ corresponds

to $\mathrm{H}$ 。

Relative humidity ${ }^{(1)} \quad 82.7 \%$ the greatest in September

(annual) $73.2 \%$ the smallest in February

Difference 9.5 its half value $4.8 \%$ corresponds to $\mathrm{H}_{0}$ :

$$
\text { Ratio }=\mathrm{H}_{\sqrt{ }} / \mathrm{T}^{-} / \mathrm{H}_{0}^{\prime} \mathrm{V} \cdot \overline{\mathrm{T}^{\prime}}=6_{3} / 446=0 . \mathrm{r}_{4}
$$

Therefore, the annual variation of humidity can only be taken into consideration when we enter into the problem of the total water content of timber, while the daily variation comes into question when we deal with the superficial wetness of the timber.

As the solution of (2), we get

$$
\begin{gathered}
\sigma=\mathrm{e}^{-\sqrt{\frac{\mathrm{b}}{2 \mathrm{k}}} \times}\{\mathrm{A} \cos (\mathrm{bt}-\mathrm{fx})+\mathrm{B} \sin (\mathrm{bt}-\mathrm{fx})\} \\
\text { where } \mathrm{A}=\frac{\left(\frac{\mathrm{I}}{\sigma_{\mathrm{m}}}+\mathrm{k}^{\prime} \sqrt{\left.\frac{\mathrm{b}}{2 \mathrm{k}}\right) \mathrm{H}_{0}}\right.}{\left(\frac{\mathrm{I}}{\sigma_{\mathrm{m}}}+\mathrm{k}^{\prime} \sqrt{\left.\frac{\mathrm{b}}{2 \mathrm{k}}\right)^{2}+\frac{\mathrm{bk}^{\prime 2}}{2 \mathrm{k}}}\right.} \\
\mathrm{B}=\frac{\mathrm{k}^{\prime} \sqrt{\frac{\mathrm{b}}{2 \mathrm{k}}} \mathrm{H}_{\circ}}{\left(\frac{\mathrm{I}}{\sigma_{\mathrm{m}}}+\mathrm{k}^{\prime} \sqrt{\left.\frac{\mathrm{b}}{2 \mathrm{k}}\right)^{2}}+\frac{\mathrm{bk} \mathrm{k}^{\prime 2}}{2 \mathrm{k}}\right.}
\end{gathered}
$$

$$
\sigma=\frac{\mathrm{H}_{\circ} \mathrm{e}^{-\sqrt{\frac{\pi}{2 \mathrm{k}} \mathrm{x}}}}{\sqrt{\left(\mathrm{\sigma}_{\mathrm{an}}^{\mathrm{I}}+\mathrm{k} / \sqrt{\frac{\mathrm{b}}{2 \mathrm{k}}}\right)^{2}+\frac{\mathrm{bk}}{2 \mathrm{k}}}} \cos \left(\mathrm{bt}-\sqrt{\frac{\mathrm{b}}{2 \mathrm{k}} \mathrm{x}}-\varepsilon\right)
$$

where $\cot \varepsilon=\mathbf{I}+\frac{\sqrt{\frac{2 \mathrm{~b}}{\mathrm{~b}}}}{\mathrm{k}^{\prime} \sigma_{3 n}}$

30 From thirty years" statistics at Huktoka Meteorolugical Observatory. 
the total quantity of water is

$$
\frac{H_{\circ} \sqrt{\frac{\mathrm{k}}{\mathrm{b}}} \cos \left(\mathrm{bt}-\frac{\pi}{4}-\varepsilon\right)}{\sqrt{\left(\frac{\mathrm{I}}{\sigma_{\mathrm{m}}}+\mathrm{k}^{\prime} \sqrt{\left.\frac{\mathrm{b}}{2 \mathrm{k}}\right)^{2}+\frac{\mathrm{bk}}{2 \mathrm{k}}}\right.}}
$$

This is more general than solution (I), because (II) becomes (I) when we put $\mathrm{k}^{\prime}=0$. On the other hand, when we put $\sigma_{n 1}=\infty$, (II) becomes

$$
\begin{aligned}
& \sigma=\frac{\mathrm{H}_{0}}{\mathrm{k}^{\prime}} \sqrt{\frac{\mathrm{k}}{\mathrm{b}}} \mathrm{e}^{-\sqrt{\frac{\mathrm{b}}{2 \mathrm{k}}} \times} \cos \left(\mathrm{bt}-\sqrt{\frac{\bar{b}}{2 \mathrm{k}}} \times-\frac{\pi}{4}\right) \\
& Q=\frac{H_{0} k}{b k^{\prime}} \cos \left(b t-\frac{\pi}{2}\right)=\frac{H_{0} k T}{2 \pi k^{\prime}} \cos \frac{2 \pi}{T^{-}}\left(t-\frac{T}{4}\right)
\end{aligned}
$$

Therefore,

(a) $\mathrm{Q}$ is proportional to amplitude of humidity, period, and diffusibility.

(b) Time-lag is $1 / 4^{\text {th }}$ of the period.

So the maximum or minimum of the total water content appears in the record six hours later in the case of daily variation, and three months later in the case of annual variation. The ratio of amplitudes of the two is 0,01 , considerably less than by (I).

Therefore, condition (2) conforms rather better to the experimental results. And formula (III) represents roughly the actual state of waterabsorption of the material.

\section{$\S 28$ DISCUSSION AND CONCLUSION}

Turning for the present from the statistical consideration, we direct attention to the effects coming from outside the material. First, the change of oxygen supply due to the weather should be considered.

(I) In this respect the influence of the wind is seen to be paramount, when it is considered for example, that if the velocity of the wind changes from $\mathrm{I} \mathrm{m} / \mathrm{sec}$ to $2 \mathrm{~m} / \mathrm{sec}$, the amount of oxygen supply becomes double in value. On the other hand, a contrary effect may be produced, that is that the wind sometimes extinguishes the fire when the cold air comes fresh from outside. The stiring effect of wind, though weak in strength, is demonstrated in the laboratory work, and was also confirmed by the statistics of fires already studied. 
(2) The low temperature, the high pressure, and the diminution of the vapour-quantity in the winter in Japan make the atmospheric oxygen denser, though only slightly, than in the summer.

Denoting temperature, atmospheric pressure vapour tension, air density and expansion coefficient of air by $t, b, e, S_{0}$ and $\alpha$ respectively, we gret the following expression for absolute humidity (air in $\mathrm{kg}$ per $\mathrm{km})$ :

$$
\frac{\mathrm{S}_{0}}{(\mathrm{I}+\mathrm{bt}) \times 7 \mathrm{~b}-\mathrm{e})}
$$

The ratio of air density of winter to that of summer is

$$
\frac{\mathrm{r}+a \mathrm{t}^{\prime}}{\mathrm{I}+a \mathrm{t}} \frac{\left(\frac{\mathrm{b}}{760}-\frac{\mathrm{e}}{760}\right)}{\frac{\mathrm{b}^{\prime}}{760}-\frac{\mathrm{e}^{\prime}}{760}}=\mathrm{x}+\alpha\left(\mathrm{t}-\mathrm{t}^{\prime}\right)+\frac{\mathrm{b}-\mathrm{b}^{\prime}}{760}-\frac{\mathrm{e}-\mathrm{e}^{\prime}}{760}
$$

where the dashed and not dashed letters denote the weather elements of winter and of summer respectively. To make a rough estimation of their influence, we make use of the following mean values of weather elements for Tokyo in the coldest and the hotest months.

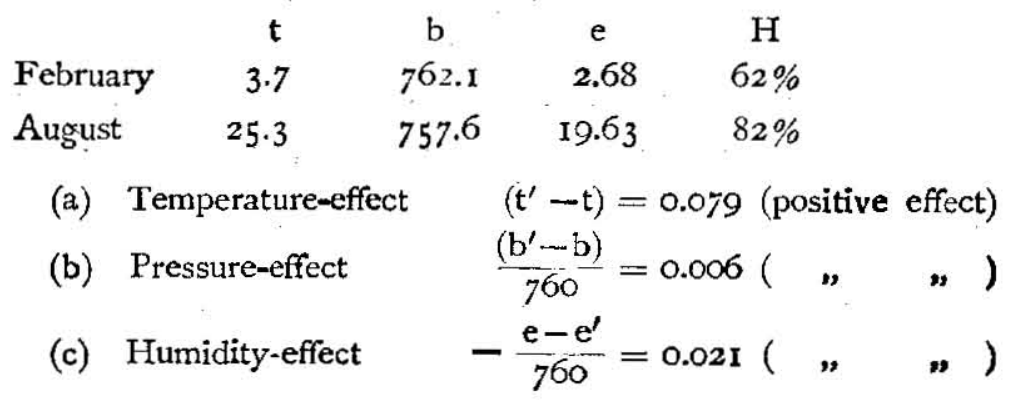

The total effect becomes 0.106 i.e. $10.6 \%$

(3) The effect of the change of heat-capacity of air (negative effect) This is expressed by the following formula, all influencing weather-factors being taken into consideration :

$$
\begin{aligned}
& \alpha\left(\mathrm{t}^{\prime}-\mathrm{t}\right)+\frac{\mathrm{b}-\mathrm{b}^{\prime}}{760}-\frac{\mathrm{e}-\mathrm{e}^{\prime}}{760}+\frac{0.623 \times 0.48}{0.23} \frac{\left(\mathrm{e}-\mathrm{e}^{\prime}\right)}{760} \\
& \quad=0.079+0.006+0.021-0.079=0.079
\end{aligned}
$$

This shows that the heat capacity increases by $7.9 \%$ in winter.

(4) The heat content of the air mass is greiter in summer than 
in winter (negative effect). Consider the ratio of the heat required to raise the air from $3.70^{\circ} \mathrm{C}$ to $4.00^{\circ} \mathrm{C}$ to that from $25.3^{\circ} \mathrm{C}$ to $400^{\circ} \mathrm{C}$. 1.056

The amount is somewhat in the order of $\frac{400-3 \cdot 7}{400-25 \cdot 3}=\frac{395}{375}=$ This negative effect amounts to $5.6 \%$.

These last three causes together being taken into account, their influence on burning becomes very insignificant.

(5) The convective effect. In the treatment of the problems of charcoal-burning, I brought the effect of air-convection into the foreground, because a pronounced convection current is naturally expected if the air ground or below the fire is colder than within. However, the quantitative argument is difficult to deal with and the following calculation gives only a partial idea in regard to it.

Suppose a vertical air column with height $h$, the air-density within and outside being $\rho_{\mathrm{t}}$ and $\rho_{\mathrm{t}}$ respectively. If $\mathrm{t}$ is higher than $\mathrm{t}$, the air current flows out from the orifice on the top of the column with the velocity,

$$
\sqrt{\frac{2\left(\rho_{\mathrm{t}^{\prime}}-\rho_{\mathrm{t}}\right) \mathrm{hg}}{\rho_{\mathrm{t}}}}
$$

where $g$ is the acceleration of gravity.

Making use of data from Tokyo, the ratio of the oxygen supply in winter to that in summer is

$$
R=\sqrt{\frac{\left(\rho_{3,7}-\rho_{t}\right)}{\left(\rho_{25,3}-\rho_{\mathrm{t}}\right)}}=1.039 \sqrt{\frac{\mathrm{t}-3.7}{\mathrm{t}-25.3}}
$$

$\mathrm{R}$ varies by temperature $\mathrm{t}$, as below,

$$
\begin{array}{lllll}
\mathrm{t} & 2.53 & 100 & 100 & \infty \\
\mathrm{R} & \infty & 1.14 & 1.06 & 1.04
\end{array}
$$

The air temperature within the burning fire is more than $100^{\circ} \mathrm{C}$, so that the effect due to the seasonal temperature change is between $14 \%$ and $4 \%$, not so great an amount as we expected.

(6) Water in burning material. If the cause of inflammability lies outside of the burning material the factors mentioned now should play important rôle, in consequence of which the air temperature, atmospheric pressure and water-vapour should have close correlation with fire 
frequency, but as a matter of fact that is not the case as we have already shown.

The fact that the relative humidity has the greatest correlation with fire-frequency among many other meteorological elements leads naturally to the conclusion that water comes remarkably into play in regard to this fire-problem. It is easily conceivable that the variation of the water content in the material is decisive on this point, and another alternative is the damping influence of water vapour in the air.

However, the correlation between the outbreak of fires and the specific humidity (vapour quantity in $\mathrm{kg}$ of air) is found to be always less than that of relative humidity, as is shown by the statistics of three piefectures and a city, widely separated from each other.

Table 49 Correlation-cceficient between the outbreak of fires acd the specific humidity

$$
\begin{array}{lll}
\text { Hukuoka } & -0.59 \pm 0.034 \\
\text { Tokyo } & -0.7^{6} \pm 0.03^{8}
\end{array} \quad \text { Ehime }-0.53 \pm 0.044 \quad \text { Ixate }-0.55 \pm 0.043
$$

As we have stated in the foregoing section, the water-quantity undergoes a change, more in accordance with the variation of the relative humidity, than with any other element not only in timber but also in many other materials of various kinds of furniture of living rooms, walls and floors. ${ }^{31}$

These things considered together, the most important controlling factors of a fire must be considered to be the water quantity in the material, which changes from minute to minute with the change of relative humidity of the air.

31 It is noteworthy fact that the correlation coefficient between fires and the saturation coefficient is not only negative, lat also small, for instance for Tokyo and Hukuoka it is

$$
-0.44 \pm 0.06 \text { and }-0.4 \mathrm{x} \pm 0.04 \text { respectively }
$$

The fact that they are negatively correlated makes no sense at all, and it should be rather interpretated that there is no correlalion between them. At the same time it must be borne in mind that the fact that the correlation between the water content of many materials and the relative humidity of the surrounding air is greater than that between the water content and the saturation deficiency, has a close relation to the statistical result just obtained.

I.S. In the physical !aboratory of the Department of Technology in the Tokyo Lniversity, the measurement of the specific heat of the same sort of incense-stick as previously experimented with was through the kindness of Prof. M. Majima many limes repeated, and 0.28 was found to be the most probable value. The time ratio calculated by this new constant approaches much nearer to the ratio observed. 
Such a conclusion was first anticipated by Prof. Fujiwara and discussed in the foot note in our former papers. Now, it has been born out by this study, provided the forthcoming experiment does not lead to any serious contradiction.

In this investigation, we are indebted to Mr. F. Omori for the experimental work and to Mr. Y. Araki for the statistical calculations to both of whom we express our hearty thanks.

\section{SUMMARY}

Burning, everyday, several incense sticks through a year, the author has found that they burn more rapidly in summer than in winter, whilst the daily variation of their burning velocity is subjected to the changing relative humidity of surrounding air. Further, using several other materials the influence of humidity on the burning together with house-nires is thoroughly investigated, thus:

r. The most important factor of the problem among the numerous meteorological elements is the relative humidity.

2. The combustion of some substances is influenced, in large degree, by the variation of the water-quantity within, when they burn in low temperature without flame.

3. The combustion of some substances is influenced by the waterquantity of air, when they burn with flame and temperature is moderately high.

4. The combustion of other substances is, if temperature is enormously high, controlled by the humidity of air, but in the way contrary to the preceeding, that is, they burn strongly with increasing humidity.

5. The influence of wind on fires is not so remarkable as it is now believed.

6. The fire-statistics in many cities and prefectures in Japan indicaies that the outbreak of fires has the most intimate correlation with the relative humidity among many other meteorological elements.

7. The outbreak of fires undergoes a change yearly and daily. It corresponds in many respects with the seasonal and daily variations of the moisture in timber, paper and cloth etc. in the room.

Therefore we can conclude that the relative humidity has the great influence not only on the burning but also on the fires. 


\section{LITERATURE}

I. Pircher J.,-Über die Haarhygrometer. Denkschriften der kajserlichen Akadenie der Wissenschaften. I,XXIII $27 \mathrm{r}$, Igor.

2. PURT, A. N.,-Investigations on the behaviour of hygrometric hairs, Quart. Jour. of Roy. Meteor. Soc. 53 115, April 1927.

3. OBATA, J.,--On the variation of manganin resistance with atmospleric humidity. Proc. of Tokyo Math.-Phys. Soc., 2nd Ser. Vol. 8, 3941916.

4. ONo, S., and OfuCHI, Y.,-Electrical conductivility of wood. Proc. of Tokyo Math.Phys Soc., 3rd Ser. Vol., 223 I9J9.

5. Naganka, H.,-Vibrations of cylincter. Proc. of the Math. Phys. Soc. of Japan, 3rd Ser Vol. I p. 277. 1919.

6 BuWLEY, A. 1.,--Element of Statistics, 4 th ed., p. 347 .

7 WALkeR, G. and Bliss, E. W.,-On correlation coefficient and their use. Quart. Jour. of Roy. Meteoro, Soc., 52, 73, 1926.

8 WoOlard, E. W., -The variate difference correlation method, Month. Weath. Rev. r33. March $192 \mathbf{r}$.

9 Gamble, S, G.,-Outbreaks of fires, their causes and means of prevention, 1926.

Io BATES, C. G.,-Evaporation as a simple index to weather conditions, Month. Weath. Rev. 570 , Nov. 1923 .

I McCarthy, E. F.,-Forest fires and storm movement. Month, Weath, Rev. 257, May 1924.

I2 McCarthy, E. F.,-Forest fire and weather in the Southern Appalachians. Month. Weath. Rev. 182, April 1923.

I3 I.arson, J. A. and Delavan, C. C.,-Climate and forest fires in Moniana and Nortbern Idaho 55, Month. Weath. Rev. 55 Feb. I9z2.

14 Bf.sLs, F. A.,-Discussion of thunderstorms and forest fires in California. Month. Weath Rev. I80, April 1923

I5 NakamurA, S.,-Great conflagration afier the destructive earthquake of 1923 in Tokyo. 1924.

$$
\text { (In Japanese) }
$$

16 Suzuki, S.,-Kisyo Syusi 34nen No. 9563 , 1915.

17 Nakazima, H.,-Sapporo Norin-Gaku-Kwaiho No. 3 55, 1920.

I8 Tagurı, K,,-The Sea and The Sky Vol.2 No. 1o Iro, Ig22.

19 WAsizima, T.,-Dai-Nippon-Sanrin-Kwaiho 456455 , I yza.

20 Hikuma, Z.,--Ringyo-siken Hokoku No.ro 61 I9I3.

21 IUzıokA, M.,-Dai-Nippon-Sanrin Kwaiho No. $38633,1915$. 







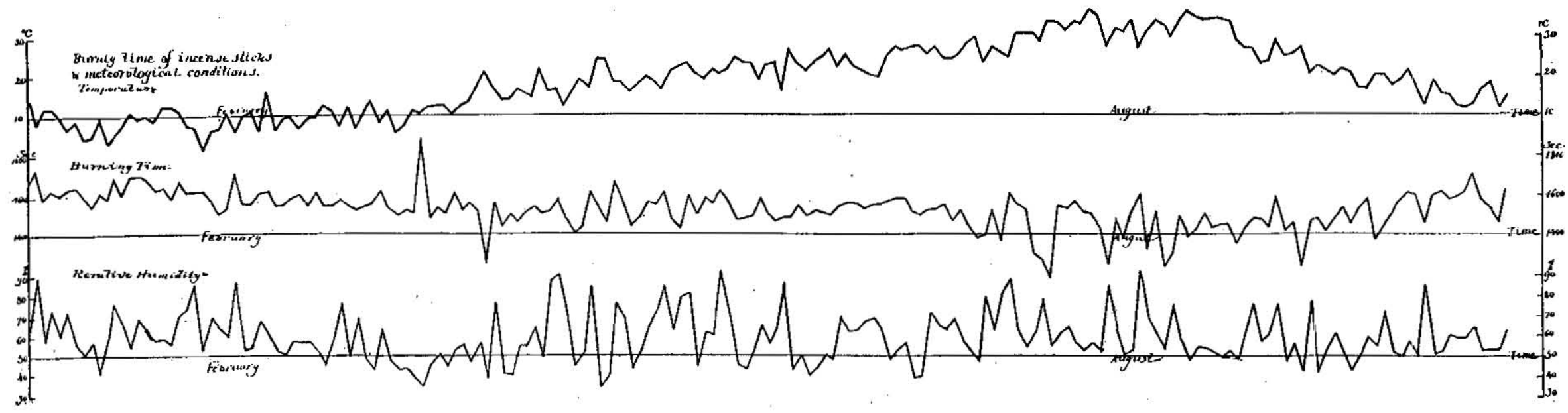


Jour. Dept. Agric., Ky ıshu Imp. Univ., Vol, 2, No. 1

Plate 3

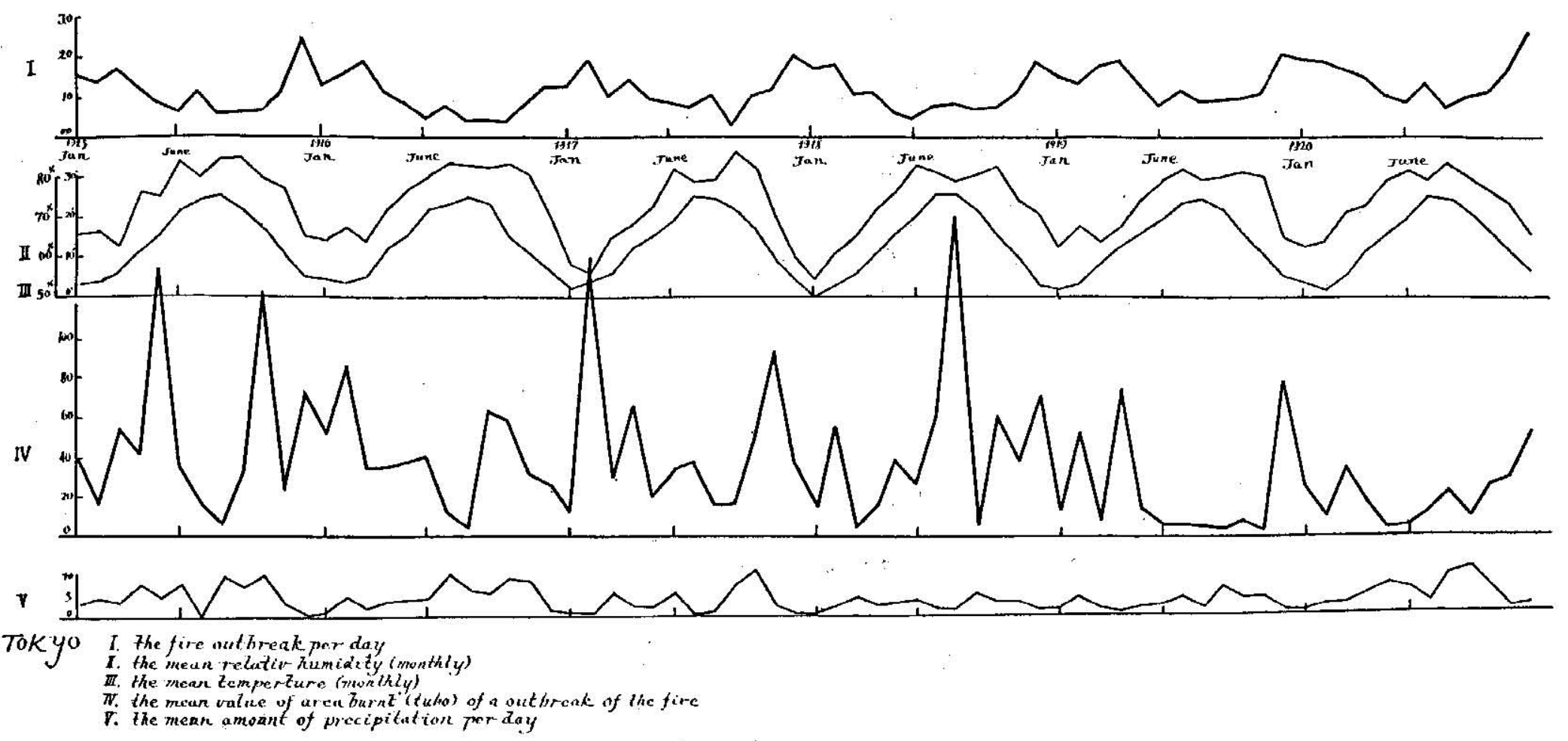

